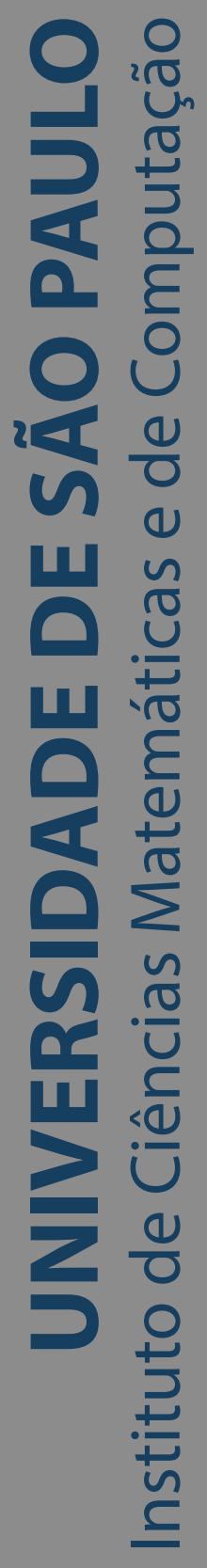

\title{
Redes de regras de associação
}

\section{Renan de Padua}

Tese de Doutorado do Programa de Pós-Graduação em Ciências de Computação e Matemática Computacional (PPG-CCMC) 

SERVIÇO DE PÓS-GRADUAÇÃO DO ICMC-USP

Data de Depósito:

Assinatura:

\title{
Renan de Padua
}

\section{Redes de regras de associação}

\begin{abstract}
Tese apresentada ao Instituto de Ciências Matemáticas e de Computação - ICMC-USP, como parte dos requisitos para obtenção do título de Doutor em Ciências - Ciências de Computação e Matemática Computacional. VERSÃO REVISADA Área de Concentração: Ciências de Computação e Matemática Computacional

Orientadora: Profa. Dra. Solange Oliveira Rezende Coorientador: Prof. Dr. Fabio Ramos
\end{abstract}


Ficha catalográfica elaborada pela Biblioteca Prof. Achille Bassi e Seção Técnica de Informática, ICMC/USP, com os dados inseridos pelo(a) autor(a)

de Padua, Renan

Redes de Regras de Associação / Renan de Padua; orientadora Solange Oliveira Rezende; coorientador Fabio Tozeto Ramos. -- São Carlos, 2019. $146 \mathrm{p}$.

Tese (Doutorado - Programa de Pós-Graduação em Matemática) -- Instituto de Ciências Matemáticas e de Computação, Universidade de São Paulo, 2019.

1. Regras de Associação. 2. Redes. 3. Grafos. 4. Pós-Processamento. I. Rezende, Solange Oliveira, orient. II. Ramos, Fabio Tozeto, coorient. III. Título. 


\section{Renan de Padua}

\section{Association rule network}

Thesis submitted to the Institute of Mathematics and Computer Sciences - ICMC-USP - in accordance with the requirements of the Computer and Mathematical Sciences Graduate Program, for the degree of Doctor in Science. FINAL VERSION

Concentration Area: Computer Science and Computational Mathematics

Advisor: Profa. Dra. Solange Oliveira Rezende Co-advisor: Prof. Dr. Fabio Ramos 

Aos meus pais, Eva e Carlos, pois através do sacrifício deles eu pude realizar o meu sonho. À minha esposa Tatiane, que me acompanhou e me amparou durante todo o processo. E ao meu filho Thomas, que me mostrou a forma mais sincera de amor existente. 

Agradeço aos meus pais, Eva e Carlos, por toda a educação que me deram e todas as possibilidades que me permitiram ter.

A minha esposa, Tatiane, pela colossal paciência e pelo apoio infindável que sempre teve comigo. Obrigado por estar ao meu lado, sempre me apoiando e me acreditando em mim, enquanto eu me esforcei ao máximo para atingir meus objetivos.

As minhas orientadoras Profa Dra. Solange Oliveira Rezende e Profa Dra. Veronica Oliveira de Carvalho, por me orientarem e serem decisivas na minha formação profissional. Uma grande parte do profissional que sou hoje é resultado direto de nossas conversas e de seus ensinamentos

Ao meu co-orientador Prof. Dr. Fabio Ramos, por ter me aceitado em um prazo bem apertado para o intercâmbio na Universidade de Sydney. Agradeço as vitais contribuições para o desenvolvimento desta tese e por toda a experiência acadêmica e de vida proporcionada.

Aos meus amigos do Laboratório de Inteligência Computacional (LABIC), com os quais convivi diariamente por mais de 5 anos durante toda a minha pós-graduação. Será sempre um prazer enorme reencontra-los por ai.

A todos do ICMC-USP que contribuíram direta ou indiretamente para a conclusão do doutorado

A CAPES pelo apoio financeiro que me permitiu o desenvolvimento de boa parte deste doutorado com dedicação exclusiva. E também pelo apoio financeiro que me permitiu vivenciar um período de estudos no exterior, convivendo em um laboratório diferente e crescendo pessoalmente e profissionalmente. 

"A realidade é frequentemente imprecisa."

(Douglas Adams) 



\section{RESUMO}

DE PADUA, R. Redes de regras de associação. 2019. 146 p. Tese (Doutorado em Ciências - Ciências de Computação e Matemática Computacional) - Instituto de Ciências Matemáticas e de Computação, Universidade de São Paulo, São Carlos - SP, 2019.

Regras de associação são amplamente utilizadas na literatura para extrair e explorar correlações dentro de bases de dados. As regras são extraídas por meio de uma análise combinatória de todos os possíveis valores de variáveis, com tamanho variando de 2 a $\mathrm{N}$, sendo filtradas por medidas como suporte e confiança. O suporte aplica um filtro de ocorrência mínima, enquanto a confiança apresenta um filtro de probabilidade condicional mínima. Por esse motivo, as regras de associação tendem a apresentar 1 dos 2 problemas: (i) os valores de suporte e confiança são muito altos e somente regras óbvias são apresentadas ou (ii) os valores de suporte e confiança são muito baixos e o número de regras extraídas é extremamente alto. No caso (i), o conhecimento extraído provavelmente não é novidade para o especialista da área, o que torna todo o processo de mineração não produtivo. Já no caso (ii), há um conhecimento potencialmente útil extraído pelas regras; entretanto, devido ao alto número de padrões, esse conhecimento é difícil de ser encontrado. Visando auxiliar o problema descrito em (ii), foram propostos algumas abordagens de pós-processamento de regras de associação, entre elas a Association Rule Network (ARN). A $A R N$ é capaz de explorar a base de regras de acordo com um item objetivo, focando toda a exploração em identificar quais itens da base estão correlacionados com o item escolhido. Ao modelar apenas um único item, a $A R N$ mostrou-se incompleta, uma vez que itens dominantes podem se relacionar com vários itens de uma base de dados mas não ser importante para a ocorrência de nenhum deles. Neste doutorado foram propostas 2 abordagens capazes de explorar as regras geradas, focando a exploração em mais de um item objetivo. A exARN Convencional e a exARN Gulosa. Ao explorar as regras com mais de um item objetivo, as abordagens propostas são capazes de identificar itens dominantes, que são itens que se relacionam com vários itens objetivos, e itens determinantes, que se relacionam com apenas um único item objetivo. Os resultados para ambas as abordagens foram promissores. A exARN Convencional apresentou bons resultados em bases menos densas, na qual há menos relações existentes entre os itens. Já a exARN Gulosa apresentou bons resultados em bases extremamente densas, uma vez que o algoritmo guloso por trás da abordagem é capaz de reduzir drasticamente a quantidade de regras modeladas.

Palavras-chave: Regras de Associação, Rede, Grafo, Pós-Processamento. 



\section{ABSTRACT}

DE PADUA, R. Association rule network. 2019. 146 p. Tese (Doutorado em Ciências - Ciências de Computação e Matemática Computacional) - Instituto de Ciências Matemáticas e de Computação, Universidade de São Paulo, São Carlos - SP, 2019.

Association rules are widely used in the literature to extract and explore correlations within databases. The rules are extracted through a combinatorial analysis of all possible variable values, ranging in size from 2 to $\mathrm{N}$, and filtered by measures such as support and confidence. Support applies a minimum occurrence filter, while confidence has a minimum conditional probability filter. For this reason, association rules tend to present 1 of 2 problems: (i) the values of support and confidence are too high and only obvious rules are presented or (ii) the values of support and confidence are too low and the number of extracted rules is extremely high. In case (i), the extracted knowledge is probably not new to the area expert, which makes the entire mining process non-productive. In case (ii), there is potentially useful knowledge extracted by the rules; However, due to the high number of standards, this knowledge is difficult to find. In order to assist the problem described in (ii), some association rule postprocessing approaches have been proposed, among them the Association Rule Network (ARN). The ARN is able to explore the rule base according to an objective item, focusing all exploration on identifying which base items correlate with the chosen item. When modeling only a single item, the ARN proved incomplete, since dominant items can relate to multiple items in a database but are not important for any of them to occur. In this doctorate we proposed 2 approaches capable of exploring the generated rules, focusing the exploration on more than one objective item. The Conventional exARN and the Greedy exARN. By exploring rules with more than one objective item, the proposed approaches are able to identify dominant items, which are items that relate to multiple objective items, and determining items, which relate to only a single objective item. The results for both approaches were promising. The Conventional exARN performed well on a less dense bases, where there are fewer relationships between items. The Greedy exARN has performed well on extremely dense bases, since the greedy algorithm behind the approach is able to drastically reduce the amount of rules modeled.

Keywords: Association Rule, Network, Graph, Post-Processing. 



\section{LISTA DE ILUSTRAÇÕES}

Figura 1 - Etapas da mineração de regras de associação. . . . . . . . . . . . . . . 32

Figura 2 - Geração de itemsets frequentes. . . . . . . . . . . . . . 35

Figura 3 - Geração de itemset frequentes com o itemset "ab" infrequente. . . . . . . . 36

Figura 4 - Árvore de padrões frequentes. . . . . . . . . . . . . . . 37

Figura 5 - Exemplo de rede extraído de Newman (2010). . . . . . . . . . . . . 45

Figura 6 - Exemplo de rede contendo similaridade entre os vértices. . . . . . . . . 45

Figura 7 - Exemplo de rede contendo auto-arestas e multi-arestas. . . . . . . . . . 46

Figura 8 - Exemplo de rede direcionada. . . . . . . . . . . . . . . . 47

Figura 9 - Exemplo de rede com hiper-arestas (a) e a sua representação como rede bipartida (b) obtidas de Newman (2010) . . . . . . . . . . . . . . . . 48

Figura 10 - Exemplo de agrupamento hierárquico retirado de Girvan e Newman (2002). 57

Figura 11 - Tabela de frequência de uma base de grafos com a separação por grupos e representação em vértices. . . . . . . . . . . . . . . . . . 60 60

Figura 12 - FPGraph construído de acordo com o exemplo da Figura 11. . . . . . . . 61

Figura 13 - Estrutura básica de uma GNP, adaptada de Yang et al. (2011b). . . . . . . . 64

Figura 14 - Grafo de relações entre itens extraído de Sheng Huijuan Hou e Chen (2018). 65

Figura 15 - Exemplo da rede direcionada utilizada por Karimi-Majd e Mahootchi (2015). 67

Figura 16 - Exemplo de ARN gerada com $\mathrm{z}=$ Lens $=$ Hard . . . . . . . . . . . . . . . . . . . . . . .

Figura 17 - Restrição - Modelagem de itens. . . . . . . . . . . . . . . . . . 74

Figura 18 - ARN construída na base Contact Lens, com "lens=Hard"como item objetivo 77

Figura 19 - ARN construída na base Contact Lens, com "lens=Soft"como item objetivo . 78

Figura 20 - ConexARN construída na base Contact Lens, com "lens=Soft"+ "lens=Hard"como itens objetivo . . . . . . . . . . . . . . . . . . . 78

Figura 21 - Greedy exARN construída na base Contact Lens, com "lens=Soft" + "lens=Hard"como itens objetivo . . . . . . . . . . . . . . . . 81

Figura 22 - Pipeline de experimentos realizado para validação das abordagens propostas. 85

Figura 23 - ARN construída na base artist20 com o item objetivo class-metallica. . . . 91

Figura 24 - Rede Bayesiana construída na base artist20 . . . . . . . . . . . . . . 92

Figura 25 - ConexARN construída na base artist20 . . . . . . . . . . . . . . . 93

Figura 26 - Greedy exARN construída na base artist20 . . . . . . . . . . . . . . . . . 94

Figura 27 - ARN construída na base genre com o item objetivo country-class. . . . . . . 95

Figura 28 - Rede Bayesiana construída na base genre . . . . . . . . . . . . . 96

Figura 29 - ConexARN construída na base genre . . . . . . . . . . . . . . . . 97 
Figura 30 - Greedy exARN construída na base genre. . . . . . . . . . . . . . . . . 98 


\section{LISTA DE ALGORITMOS}

Algoritmo 1 - Algoritmo de construção da ConexARN . . . . . . . . . . . . . 76

Algoritmo 2 - Algoritmo de construção da Greedy exARN . . . . . . . . . . . . . . 80 

Tabela 1 - Transações utilizadas para modelar a árvore de padrões frequentes na Figura 4. 38

Tabela 2 - Matriz de adjacência da Figura 5. . . . . . . . . . . . . . . . 45

Tabela 3 - Matriz de similaridade da rede da Figura 6. . . . . . . . . . . . . 46

Tabela 4 - Matriz de similaridade da rede da Figura 7. . . . . . . . . . . . . . 46

Tabela 5 - Matriz de adjacência da rede da Figura 8. . . . . . . . . . . . . . . . . . 47

Tabela 6 - Matriz de pertinência da rede da Figura $9 . \ldots \ldots$. . . . . . . . . . . . . . . . . . . .

Tabela 7 - Bases de dados utilizadas nos experimentos e suas características. . . . . . . 84

Tabela 8 - Lista de parâmetros utilizado nos experimentos de Regras de Associação. . . 86

Tabela 9 - Resultados obtidos por base de dados. . . . . . . . . . . . . . . 89

Tabela 10 - Resultados obtidos usando a abordagem ARN . . . . . . . . . . . . . 115

Tabela 11 - Resultados obtidos usando rede Bayesiana. . . . . . . . . . . . . . . 132

Tabela 12 - Resultados obtidos usando a abordagem ConexARN . . . . . . . . . . . 138

Tabela 13 - Resultados obtidos usando a abordagem Greedy exARN. . . . . . . . . . . . 142 



\section{LISTA DE ABREVIATURAS E SIGLAS}

ConexARN Conventional Extended Association Rule Network

exARN Extended Association Rule Network

Greedy exARN Greedy Extended Association Rule Network

A conjunto de itens

ARIPSO Association Rule Interactive Postmining using Schemas and Ontologies

ARN Association Rule Network

CLASD CLustering for ASsociation Discovery

D base de dados

E conjunto de arestas

FP-growth frequent pattern growth

GARPA Generalized Association Rules Post-Processing Approach

GNP Genetic Network Programming

LHS Left-hand side ou antecedente da regra

LLGC Learning with Local and Global Consistency

LPBHN Label Propagation using Bipartite Heterogeneous Network

$\mathrm{R} \quad$ rede

RHS Right-hand side, ou consequente da regra

$\mathrm{T} \quad$ conjunto de transações

V conjunto de vértices

W conjunto de pesos das arestas 

INTRODUÇÃO . . . . . . . . . . . . . . . . 25

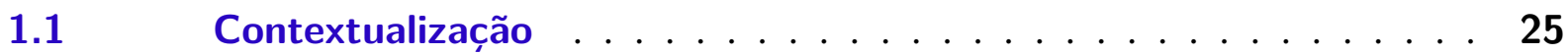

1.2 Desafios e Objetivos . . . . . . . . . . . . . 26

$1.3 \quad$ Principais Resultados . . . . . . . . . . . . . . . 28

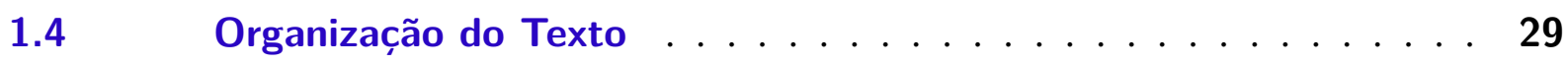

2 REVISÃo BIBLIOGRÁfICA . . . . . . . . . . . . . . 31

$2.1 \quad$ Regras de Associação . . . . . . . . . . . . . . 31

2.1.1 Definições e Conceitos . . . . . . . . . . . . . . 32

2.1.2 Etapa de Pré-Processamento . . . . . . . . . . . . . 33

2.1.3 Etapa de Extração . . . . . . . . . . . . . . . . . . . . . 34

2.1.4 Etapa de Pós-Processamento . . . . . . . . . . . . . . . 38

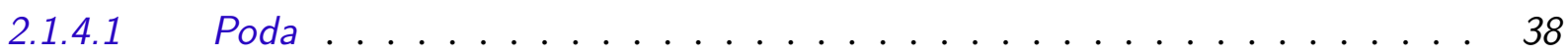

2.1.4.2 Medidas de Avaliação . . . . . . . . . . . . . . . . . 40

2.1.4.3 Sumarização . . . . . . . . . . . . . . . . . . 40

2.1.4. Agrupamento...................... 41

2.1.4.5 Abordagens Híbridas . . . . . . . . . . . . . . . . . . 42

2.1.5 Considerações Finais . . . . . . . . . . . . . . . 43

$2.2 \quad$ Redes . . . . . . . . . . . . . . . . . . 44

2.2.1 Definições e Conceitos . . . . . . . . . . . . . . . . 44

2.2.2 Medidas para analide de redes . . . . . . . . . . . . . 48

2.2.3 Técnicas de Processamento de Redes . . . . . . . . . . . . . . . 52

2.2.3.1 Abordagens de Classificação . . . . . . . . . . . . . . . . 52

2.2.3.2 Abordagens de Agrupamento . . . . . . . . . . . . . . . 55

2.2.4 Considerações Finais . . . . . . . . . . . . . . . 58

$2.3 \quad$ Redes e Regras de Associação . . . . . . . . . . . . . . . . . 59

2.3.1 Abordagens de Pré-Processamento . . . . . . . . . . . . . . 59

2.3.2 Abordagens de Extração de Regras . . . . . . . . . . . . . . . . 63

2.3.3 Abordagens de Pós-Processamento . . . . . . . . . . . . 66

2.3.4 Considerações Finais . . . . . . . . . . . . . . . 68

3 EXARN CONVENCIONAL E GULOSA . . . . . . . . . . . 71

3.1 Motivação e Problemas em Aberto . . . . . . . . . . . . 71 
3.2 ARN e Redes de Regras de Associação Extendidas . . . . . . . . 73

3.2.1 ConexARN . . . . . . . . . . . . . . . . . . 75

3.2.2 Greedy $\operatorname{exARN} \ldots \ldots \ldots \ldots \ldots \ldots \ldots$

$3.3 \quad$ Considerações Finais $\ldots \ldots \ldots \ldots \ldots$. . . . . . . . 81

4 EXPERIMENTOS E RESULTADOS . . . . . . . . . 83

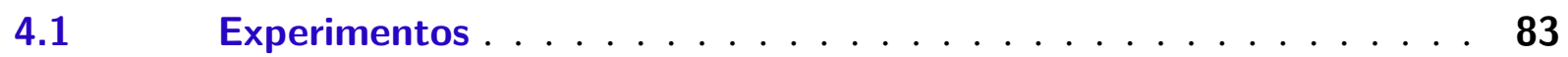

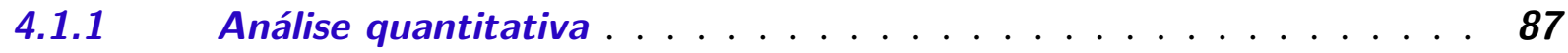

4.1.2 Análise qualitativa . . . . . . . . . . . . . . . . . 90

$4.2 \quad$ Considerações Finais $\ldots \ldots \ldots \ldots \ldots$

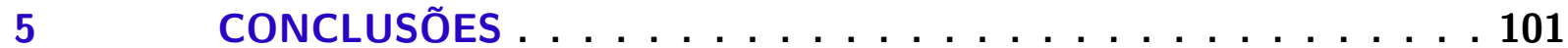

5.1 Inovações e Contribuições Científicas . . . . . . . . . . . . . . 101

$5.2 \quad$ Publicações . . . . . . . . . . . . . . . . . . . 102

5.3 Limitações e Trabalhos Futuros . . . . . . . . . . . . . . . . . . . . 104

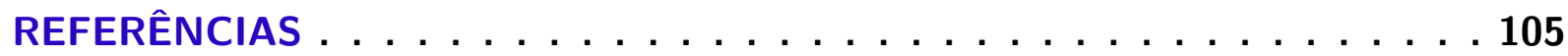

APÊNDICE A TABELAS DE RESULTADOS . . . . . . . 115 


\section{1}

\section{INTRODUÇÃO}

\subsection{Contextualização}

Proposto inicialmente por Agrawal, Imielinski e Swami (1994), regras de associação buscam correlações implícitas em bases de dados. O objetivo inicial era analisar cestas de compras de clientes, em busca de itens que possuiam uma alta correlação, focando em marketing e otimização da distribuição dos produtos nas prateleiras.

As regras de associação são extraídas a partir de combinações de itens da base de dados, combinando 2 itens, depois 3 itens e assim por diante, até que não seja mais possível realizar combinações. Entretanto, se todos os itens disponíveis na base de dados fossem combinados, o trabalho seria computacionalmente inviável, uma vez que o número de combinações se tornaria inexequível. Portanto, as regras de associação são geradas de acordo com valores mínimos de 2 medidas: suporte e confiança. Suporte visa calcular a quantidade mínima de ocorrências de um item/conjunto de itens. Já a confiança visa calcular a probabilidade do consequente de uma regra acontecer dado que o antecedente ocorreu.

As regras de associação são representadas no formato $L H S \rightarrow R H S$, sendo Left-hand side ou antecedente da regra (LHS) e Right-hand side, ou consequente da regra (RHS). A leitura da regra é feita da seguinte maneira: dado que $L H S$ ocorreu, então $R H S$ poderá ocorrer com c\% chance, sendo c\% a medida confiança.

Mesmo com as medidas de suporte e confiança podando a quantidade de regras extraídas, ainda assim o número de regras final é muito grande, impossibilitando, na maioria das vezes, a análise do especialista. Se os valores de suporte e confiança são próximos de 1, então apenas regras óbvias ou altamente comuns serão apresentadas. Em grande parte, essas regras normalmente não apresentam novidade para especialistas da área. Se os valores de suporte e confiança forem muito baixos, então a quantidade de regras extraídas será enorme, o que inviabilizará a análise. Existem outras medidas objetivas, com objetivos diferentes dessas apresentadas. Entretanto, por 
mais que essas medidas sejam capazes de podar ou criar um ranking, dificilmente essas medidas são capazes de representar toda a subjetividade do interesse de um usuário.

Além do número grande de regras, também há a dificuldade de se explorar as regras de associação de acordo com um conjunto de itens específicos. Por exemplo, supondo que um médico possui um base de dados contendo 3 doenças, $d_{1}, d_{2}$ e $d_{3}$ e 25 sintomas, de $s_{1}$ até $s_{2} 5$. Não foi encontrado na literatura uma abordagem que permita uma exploração conjunta da relação entre todos os sintomas e todas as doenças, considerando ligações diretas $\left(s_{x} \rightarrow d_{y}\right)$ e ligações indiretas ( $s_{x} \rightarrow s_{z} \rightarrow d_{y}$ ). Esse tipo de exploração possibilitaria um entendimento mais profundo das correlações, possibilitando até a construção de hipóteses de pesquisa baseado em dados.

\subsection{Desafios e Objetivos}

Existem diversos trabalhos na literatura que visam reduzir a quantidade de regras geradas e/ou remover as regras não interessantes. Alguns desses trabalhos são apresentados no Capítulo 2. Apesar de todos esses trabalhos, ainda sim há uma grande lacuna na área: exploração direcionada por atributos. Para realizar essa exploração, optou-se por utilizar abordagens baseadas em grafos, uma vez que os grafos conseguem representar as visualmente as relações entre os itens de uma base de dados.

Foi proposto em Pandey et al. (2009) uma abordagem chamada Association Rule Network $(\mathrm{ARN})$ que visa explorar as regras de associação extraídas de acordo com um item definido como objetivo. Essa exploração é realizada ao modelar as regras em um grafo ${ }^{1}$ direcionado, proporcionando uma visualização das correlações existentes na base de dados. Por mais que a ARN seja bem sucedida em alguns pontos, ela possui algumas limitações. Por exemplo, ao explorar uma base de dados no qual se deseja entender como mais de um item objetivo se relaciona com o restante da base, seria necessário construir mais de uma ARN. Ao separar as visualizações, dificulta entender quais os itens que se correlacionam com mais de um item objetivo.

Neste doutorado, buscou-se modelar mais de um item objetivo em uma única rede. Assim, o desenvolvimento deste trabalho foi guiado pelas seguintes hipóteses:

H1 - É possível o desenvolvimento de abordagens baseadas em grafos, capazes de modelar mais de um item objetivo

H2 - Abordagens com vários itens objetivos possibilitam a visualização de itens dominantes e itens determinantes

H3 - Abordagens com vários itens objetivos possibilitam maximizar a qualidade das regras a serem visualizadas

1 Neste trabalho, os termos grafos e redes foram utilizados como correlatos 
H4 - abordagens com vários itens objetivos possibilitam uma redução no numero de regras a serem visualizadas/exploradas

Em relação a H1 tem-se que a ARN é capaz de modelar 1 único item objetivo por vez. Essa limitação existe devido a complexidade das regras de associação. Em um cenário em que o usuário poderia definir $\mathrm{N}$ itens objetivos, a quantidade de regras modeladas provavelmente seria muito grande, o que impossibilitaria a exploração visual. Assim, o desafio aqui é apresentar as regras de associação, de acordo com o conjunto de itens objetivos, de maneira que seja possível explorar e identificar os itens modelados.

Em relação a $\mathrm{H} 2$ tem-se que em diversas bases de dados existem itens que dominam a ocorrência. Por exemplo, em uma base de compras de determinado supermercado, um refrigerante específico pode estar sendo vendido na grande maioria dos casos, fazendo com que a correlação dele com os outros itens seja grande. Além desses itens, também há os itens que ocorrem com apenas um único item objetivo, sendo de extrema importância para a ocorrência do item objetivo. Assim o desafio consistiu em modelar o resultado possibilitando a identificação desses itens.

Em relação a H3 tem-se que uma medida objetiva pode ser utilizada como meio de avaliar a qualidade de uma regra. Ao realizar uma poda na medida objetiva, focando apenas em regras com valores altos da medida objetivo, há o risco de apenas manter regras óbvias. Também, ao realizar uma poda por valor, as regras resultantes não necessariamente estão relacionadas ao item objetivo. Caso a poda não seja realiza ou o valor da medida objetiva seja baixa, então a quantidade de regras mantidas será muito alta, o que tornará a exploração das regra extremamente complexa. Assim o desafio consistiu em maximizar o valor da medida objetiva das regras apresentadas, focando em uma maior qualidade, mantendo apenas as regras correlacionadas com os itens objetivos escolhidos.

Em relação a $\mathrm{H} 4$ tem-se que a $\mathrm{ARN}$ possui a limitação de modelar apenas um único item objetivo. Devido a essa limitação, é necessário gerar uma ARN para cada item objetivo que se deseja explorar. Dessa maneira, a quantidade total de correlações modeladas é muito alta, aumentando a complexidade de se explorar as regras. Assim o desafio consistiu em reduzir a quantidade de regras a serem exploradas. Essa redução foi buscada por meio da junção de diferentes itens objetivos em um único grafo.

Tendo em vista as hipóteses apresentadas, os objetivos deste trabalho são:

- Propor, desenvolver e avaliar abordagens capazes de modelar mais um item objetivo para exploração de regras de associação. Essas abordagens devem ser capazes de apresentar itens dominantes e itens que se relacionam com apenas 1 item objetivo (referente à Hipótese 1 e 2 )

- Propor, desenvolver e avaliar abordagens capazes de maximizar, na modelagem no grafo, uma determinada medida de interesse. Essa otimização deve focar em manter um baixo 
número de regras modeladas, mantendo assim a exploração simples. (referente à Hipótese $1,3$ e 4$)$

\subsection{Principais Resultados}

Baseado nos desenvolvimentos das propostas para atingir os objetivos deste doutorado, foram realizadas as seguintes contribuições científicas:

- Representação das regras usando redes capaz de modelar mais de um item objetivo. Foi proposta, desenvolvida e analisada a abordagem Conventional Extended Association Rule Network (ConexARN). Essa abordagem é capaz de modelar mais de um item objetivo, visando manter uma visualização possível de exploração. Publicada em Padua et al. (2018a) e Padua et al. (2018b), a abordagem apresentou resultados interessantes, direcionando a exploração do usuário e auxiliando no entendimento da base de dados. Esse resultado refere-se as hipóteses $\mathrm{H1}$ e $\mathbf{H 4}$.

- Representação usando redes capaz de maximizar uma determinada medida objetivo. Foi proposta, desenvolvida e analisa a abordagem Greedy Extended Association Rule Network (Greedy exARN). Além de ser capaz de modelar mais de um item objetivo, essa abordagem visa maximizar uma medida objetivo escolhida. Ao maximizar uma determinada medida, a abordagem consegue maximizar a qualidade das regras de acordo de acordo com a medida selecionada. Esse trabalho foi submetido para o periódico Knowledge and Information Systems e está atualmente em revisão. Esse resultado refere-se as hipóteses H1, H3 e H4.

- Representação capaz de apresentar itens dominantes e itens determinantes. Ambas as abordagens propostas, a ConexARN e a Greedy exARN, são capazes de modelar vários itens objetivos. Com essa modelagem, a visualização de itens que se relacionam com vários itens objetivos, chamados itens dominantes, e itens que se relacionam com apenas um item objetivo, chamados itens determinantes, torna-se possível. Ao analisar esses itens, o usuário é capaz de identificar quais itens provavelmente são mais ou menos importantes para a ocorrência de um ou mais itens objetivos. Esse resultado refere-se as hipóteses $\mathbf{H 1}$ e H2.

- Nova abordagem para exploração de correlações na base de dados. Apresentado em Padua et al. (2018b), a ConexARN foi capaz de apresentar excelentes resultados na exploração de padrões musicais com determinadas características (gêneros musicais e artistas, por exemplo). Essa abordagem abre novas possibilidades no campo de exploração musical, introduzindo o conceito de regras de associação com grafos para entender novos meios de se classificar/descrever as músicas. Apesar de ter sido aplicada em um problema 
na área de processamento de músicas, a abordagem é de uso geral e pode ser utilizada em qualquer domínio. Esse resultado refere-se as hipóteses H2 e H4.

\subsection{Organização do Texto}

A fim de apresentar o trabalho desenvolvido esta tese está organizada da seguinte maneira:

- Capítulo 2 - Revisão Bibliográfica. Neste capítulo é apresentada a revisão da literatura no que tange os métodos utilizados. Na Seção 2.1 são apresentados os conceitos básicos, definições e alguns trabalhos desenvolvidos na área de regras de associação. Já na Seção 2.2 são apresentados os conceitos básicos, definições e alguns trabalhos desenvolvidos na área de redes complexas. Esta seção foca em esclarecer alguns conceitos que foram utilizados em trabalhos relacionados e nas abordagens propostas. Esta seção também apresenta toda a abrangência do uso de redes para explorar dados. Por fim, na Seção 2.3 apresentamos trabalhos que utilizam redes e regras de associação em conjunto.

- Capítulo 3 - Proposta. Neste capítulo são descritas as 2 abordagens propostas neste doutorado: ConexARN e Greedy exARN. Ambas as abordagens tem como objetivo a modelagem de diversos itens objetivos, visando apresentar todas as correlações entre os itens da base de dados. AS abordagens também visam apresentar os itens dominantes e determinantes, o que facilita o entendimento do usuário da base explorada. A ConexARN visa modelar as regras considerando mais de um item objetivo definido pelo usuário. $\mathrm{O}$ foco dessa abordagem é apresentar as regras com mais abrangência, mantendo as restrições da ARN mas sem considerar otimização de medidas objetivas de qualidade. Já a Greedy exARN visa modelar as regras de maneira gulosa, escolhendo sempre a melhor regra a cada novo passo, de acordo com uma medida objetiva.

- Capítulo 4 - Experimentos e Resultados. Neste capítulo cada uma das abordagens propostas foram analisadas e foi realizada uma discussão sobre seus benefícios, pontos fortes e limitações. Aqui é discutido quando é melhor usar cada uma das abordagens propostas e realizamos comparações com outras abordagens da literatura.

- Capítulo 5 - Conclusões. Neste capítulo são apresentadas as contribuições científicas decorrentes desta tese, assim como são apresentadas as publicações, as limitações do trabalho desenvolvido e sugestões de trabalhos futuros. 



\section{REVISÃO BIBLIOGRÁFICA}

Neste doutorado foram propostas 2 abordagens: a ConexARNe a Greedy exARN, que combinam regras de associação com grafos. Portanto, neste capítulo de revisão bibliográfica, é feita toda uma revisão da literatura de abordagens de regras de associação e grafos individualmente. A seção de regras de associação tem como objetivo apresentar as diversas técnicas disponíveis na literatura que exploram as regras, apresentando diversas maneiras de se extrair conhecimento útil da base de dados. Já a seção dedicada a grafos busca apresentar um estudo de abrangência, focando em abordagens que serão úteis para entender os trabalhos da Seção 2.3. Também são apresentados alguns trabalhos que se utilizam de grafos para processar e identificar conhecimento útil nas bases de dados. Após essa introdução a ambos os temas, é apresentado uma seção com trabalhos que já combinam ambas as abordagens.

\subsection{Regras de Associação}

A ideia de minerar regras de associação surgiu da análise de dados de cestas de compras em que regras do tipo "um cliente que compra os produtos $a_{1}, a_{2}, \ldots, a_{n}$ também irá comprar o produto $a_{m}$ com probabilidade c\%" são geradas (AGRAWAL; IMIELINSKI; SWAMI, 1994). Entretanto, as regras de associação não estão restritas a análises de dependência no contexto de aplicações de varejo, uma vez que elas são aplicadas com sucesso a uma ampla gama de problemas (JADHAV; DESHPANDE, 2016; WU; LIU; WU, 2016; CHOI; KIM, 2014; OELLRICH et al., 2014; YU et al., 2014; DADASER-CELIK; CELIK; DOKUZ, 2012; XIAO, 2011; NUWANGI et al., 2010; CHANGGUO et al., 2009). As regras de associação visam encontrar relacionamentos entre os itens de uma determinada base de dados, com o objetivo de explorar as relações visando descobrir conhecimentos implícitos na base, que normalmente não seriam descobertos por meios manuais de exploração.

Contudo, a quantidade de regras de associação geradas normalmente excede a capacidade de compreensão humana, tornando o processo de mineração de regras de associação bastante 
complexo, sendo esforços extras necessários para garantir a qualidade dos resultados obtidos. Neste capítulo será apresentado e explicado o processo completo de mineração de regras de associação, focando na preparação da base, extração e na exploração das regras geradas.

\subsubsection{Definições e Conceitos}

Segundo Agrawal, Imielinski e Swami (1994), uma regra de associação é definida da seguinte maneira: seja uma base de dados (D) composta por um conjunto de itens (A) $=\left\{a_{1}, \ldots a_{m}\right\}$ e por um conjunto de transações $(\mathrm{T})=\left\{t_{1}, \ldots t_{n}\right\}$, em que cada transação $t_{i} \in T$ é tal que $t_{i} \subseteq A$. É dito que uma transação $t_{i}$ suporta um itemset $I$, conjunto de itens tal que $I \subseteq A$, se $I \subseteq t_{i}$. Portanto, uma regra de associação $r l$ é uma implicação na forma $L H S \Rightarrow R H S$, em que $L H S$ e RHS são itemsets ( $L H S \subset A, R H S \subset A, L H S \cap R H S=\emptyset), L H S$ representa o antecedente (Left Hand Side) e RHS o consequente (Right Hand Side). A regra $r l$ só é gerada caso possua os valores mínimos de confiança e suporte. O suporte do itemset $I$ representa a frequência de $I$ em $T$, i.e., $\sup (I)=\frac{n(I)}{|T|}$, em que $n(I)$ indica o número de transações que suportam $I$ e $|T|$ o número de transações. A regra $r l: L H S \Rightarrow R H S$ ocorre no conjunto de transações $T$ com confiança conf e suporte sup, em que $\sup (r l)=\frac{n(L H S \cup R H S)}{|T|}$ representa o suporte da regra e $\operatorname{con} f(r l)=\frac{n(L H S \cup R H S)}{n(L H S)}$ a confiança da regra.

Todo o processo de mineração de regras de associação pode ser divido em 3 etapas, conforme apresentado na Figura 1, sendo elas pré-processamento, extração das regras e pósprocessamento.

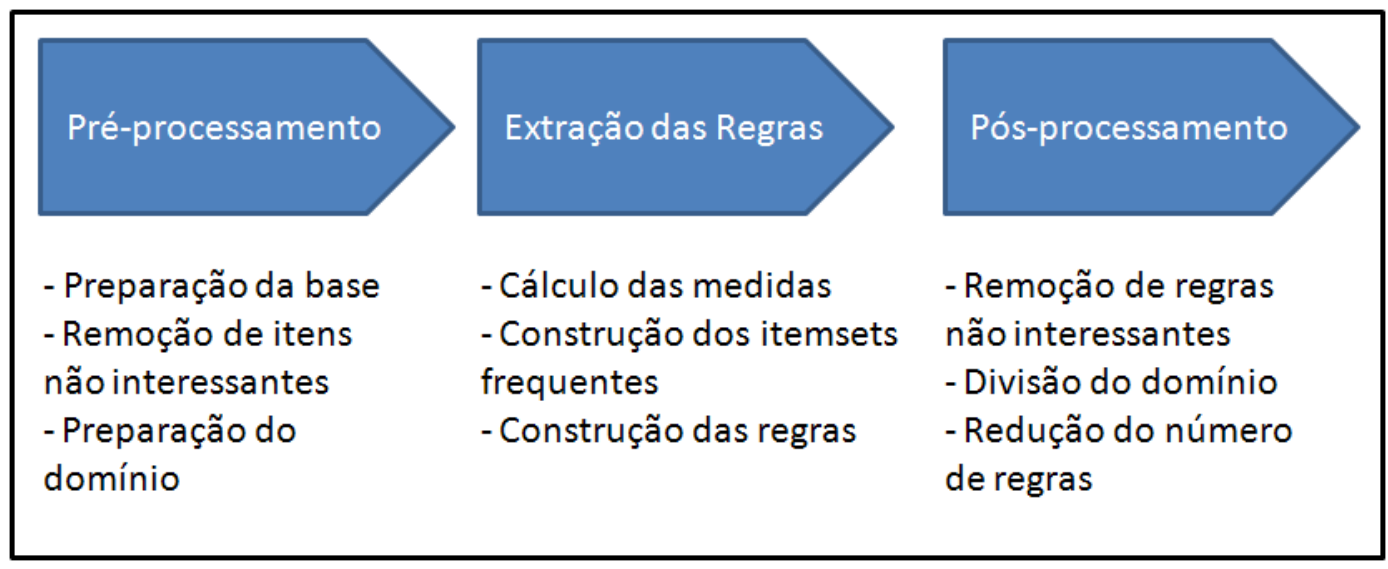

Figura 1 - Etapas da mineração de regras de associação.

A primeira etapa é o pré-processamento da base de dados, que é responsável por preparar a base para a extração das regras. Nesta parte do processo é necessário deixar a base em um padrão compatível com o algoritmo de extração de padrões; porém, esse não é o único objetivo do pré-processamento. É possível também realizar uma exploração inicial no domínio, em busca dos itens ou conjuntos de itens mais interessantes, ou até mesmo reduzir a quantidade de itens que será considerada na extração das regras. 
A segunda etapa, que é a extração das regras de associação, é responsável por analisar todo o domínio, realizar as combinações entre os itens e extrair as regras de associação. $\mathrm{O}$ algoritmo mais conhecido na área é o Apriori, que constrói uma estrutura com os itens frequentes e extraí as regras de associação (AGRAWAL; IMIELINSKI; SWAMI, 1994).

Como a quantidade de regras geradas normalmente excede a capacidade humana de interpretação, no pós-processamento é realizada uma análise das regras geradas, visando reduzir a quantidade de regras a serem exploradas pelo usuário. Essa redução é feita por poda, agrupamento, sumarização, etc. Essas 3 etapas serão explicadas a seguir.

\subsubsection{Etapa de Pré-Processamento}

Abordagens de pré-processamento visam trabalhar os dados originais, possibilitando a extração de regras de associação que dificilmente seriam geradas na base sem processamento. Uma base original normalmente possui vários conceitos diferentes sendo representados, fazendo com que alguns conceitos possivelmente úteis passem despercebidos. Outro problema que visa ser resolvido nesta etapa é a redução de regras pouco interessantes geradas, que aparecem devido a grande variedade de conceitos contidos na mesma base.

Para realizar o processamento da base de dados, o pré-processamento normalmente é realizado por técnicas de agrupamento, capazes de particionar o domínio de acordo com os diferentes conceitos contidos dentro das bases de dados. Ao realizar o particionamento dos dados, alguns itens que possuem domínio absoluto na base tem sua ocorrência dividida em diferentes grupos, fazendo com que a força desses itens reduza e itens que aparecem em pontos muito específicos da base sejam mais valorizados.

Aggarwal, Procopiuc e Yu (2002) propuseram um trabalho de agrupamento de transações para geração das regras de associação. No trabalho foi proposto um algoritmo de agrupamento especificamente para essa área, denominado CLustering for ASsociation Discovery (CLASD), que é um algoritmo de agrupamento baseado na união de grupos, de acordo com algumas medidas de similaridade proposta por eles. A exploração do agrupamento de transações visa encontrar regras que não seriam encontradas na base geral, ou seja, as partições tendem a valorizar itens que possuem um conhecimento mais local, que é perdido dentro do conhecimento do todo nas bases de dados.

Já no trabalho de Plasse et al. (2007), o agrupamento é realizado nos itens da base de dados, com uma exploração diferenciada. Nesta abordagem, não são geradas regras repetidas, uma vez que cada item está contido em apenas um único grupo, criando regras novas e deixando de criar diversas regras que seriam criadas na base completa. Essa análise visa a geração de regras apenas com itens que possuem uma alta correlação, removendo as regras de associação contendo itens com baixa correlação e de temas diferentes.

Wulandari Chao Ou-Yang (2019) propõe a discretização de intervalos contínuos utilizando- 
se da medida mutual information. Essa abordagem é feita em 2 etapas: i) realiza a discretização em intervalos iguais e ii) realiza-se a mescla de intervalos próximos maximizando a medida mutual information. Para a divisão inicial, define-se o número de intervalos como $\log _{2} N_{\text {transacoes }}$, sendo $N_{\text {transacoes }}$ o número de transações contidas na base. Após isso, os intervalos são mesclados e o valor da medida é calculado; a mescla é mantida caso a medida tenha um ganho. Assim, os atributos são enviados para a extração das regras.

Os algoritmos anteriores apresentam algumas metodologias de pré-processamento, agrupando as transações ou agrupando os itens. O agrupamento apresentado por Aggarwal, Procopiuc e Yu (2002) é realizado nas transações, facilitando a extração de regras com itens que provavelmente não apareceriam na base inteira. Já a abordagem de Plasse et al. (2007) trabalha nos atributos (ou itens) da base, dividindo os itens de acordo com sua similaridade. O ponto interessante da segunda abordagem é que não são geradas regras repetidas, uma vez que um item está contido em apenas um grupo, e também remove a possibilidade de geração de regras entre itens que possuem pouca similaridade. O resultado desta etapa é utilizada na extração de regras, conforme explicado na próxima seção.

\subsubsection{Etapa de Extração}

O processo de extração de regras de associação recebe como entrada uma base padronizada, em que cada linha da base representa uma transação. Cada transação contém um conjunto de itens que ocorreram, ou seja, a transação não possui todos os itens da base, apenas os que estão vinculados àquela determinada transação. Outra representação possível é uma matriz, em que cada linha representa uma transação e cada coluna representa um item, recebendo 1 quando o item está presente e 0 quando está ausente. A base então é explorada, para a geração de regras de associação em 2 etapas, sendo elas: extração de itemsets frequentes e extração das regras (AGRAWAL; IMIELINSKI; SWAMI, 1994), descritos a seguir:

1. Encontrar todos os k-itemsets (conjunto de $\mathrm{k}$ itens) que possuam suporte maior ou igual ao suporte mínimo especificado pelo usuário (sup-min). Os itemsets com suporte igual ou superior a sup-min são definidos como itemsets frequentes $(l)$, os demais conjuntos são denominados itemsets não-frequentes;

2. Utilizar todos os k-itemsets frequentes, com $\mathrm{k} \geq 2$, para gerar as regras de associação. Para cada itemset frequente $l \subseteq A$, encontrar todos os subconjuntos $a^{\prime}$ de itens não vazios e diferentes de $l$. Para cada subconjunto $a^{\prime} \subseteq l$, gerar uma regra na forma $a^{\prime} \Rightarrow\left(l-a^{\prime}\right)$ se a razão de $\sup (l)$ por $\sup \left(a^{\prime}\right)$ é maior ou igual à confiança mínima especificada pelo usuário (conf-min).

Para realizar a extração dos itemsets e das regras, alguns algoritmos foram propostos na literatura. Esta seção é focada nos algoritmos mais marcantes da literatura: o algoritmo Apriori, 
proposto por Agrawal, Imielinski e Swami (1994), que foi o primeiro algoritmo da literatura; o algoritmo Apriori-tid, proposto por Agrawal et al. (1996), que visa corrigir a complexidade computacional do algoritmo anterior; e o FP-Growth ${ }^{1}$ Han et al. (2004) que se utiliza de uma estrutura de árvore para gerar os itemsets frequentes.

O algoritmo Apriori, proposto por Agrawal, Imielinski e Swami (1994), foi o primeiro algoritmo proposto na área. $\mathrm{O}$ algoritmo inicia percorrendo toda a base de dados, em busca dos itens frequentes de acordo com o suporte mínimo definido, chamado de sup-min. Após definir os itens frequentes, a abordagem combina esses itens e busca na base pelos 2-itemsets frequentes, que são conjuntos de itens de tamanho 2 que possuem suporte maior que o suporte mínimo. Esse processo continua até que não haja mais itemsets frequentes ou o tamanho dos itemsets seja limitado pelo usuário. Na Figura 2 é apresentada a busca por itemsets frequentes considerando os itens frequentes "a", "b", "c", "d" e "e". É possível visualizar que essa busca gera uma grade 2 contendo todos os itemsets frequentes. Já a Figura 3 apresenta a mesma grade, porém, nesse caso, o itemset "ab" foi considerado infrequente, removendo todas as possíveis combinações utilizando esses itemsets.

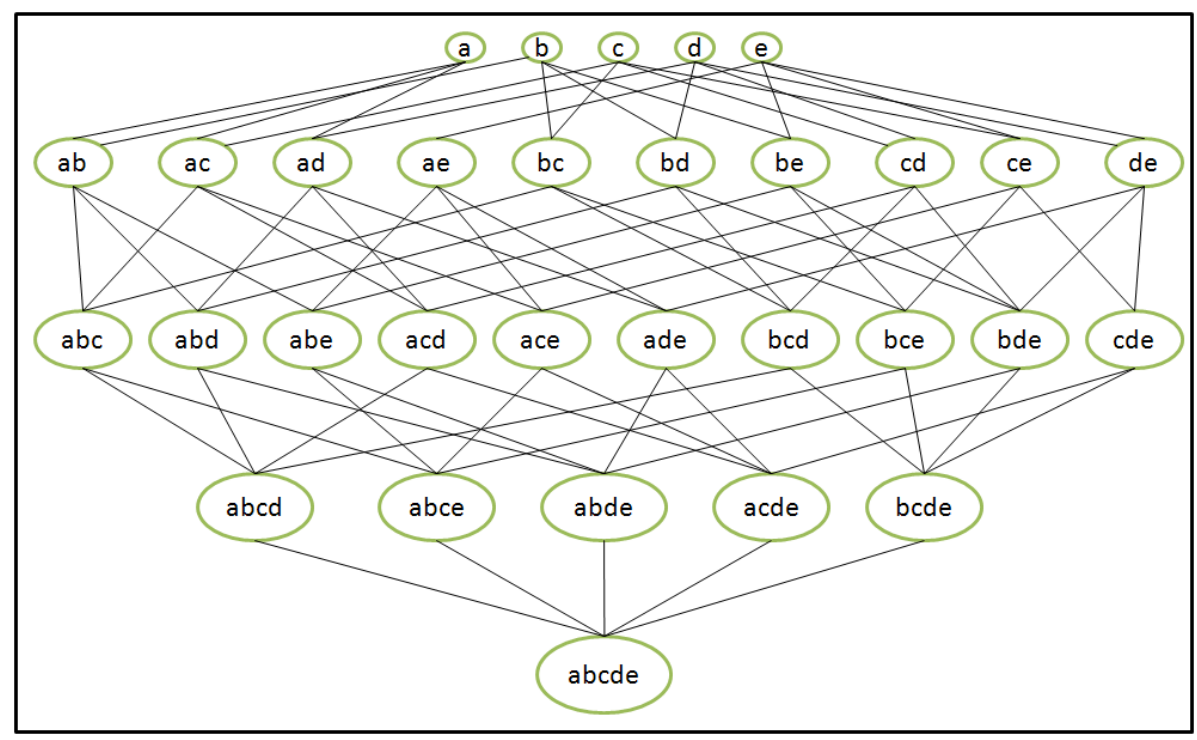

Figura 2 - Geração de itemsets frequentes.

A poda dos itemsets é realizada utilizando a teoria dos conjuntos, ou seja, um superconjunto terá como valor máximo de suporte o menor valor de suporte considerando todos seus subconjuntos. Um exemplo, o itemset "abc" é formado pelos itemsets "a", "b", "c", "ab", "ac" e "bc". Caso o menor suporte dessa lista de itemsets seja 40\%, então, o itemset "abc" terá no máximo $40 \%$ de suporte, pois o itemset com menor suporte deve ocorrer para que todo o itemset ocorra.

Após a geração dos itemsets frequentes, inicia-se o processo de geração de regras de

1 Frequent Pattern Growth - Crescimento de padrões frequentes.

2 ou lattice. 


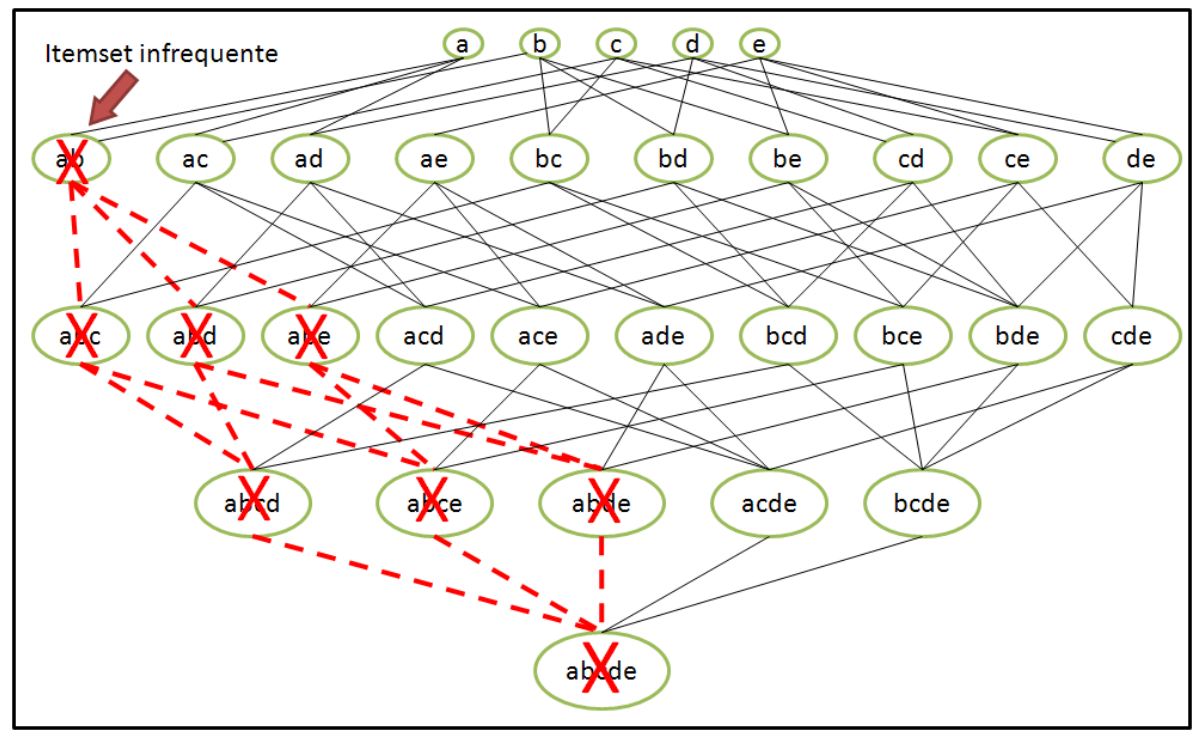

Figura 3 - Geração de itemset frequentes com o itemset "ab" infrequente.

associação. O processo de geração de regras de associação começa com os itemsets de tamanho 2 e realiza testes de possíveis regras, de acordo com a confiança mínima, chamada de conf-min, e geram-se as regras. Por exemplo, supondo um itemset "ab", é feito um teste na regra $a \rightarrow b$ de acordo com a confiança mínima; caso seja maior ou igual, a regra é gerada. Após isso, cria-se a regra $b \rightarrow a$ e realiza-se o teste novamente. Como todas as possibilidades com esse itemset foram esgotadas, ele é descartado e o próximo itemset é testado até que todos os itemsets tenham sidos testados.

O algoritmo Apriori encontra todas as regras que possuem suporte e confiança mínimos, sendo um algoritmo determinístico. O grande problema com esse algoritmo é o tempo necessário para extrair os itemsets frequentes, uma vez que sempre que o tamanho do itemset aumenta é necessário realizar uma varredura total na base de dados novamente.

Visando reduzir essa complexidade, foi proposto por Agrawal et al. (1996) uma extensão do algoritmo Apriori, denominado Apriori-tid (Transaction ID). Nesse algoritmo a geração das regras a partir dos itemsets continua a mesma, porém, a principal alteração foi na contagem de suporte mínimo dos itens da base de dados. Foi adicionada uma estrutura para que seja necessário varrer a base toda apenas uma única vez.

Quando a base de dados é lida, cada item recebe uma lista das transações que pertence ordenadamente. Por exemplo, suponha que o item "a" esteja presente nas transações 1, 2, 3 e 5, então será criada uma estrutura que irá armazenar esses ids de transações, para que não seja necessário reler toda a base. Quando os itens são combinados para gerar itemsets maiores, as listas de transações são então comparadas e as transações que estão presentes em todos os itemsets combinados para gerar o maior permanece. O suporte desses itemsets é calculado utilizando a quantidade de transações que foram mantidas na sua estrutura, dividido pelo total de transações da base de dados. 
Tanto o algoritmo Apriori quanto o algoritmo Apriori-tid possuem a mesma lógica e geram o mesmo resultado, sendo diferentes na construção dos itemsets frequentes, no qual o segundo é muito mais eficiente computacionalmente do que o primeiro.

Já o algoritmo proposto por Han et al. (2004), denominado frequent pattern growth (FP-growth) utiliza a estrutura de uma árvore para minerar as regras. Na Figura 4 é apresentada a árvore de padrões frequentes. A árvore representa as transações apresentadas na Tabela 1. Supondo que o suporte mínimo seja $25 \%$ é realizada uma varredura na base de dados, calculando o suporte individual de cada item. Os itens " $d$ " e "e" são removidos, pois não possuem o suporte mínimo estipulado. Com os itens restantes, é realizada uma ordenação decrescente de acordo com o suporte, sendo a ordem de importância "b", "c" e "a". A primeira transação é processada, criando o vértice " $b$ " na base da árvore, com o filho "a". A segunda transação aumenta a ocorrência dos dois vértices existentes, subindo o valor para 2. Na terceira transação, adiciona-se "c" como vértice filho de "b" e "a" como vértice filho de "c", seguindo assim até o último elemento. Nesta árvore, temos que o item " $b$ " apareceu 8 vezes, o itemset "ab" apareceu 3 vezes ${ }^{3}$, sendo um itemset frequente. Já o itemset "bca" não é frequente, pois aparece uma única vez, conforme visto no item "a" percorrendo o caminho "bc". Com essa árvore construída, é possível extrair os itemsets frequentes e, a partir deles, gerar as regras de associação de maneira convencional pela confiança mínima.

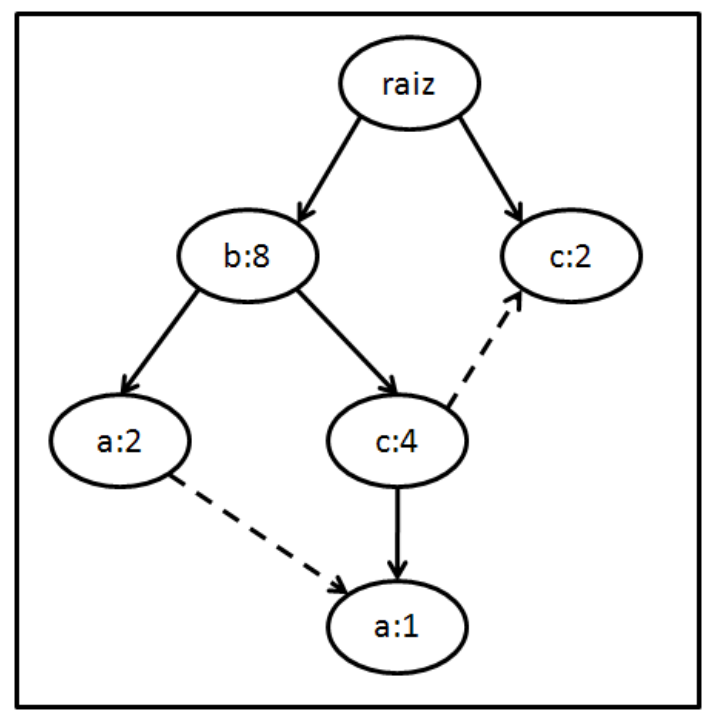

Figura 4 - Árvore de padrões frequentes.

Nesta seção foram apresentados 3 algoritmos para geração de regras de associação, sendo eles: Apriori, Apriori-tid e FPTree. O algoritmo Apriori foi o primeiro proposto na área e realiza diversas leituras na base de dados, sendo o menos otimizado (AGRAWAL; IMIELINSKI; SWAMI, 1994). Porém, o mesmo autor propôs em Agrawal et al. (1996) manter o número da transação que cada item pertence, sendo necessário apenas uma única leitura na base de dados. O último trabalho apresentado, proposto por Han et al. (2004), cria uma árvore de padrões

3 vezes com a transação "ab" e uma vez na transação "abc". 
Tabela 1 - Transações utilizadas para modelar a árvore de padrões frequentes na Figura 4.

\begin{tabular}{|c|c|c|c|c|c|}
\hline Transação & $\mathrm{a}$ & $\mathrm{b}$ & $\mathrm{c}$ & $\mathrm{d}$ & $\mathrm{e}$ \\
\hline 1 & 1 & 1 & 0 & 0 & 1 \\
\hline 2 & 1 & 1 & 0 & 0 & 0 \\
\hline 3 & 1 & 1 & 1 & 0 & 0 \\
\hline 4 & 0 & 1 & 1 & 0 & 0 \\
\hline 5 & 0 & 1 & 1 & 0 & 0 \\
\hline 6 & 0 & 1 & 1 & 1 & 0 \\
\hline 7 & 0 & 1 & 0 & 0 & 0 \\
\hline 8 & 0 & 1 & 0 & 0 & 0 \\
\hline 9 & 0 & 0 & 1 & 1 & 0 \\
\hline 10 & 0 & 0 & 1 & 0 & 1 \\
\hline Suporte & $30 \%$ & $80 \%$ & $60 \%$ & $30 \%$ & $20 \%$ \\
\hline
\end{tabular}

frequentes sem a necessidade de se manter uma grande estrutura, contendo todas as transações da base de dados que cada item apareceu.

Todos os algoritmos se concentraram na redução de complexidade para geração dos itemsets frequentes, que é um dos principais problemas da mineração de regras de associação. Porém, outro grande problema que continua em aberto na etapa de extração de regras de associação é o alto número de regras geradas, que dificulta a análise e separação do conhecimento verdadeiramente útil das regras com conhecimento óbvio. Na próxima seção são apresentados trabalhos que visam tratar, diretamente, essa questão.

\subsubsection{Etapa de Pós-Processamento}

Conforme já mencionado, a quantidade de regras geradas supera a capacidade de interpretação humana, sendo a busca por regras interessantes praticamente inviáveis para os especialistas. Visando solucionar essa dificuldade, diversas abordagens foram propostas para explorar as regras automaticamente, direcionando o usuário para o conhecimento potencialmente útil. Foi realizado um mapeamento da área de acordo com os trabalhos encontrados, dividindo os trabalhos de pósprocessamento em diferentes categorias; a explicação de cada uma dessas categorias é realizada nas subseções a seguir. É importante ressaltar que todas as abordagens de pós-processamento recebem como entrada um conjunto de regras e, como resultado, são apresentadas as regras mais definidas como mais interessantes pelos autores, de acordo com o processamento realizado.

\subsubsection{Poda}

Abordagens de poda visam remover regras de acordo com algum critério estabelecido. Segundo Baesens, Viaene e Vanthienen (2000), as regras removidas no processo de poda expressam fenômenos não desejados, como redundância, por exemplo, ou até mesmo fenômenos que não sejam interessantes para um determinado usuário. 
Para realizar essa poda, diversas abordagens foram propostas na literatura. Alguns trabalhos focam mais na remoção de regras redundantes, removendo da base de regras as regras mais específicas que apresentam os mesmos conceitos das regras mais gerais. Essa remoção permite que o número de regras seja reduzido sem perder o conhecimento. Outro tipo de poda comumente utilizado é a remoção por schemas, em que é possível descrever o conhecimento que o usuário já possui e o conhecimento óbvio, assim como o conhecimento que o usuário julga não interessante, para realizar a remoção na base de regras.

Sweetlin e Kalaivani (2012) propuseram a criação de uma ontologia, contendo a descrição dos itens contidos em uma base de dados. Neste trabalho foi utilizada uma base de supermercado, sobre a qual foi criada uma hierarquia de produtos, agrupando os itens de acordo com seu tipo. Por exemplo, foi criado um nó "alimentos". Abaixo desse nó criou-se uma segunda classificação de acordo com o interesse do usuário, que no caso foi "saudável" e "gorduroso". O pós-processamento é realizado de acordo com o interesse do usuário, selecionando quais grupos de itens ele deseja ver para que os outros não sejam exibidos para a exploração. Essa seleção é realizada por schemas de regras. Após esse processamento, o algoritmo remove as regras redundantes fixando primeiro o antecedente e depois o consequente. As conclusões do trabalho apresentam uma grande redução na quantidade de regras geradas e na redundância das regras apresentadas.

No trabalho de Sulthana e Murugeswari (2011) foi proposto um framework de pósprocessamento de regras de associação chamado Association Rule Interactive Postmining using Schemas and Ontologies (ARIPSO). Conforme o nome da abordagem já apresenta, neste trabalho também é definida uma ontologia do domínio, visando descrever todo o conhecimento contido na base de dados. Com a ontologia definida, o framework busca remover as regras de associação utilizando-se de schemas baseados na ontologia. Esses schemas foram divididos em 4 grupos: regras podadas, regras de confirmação, regras inesperadas e exceções. Cada uma dessas categorias possuem um operador próprio, capaz de identificar as regras e apresentar para o usuário. $\mathrm{O}$ grupo de interesse dessa mineração são as regras inesperadas, que são responsáveis por trazer conhecimento novo para o usuário. As regras de confirmação também são importantes para comprovar a validade do algoritmo de mineração de regras.

Os algoritmos apresentados nesta etapa tendem a remover regras consideradas não interessantes de acordo com schemas, podendo ou não ter uma ontologia definida para auxiliar na escolha das regras a serem removidas. Os resultados obtidos foram satisfatórios, porém, essa poda normalmente é realizada de acordo com uma medida específica, limitando a exploração a semântica da medida, sem permitir direcionamentos do usuário. As abordagens que utilizam o conhecimento do usuário acabam sendo bastante complexas, forçando o usuário a analisar um conjunto muito grande de regras. 


\subsubsection{Medidas de Avaliação}

Abordagens que utilizam medidas de avaliação visam criar um ranking de regras, sendo as regras melhores colocadas as mais interessantes de acordo com a medida selecionada e as regras que estão no fim da lista as piores ou menos interessantes. Essa abordagem visa organizar o domínio, direcionando a exploração para as regras consideradas interessantes em detrimento das não interessantes. As medidas aqui utilizadas são divididas em 2 grupos. Medidas objetivas são medidas que são calculadas de acordo com a base de dados, sem nenhuma informação externa. Já medidas subjetivas consideram um conhecimento extra, além do informado na base de dados, para encontrar as regras consideradas interessantes. Esse conhecimento extra normalmente é o conceito de "interessante" e "não interessante" que o usuário possui. O uso dessas medidas normalmente é muito custoso, uma vez que o usuário precisa informar manualmente o que ele considera interessante, fazendo com que muitas das vezes o uso das medidas subjetivas seja inviável.

No trabalho de Rezende et al. (2009) várias medidas diferentes são exploradas, incluindo algumas objetivas e outras subjetivas para encontrar as regras interessantes. A primeira etapa do trabalho é criar o ranking das regras considerando apenas medidas objetivas, para preparar previamente as regras para serem exploradas pelo usuário. Com o ranking gerado, o usuário então analisa as melhoras regras e realiza o seu ranking, de acordo com seu interesse, adicionando subjetividade no processo. No final, essa junção de medidas objetivas e subjetivas, apoiadas por um ambiente de exploração, tende a minimizar os aspectos não favoráveis de cada abordagem. Após o ranking criado, exibem-se então as regras para que o usuário possa classificá-las subjetivamente, de acordo com os seus interesses. Esse trabalho mostra que a junção desses dois tipos de medidas, apoiados por um ambiente de exploração, tende a minimizar os aspectos não favoráveis de cada tipo de medida.

Outras abordagens desse tipo tem o mesmo objetivo, criar um ranking capaz de direcionar o usuário para as regras consideradas mais interessantes de acordo com algum tipo de medida. Outros trabalhos que utilizam essa abordagem pode ser vistos em Carvalho, Padua e Rezende (2016), Natarajan e Shekar (2005). As abordagens que utilizam medidas objetivas possuem a limitação de considerar interessante apenas as regras que obtém um bom resultado em uma determinada medida, sendo extremamente complexo a escolha de uma medida que seja capaz de representar o interesse do usuário de maneira acurada.

\subsubsection{Sumarização}

Abordagens de sumarização visam reduzir a quantidade de regras a serem exploradas, removendo redundância, deixando o conhecimento mais direto e também visando remover as regras muito específicas deixando as mais gerais, aquelas capazes de representar um conjunto maior de regras, reduzindo assim a quantidade de regras a serem exploradas. Caso o usuário se interesse pelo conhecimento da regra geral é possível expandi-la, explorando as regras que foram 
representadas pela regra sumarizada.

Carvalho, Rezende e Castro (2007) desenvolveram uma abordagem de sumarização utilizando taxonomias, chamada de Generalized Association Rules Post-Processing Approach (GARPA). A primeira etapa do processo consiste na geração da taxonomia da base de dados, feita pelo usuário. A taxonomia visa agrupar itens iguais, que possuem pequenas diferenças, em um único item, por exemplo: agrupa diferentes marcas de "leite" (leiteA, leiteB, leiteC, etc.) apenas como "leite". Essa taxonomia é bastante interessante, uma vez que diversas bases da mesma área podem utilizar a mesma taxonomia, inclusive podem colaborar para a sua maior completude. Com a taxonomia gerada, as regras de associação são sumarizadas considerando os itens da taxonomia. Dentro de cada regra é possível visualizar os itens que a compõe; no exemplo do leite, toda a regra que possui leite pode ser aberta para verificar as marcas de leite que geraram aquela determinada regra. Experimentos mostraram que o GARPA é capaz de reduzir a quantidade de regras geradas pelo agrupamento dos itens de acordo com uma categoria específica.

Já no trabalho de Liu, Hsu e Ma (1999) tem uma proposta diferente de sumarização. Neste trabalho, as regras que possuem menos itens são incorporadas às regras que possuem mais itens. Dessa maneira, uma regra que possui 3 itens no antecedente e 1 item no consequente $(a, b$, $\mathrm{c} \Rightarrow \mathrm{d}$ ) consegue representar, além dela mesma, todas as seguintes regras: $\mathrm{a} \Rightarrow \mathrm{d} ; \mathrm{b} \Rightarrow \mathrm{d} ; \mathrm{c} \Rightarrow \mathrm{d}$; $\mathrm{a}, \mathrm{b} \Rightarrow \mathrm{d} ; \mathrm{a}, \mathrm{c} \Rightarrow \mathrm{d} ; \mathrm{b}, \mathrm{c} \Rightarrow \mathrm{d}$. A abordagem proposta foi capaz de reduzir a quantidade de regras a ser exploradas pelo usuário.

As abordagens de sumarização tendem a auxiliar o usuário a navegar entre as regras sumarizando o conhecimento, porém, essa sumarização pode esconder algum conhecimento interessante em alguns casos ou, dependendo da base de dados, não reduzir satisfatoriamente o número de regras a serem exploradas.

\subsubsection{Agrupamento}

Abordagens de pós-processamento que utilizam agrupamento visam particionar a base de regras, separando as regras com conhecimento diferente em diferentes grupos e mantendo as regras com conhecimento similar nos mesmos grupos. Normalmente, após utilizar uma abordagem de agrupamento, outra abordagem é utilizada em seguida para facilitar a exploração do conhecimento contido em cada grupo.

Berrado e Runger (2007) propuseram uma abordagem de agrupamento a ser aplicada em uma base de regras contendo meta regras (regras de associação sumarizadas), geradas por abordagens de sumarização. $\mathrm{O}$ agrupamento das regras é realizado de acordo com o consequente da regra, criando grupos de acordo com o item cuja ação é o objetivo. Dentro desses grupos baseados no consequente, são criados subgrupos de acordo com a semelhança entre as regras. Neste trabalho específico foi proposto um agrupamento diferenciado, baseado na dependência entre o antecedente e o consequente da regra, que trouxe uma análise diferente para o processo 
de agrupamento de regras de associação, que considera a similaridade do itemset.

O agrupamento é capaz de dividir a base de regras de associação em grupos de conhecimento similar. $\mathrm{O}$ usuário então avalia os grupos que possuem as regras de seu interesse em busca do conhecimento interessante. Porém, dependendo da base de dados, todas as regras podem ser consideradas bastante similares entre si, resultando em poucos grupos com muitas regras e falhando em reduzir a quantidade de regras a ser explorada.

As abordagens apresentadas até o agrupamento são abordagens que usam apenas um tipo de técnica para pós-processar regras de associação, com exceção da abordagem proposta por Berrado e Runger (2007), que executa uma sumarização antes de realizar o agrupamento. Em casos reais, normalmente as abordagens executadas são híbridas, ou seja, possuem mais de um tipo de abordagem sendo executada para obter os resultados. Essas abordagens híbridas são explicadas a seguir.

\subsubsection{Abordagens Híbridas}

Muitos dos trabalhos atuais em pós-processamento têm focado em abordagens híbridas, i.e., aquelas direcionadas a unificação de duas ou mais abordagens. O objetivo é aproveitar os melhores aspectos de cada abordagem. Essas abordagens são propostas pelos autores como frameworks e/ou ambientes de exploração, mas todas visando auxiliar o usuário durante o pósprocessamento das regras. Além disso, a maioria dessas abordagens é voltada para um processo interativo, i.e., aquele em que a participação do usuário se faz necessária. Nesses casos, essa interação tem sido realizada via ontologia/taxonomia e schemas, i.e., por meio da codificação de um conhecimento e/ou interesse do usuário, uma vez que a subjetividade deve fazer parte do processo. Por fim, algumas das abordagens fornecem ainda mecanismos de representações gráficas para a visualização dos conjuntos e/ou subconjuntos de regras. Alguns trabalhos que fazem uso dessa abordagem são: Sweetlin e Kalaivani (2012) (filtragem via schemas apoiados por ontologia, medidas objetivas e poda via redução de redundância); Carvalho et al. (2012), Carvalho, Santos e Rezende (2011) (agrupamento, medidas objetivas); Mansingh, Osei-Bryson e Reichgelt (2011) (filtragem via schemas apoiados por ontologia, medidas objetivas, agrupamento, poda); Kliegr et al. (2011) (uso de CMS - Content Management System para gerenciar o processo de pós-processamento); Marinica e Guillet (2010) (poda via schemas apoiados por ontologia, filtragem via schemas apoiados por ontologia, medidas objetivas e subjetivas); Fujimoto, Carvalho e Rezende (2009) (sumarização via generalização, medidas objetivas e subjetivas, visualização); Zhao, Zhang e Cao (2009) (diversas abordagens híbridas são apresentadas); Ferraz e Garcia (2008) (sumarização via generalização, medidas objetivas); Chen et al. (2008) (filtragem via schemas apoiados por rede semântica, agrupamento, poda); Blanchard, Guillet e Briand (2007) (sumarização, visualização); Berrado e Runger (2007) (agrupamento, poda); An, Khan e Huang (2003) (agrupamento, sumarização). Por fim, existem aqueles trabalhos que embora também englobem o conceito híbrido está mais voltados para ambientes de exploração e/ou de visualiza- 
ção de regras como Romero et al. (2011), Techapichetvanich e Datta (2005), Klemettinen et al. (1994).

\subsubsection{Considerações Finais}

Nesta seção foi apresentado o processo de mineração de regras de associação, apresentando o seu objetivo e como o processo de mineração funciona, envolvendo as três etapas: pré-processamento, extração de padrões e pós-processamento.

Os algoritmos de pré-processamento visam particionar a base de dados com diferentes objetivos, visando o direcionamento da extração de regras e separando os diversos itens contidos na base para facilitar a geração de regras mais interessantes. Os trabalhos apresentados utilizaram agrupamento para realizar o particionamento dos dados para geração de regras de associação. Os agrupamentos foram realizados tanto nas transações como também nos itens. Esses agrupamentos direcionam a extração de regras para o conhecimento que normalmente seria perdido dentro da base de dados sem processamento.

Já os algoritmos de extração de regras visam explorar a base de dados, transação por transação, visando calcular o suporte dos conjuntos de itens de tamanho variado, iniciando no tamanho 1 e indo até o tamanho máximo estabelecido pelo usuário ou até que o conjunto de itens não consiga superar o suporte mínimo. Foram apresentados alguns algoritmos, que vão desde o primeiro e mais complexo (Apriori), mostrando a evolução e apresentando o algoritmo que é o estado da arte para geração de itemsets, o FPTree. A geração das regras, usando a confiança mínima, é realizada pela permutação dos itens obtidos na mineração de itemsets frequentes.

Após a geração das regras de associação, vários autores propuseram abordagens de pós-processamento, visando reduzir a quantidade de regras a serem analisadas pelo usuário ou até mesmo visando organizar as regras para que o usuário possa explorá-las com mais facilidade. As abordagens foram divididas, de acordo com as técnicas utilizadas para pós-processar as regras, finalizando com as abordagens híbridas, que usam 2 ou mais tipos de abordagens em uma única aplicação.

Em todas essas abordagens apresentadas, é possível perceber que muitas delas ainda são complexas, fazendo com que o processo de mineração de regras de associação seja inviável, enquanto outras são computacionalmente viáveis, porém, a quantidade de regras geradas acaba tornando o processo inviável. Visando auxiliar nessas dificuldades, diversos autores na literatura propuseram o uso de redes para minerar regras de associação. As redes e os trabalhos que utilizam redes para minerar regras de associação são explicados na Seção 2.3. 


\subsection{Redes}

Segundo Newman (2010), as redes são, em sua forma mais simples, compostas por pontos que são ligados aos pares por linhas. Na literatura, esses pontos são conhecidos como vértices ou nós, enquanto as linhas que os ligam são chamados de arestas. Muitos domínios podem ser modelados utilizando esse conceito, colocando o conteúdo como vértice e a ligação entre eles como as arestas.

Existem vários sistemas que são interessantes para cientistas que possuem uma estrutura similar a uma rede. Exemplos incluem a internet, redes sociais e até mesmo cadeias de proteínas. Alguns estudos são focados nos indivíduos do domínio, por exemplo: o funcionamento de uma proteína específica ou até mesmo o comportamento de um único indivíduo em uma sociedade. Outros estudos visam analisar a natureza das conexões, por exemplo: por que duas proteínas se conectam, por que um grupo de pessoas se conectam, etc. Porém, existe um terceiro aspecto, que nem sempre é estudado, que é a importância dos padrões existentes entre os elementos da base de dados.

Esses padrões de conexões podem ser representados em uma rede, sendo os componentes (ou elementos) das bases de dados representados pelos vértices e as ligações entre eles representados pelas arestas. Segundo Newman (2010), o padrão de interação contido na estrutura da rede tem um grande efeito no comportamento do sistema, sendo as redes uma maneira simples, mas extremamente poderosa de representar os padrões dessas conexões.

Neste capítulo as redes são definidas, descritas e explicadas. Com os conceitos básicos definidos, são exploradas algumas medidas para exploração de rede, bem como técnicas de processamento de rede em busca de conhecimento implícito, terminando com algumas considerações finais sobre o tema. Todo este capítulo foi baseado no livro de Newman (2010).

\subsubsection{Definições e Conceitos}

Formalmente, uma rede (R) pode ser definida como: $R=(V, E, W)$, formado por um conjunto de vértices (V), conjunto de arestas (E) que simboliza as ligações entre esses vértices e conjunto de pesos das arestas $(\mathrm{W})$, tendo o valor padrão em 1 quando a conexão existe em redes mais simples. Existem várias maneiras de se modelar essa rede, porém, uma das mais utilizadas é a matriz de adjacência. A Figura 5 apresenta uma rede com 6 vértices, 7 arestas e peso fixo em 1 quando a conexão existe. A Tabela 2 mostra a matriz de adjacência referente a Figura 5. A matriz tem tamanho $\mathrm{NxN}$, em que $\mathrm{N}$ é o total de elementos modelados na rede (vértices) e cada posição na matriz representa a conexão entre o elemento $i$ e o elemento $j$, sendo $i$ a linha da matriz e $j$ a coluna.

Essa configuração de rede é a mais simples existente na literatura. As ligações entre os vértices apenas existem (1) ou não existem (0). Um conceito interessante a se adicionar nessas redes é o peso nas arestas simbolizando a conexão entre dois vértices. Esse peso pode representar, 


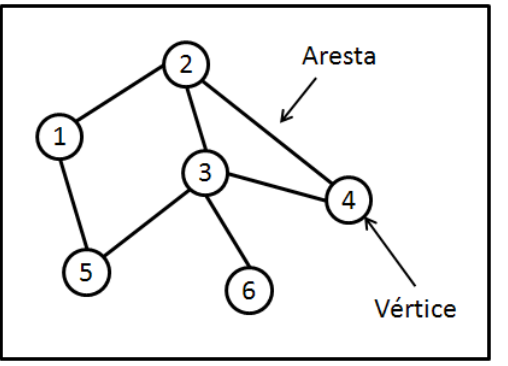

Figura 5 - Exemplo de rede extraído de Newman (2010).

Tabela 2 - Matriz de adjacência da Figura 5.

\begin{tabular}{|l|l|l|l|l|l|l|}
\hline & 1 & 2 & 3 & 4 & 5 & 6 \\
\hline 1 & 0 & 1 & 0 & 0 & 1 & 0 \\
\hline 2 & 1 & 0 & 1 & 1 & 0 & 0 \\
\hline 3 & 0 & 1 & 0 & 1 & 1 & 1 \\
\hline 4 & 0 & 1 & 1 & 0 & 0 & 0 \\
\hline 5 & 1 & 0 & 1 & 0 & 0 & 0 \\
\hline 6 & 0 & 0 & 1 & 0 & 0 & 0 \\
\hline
\end{tabular}

por exemplo, a similaridade entre esses vértices, tendo valores entre 0 e 1 , ou até mesmo a co-ocorrência entre os vértices na base de dados, variando entre 0 e $\mathrm{N}$, com $\mathrm{N}$ sendo o total de exemplos na base de dados. Esses pesos são representados em $W$ utilizando a seguinte notação: $W_{i, j}$, em que $i$ e $j$ são vértices contidos na rede. A Figura 6 apresenta a mesma rede, porém com valores de similaridades atribuídos às arestas. A Tabela 3 apresenta a matriz de similaridade dessa rede. É importante ressaltar que, quando se tem valores de similaridade entre os vértices, a matriz de adjacência pode ser chamada de matriz de similaridade.

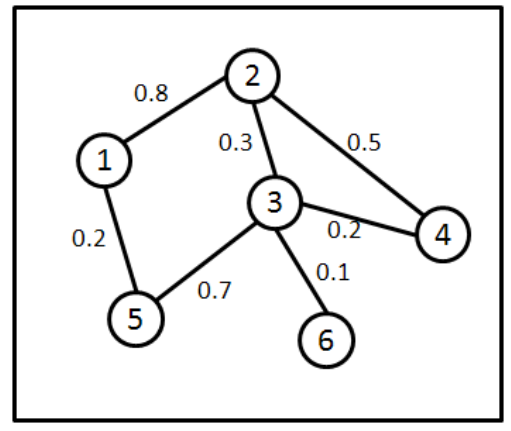

Figura 6 - Exemplo de rede contendo similaridade entre os vértices.

Os pesos das conexões nessa rede representam a força das conexões entre os elementos, ou seja, quanto mais próximo de 1, maior a força da relação entre os vértices. Esse peso permite adicionar conhecimento na rede, fazendo com que a representação seja ainda mais rica. Outra característica que permite adicionar ainda mais conhecimento é o uso de auto-arestas e multiarestas. As auto-arestas representam ligações de um elemento com ele mesmo e são utilizadas quando essa relação é interessante no domínio da base de dados modelada. Já as multi-arestas são utilizadas para conectar o mesmo par de vértices, porém, com diferentes significados. A 
Tabela 3 - Matriz de similaridade da rede da Figura 6.

\begin{tabular}{|c|c|c|c|c|c|c|}
\hline & 1 & 2 & 3 & 4 & 5 & 6 \\
\hline 1 & 0 & 0.8 & 0 & 0 & 0.2 & 0 \\
\hline 2 & 0.8 & 0 & 0.3 & 0.5 & 0 & 0 \\
\hline 3 & 0 & 0.3 & 0 & 0.2 & 0.7 & 0.1 \\
\hline 4 & 0 & 0.5 & 0.2 & 0 & 0 & 0 \\
\hline 5 & 0.2 & 0 & 0.7 & 0 & 0 & 0 \\
\hline 6 & 0 & 0 & 0.1 & 0 & 0 & 0 \\
\hline
\end{tabular}

Figura 7 apresenta um exemplo de rede com auto-aresta e multi-aresta. Nessa rede, a auto-aresta em 6 pode representar a falta de transição em uma base de dados. Já a multi-aresta ligando 1 e 5 pode representar a similaridade entre esses dois vértices de acordo com mais de uma medida ou até mesmo a similaridade em 3 aspectos diferentes dentro da base de dados. A Tabela 4 apresenta uma possível representação da rede com auto-arestas e multi-arestas. Nessa representação é realizada a soma dos pesos de todas as arestas como o valor utilizado na similaridade entre os vértices. É importante ressaltar que nesse exemplo cada vértice possui um valor de similaridade, portanto, o auto-vértice em 6 possui valor 1.0. Também é importante ressaltar que a conexão entre 2 e 4 ficou com o valor de 1.2 pois é a soma de dois vértices com valores máximos fixado em 1. Essa não é a única representação possível; pode-se utilizar diversas matrizes de similaridade, cada uma representando um significado de uma multi-aresta, ou até mesmo modelar a rede utilizando uma outra estrutura de dados, que seja capaz de criar a ligação entre vértices sem o uso de uma matriz.

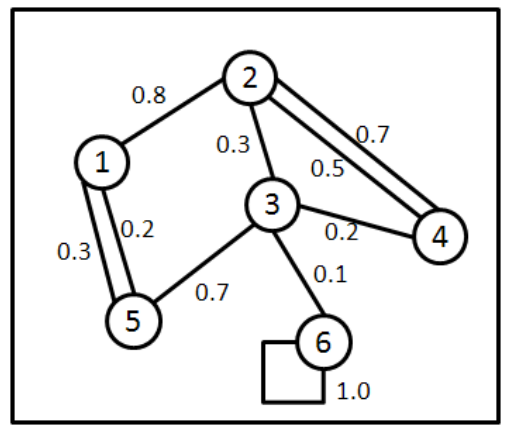

Figura 7 - Exemplo de rede contendo auto-arestas e multi-arestas.

Tabela 4 - Matriz de similaridade da rede da Figura 7.

\begin{tabular}{|c|c|c|c|c|c|c|}
\hline & 1 & 2 & 3 & 4 & 5 & 6 \\
\hline 1 & 0 & 0.8 & 0 & 0 & 0.5 & 0 \\
\hline 2 & 0.8 & 0 & 0.3 & 1.2 & 0 & 0 \\
\hline 3 & 0 & 0.3 & 0 & 0.2 & 0.7 & 0.1 \\
\hline 4 & 0 & 1.2 & 0.2 & 0 & 0 & 0 \\
\hline 5 & 0.5 & 0 & 0.7 & 0 & 0 & 0 \\
\hline 6 & 0 & 0 & 0.1 & 0 & 0 & 1.0 \\
\hline
\end{tabular}


Até agora todas as redes apresentadas não possuem direção em suas conexões, ou seja, se o vértice 1 está conectado com o vértice 5 com peso 0.2 , então na matriz de similaridade haverá um valor igual para a conexão entre o vértice 5 e o vértice 1 . Medidas de similaridade sempre resultam no mesmo valor entre 2 vértices, independente da ordem. Porém, algumas bases possuem o valor da conexão definido ou são modeladas com diferentes medidas. Nesses casos, a rede torna-se "direcionada", ou seja, as conexões têm um ponto de saída e um ponto de destino, podendo a volta ter um peso diferente ou até mesmo ser inexistente. Na Figura 8 é apresentada uma rede direcionada e na Tabela 5 a sua matriz de adjacência. Nessa configuração de rede, tem-se que $W_{i, j}$ pode ser diferente de $W_{j, i}$. Isso é visto no exemplo dado, uma vez que $W_{1,5}=0.2$ e $W_{5,1}=0.0$.

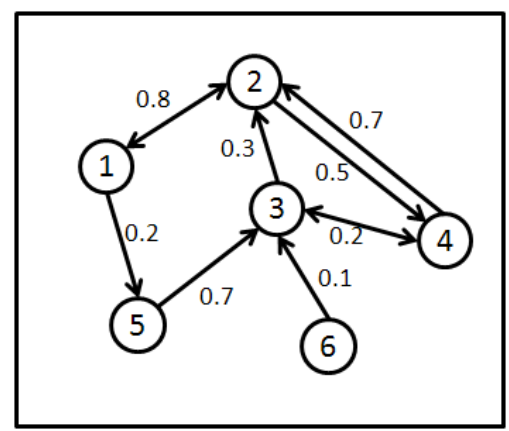

Figura 8 - Exemplo de rede direcionada.

Tabela 5 - Matriz de adjacência da rede da Figura 8.

\begin{tabular}{|c|c|c|c|c|c|c|}
\hline & 1 & 2 & 3 & 4 & 5 & 6 \\
\hline 1 & 0 & 0.8 & 0 & 0 & 0.2 & 0 \\
\hline 2 & 0.8 & 0 & 0 & 0.5 & 0 & 0 \\
\hline 3 & 0 & 0.3 & 0 & 0 & 0 & 0 \\
\hline 4 & 0 & 0.7 & 0.2 & 0 & 0 & 0 \\
\hline 5 & 0 & 0 & 0.7 & 0 & 0 & 0 \\
\hline 6 & 0 & 0 & 0.1 & 0 & 0 & 0 \\
\hline
\end{tabular}

Todas as redes apresentadas até agora apresentam ligações entre 2 elementos. Porém, existem casos em que é necessário unir 3 ou mais elementos com uma mesma aresta. Essas redes apresentadas, até agora, não são capazes de realizar essa modelagem; portanto, foram propostas as hiper-arestas. Uma hiper-aresta é uma aresta capaz de unir 3 ou mais vértices de uma única vez e uma rede que possui hiper-arestas é chamada de hiper-grafo. Outra configuração capaz de representar essas ligações é a rede bipartida. Redes bipartidas possuem uma organização definida, modelando os dados de acordo com 2 tipos de vértices: agrupadores $(\mathrm{G})$ e dados $(\mathrm{H})$. Os vértices do tipo dados representam os dados originais da base e os vértices agrupadores representam as hiper-arestas. Uma diferença dessa rede é que não há conexões entre vértices de um mesmo tipo, ou seja, vértices do tipo dados só podem se conectar com vértices agrupadores e vice-versa. $\mathrm{Na}$ Figura 9 é apresentado um exemplo de uma rede com hiper-arestas e a sua representação em 
uma rede bipartida. Para fins de simplicidade, a rede construída nesse exemplo não possui pesos, porém, a adição deles segue o mesmo padrão utilizado até agora.

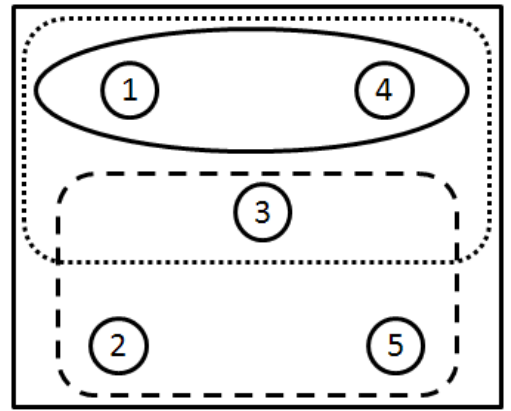

(a)

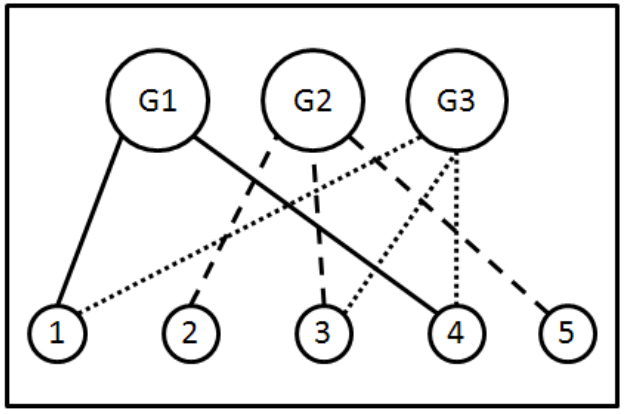

(b)

Figura 9 - Exemplo de rede com hiper-arestas (a) e a sua representação como rede bipartida (b) obtidas de Newman (2010)

A matriz de adjacência, que foi utilizada até agora, não é capaz de modelar essas conexões entre 3 ou mais elementos. Para esses casos é utilizada uma matriz de pertinência, conforme pode ser visto na Tabela 6, na qual as linhas representam os vértices e as colunas representam os vértices agrupadores. É importante ressaltar que alguns autores utilizam a matriz de pertinência com os vértices agrupadores nas linhas e os vértices de dados nas colunas; porém, ambas as matrizes são equivalentes. No caso do exemplo (Figura 6), a rede possui 3 hiper-arestas, sendo elas ligando $V_{1}$ e $V_{4} ; V_{1}, V_{3}$ e $V_{4} ;$ e $V_{2}, V_{3}$ e $V_{5}$.

Tabela 6 - Matriz de pertinência da rede da Figura 9.

\begin{tabular}{|c|c|c|c|}
\hline & G1 & G2 & G3 \\
\hline 1 & 1 & 0 & 1 \\
\hline 2 & 0 & 1 & 0 \\
\hline 3 & 0 & 1 & 1 \\
\hline 4 & 1 & 0 & 1 \\
\hline 5 & 0 & 1 & 0 \\
\hline
\end{tabular}

As redes descritas são as mais básicas encontradas na literatura, e são capazes de representar os padrões de conexões em vários domínios existentes com bastante sucesso, conforme discutido em Newman (2010). Após a modelagem dos dados utilizando as redes, é necessário que as redes sejam exploradas em busca de conhecimento. Nas próximas seções serão apresentadas algumas medidas para exploração de redes e algumas abordagens de classificação e agrupamento, também utilizadas para exploração dos dados.

\subsubsection{Medidas para analide de redes}

Medidas de análise de redes são capazes de encontrar atributos e padrões importantes dentro de redes, que podem ser por si só um conhecimento importante ou até mesmo serem utilizados como base para futuras explorações (NEWMAN, 2010). Uma grande quantidade de 
pesquisas vêm sendo realizadas no conceito de "centralidade". Essas pesquisas visam responder a seguinte questão: Quais são os vértices mais importantes ou mais centrais em uma rede? Existem várias possíveis respostas para essas perguntas e, por consequencia, diversas medidas para calcular a centralidade. A seguir algumas medidas serão apresentadas.

- Centralidade de Grau - A medida mais simples de centralidade é a centralidade de grau, que calcula o grau de cada vértice. O grau de um vértice é calculado pela soma de suas conexões. Por exemplo, em uma rede com pesos, supondo que um vértice possua 3 ligações com peso de $0.1,0.4$ e 0.8 , a centralidade de grau desse vértice é 1.3 , que é a soma de todas as conexões. Nos casos de redes direcionadas cada vértice possui grau de entrada e de saída, calculando a somatória de cada um dos tipos de vértices separadamente. Supondo o cálculo dos graus de entrada e saída de um vértice $V_{i}$, o cálculo do grau de saída é calculado com a somatória de $W_{i, j}$ e o grau de entrada pela somatória de $W_{j, i}$, sendo que $j$ representa todos os vértices da rede. Um exemplo de utilização é a análise de citação de que um artigo científico recebe, que é o grau de entrada do vértice, e mostra uma informação bastante interessante para o domínio.

- Centralidade de Auto-vetor - É uma evolução da centralidade de grau, explicada anteriormente. Nessa medida não é considerada apenas a centralidade de acordo com o vértice em si, mas também considera a centralidade dos vértices vizinhos. Na Equação 2.1 é possível visualizar como é calculada a similaridade, sendo $C_{i}^{\prime}$ o valor de centralidade de auto-vetor do i-ésimo vértice e $J$ o conjunto de todos os vértices vizinhos de $i$. Inicialmente, atribui-se o valor 1 para todas as centralidades e, então, o processo é realizado iterativamente até o valor convergir. Segundo Newman (2010), apenas vértices que estão fortemente conectados em setores densos da rede podem ter uma centralidade de auto-vetor diferente de zero e vértices que possuem um grau de entrada extremamente alto. Também, redes que não possuem ciclos (ou seja, a conexão que sai de um vértice $i$ não possui caminha de volta para o mesmo vértice $i$ ) tendem a ter uma centralidade de auto-vetor zero em todos os seus elementos. Visando solucionar esse problema, foi proposta a centralidade de Katz

$$
C_{i}^{\prime}=\sum_{J} W_{i, j} * C_{j}
$$

- Centralidade de Katz - Uma solução para os pontos levantados anteriormente é a adição de um valor mínimo por vértice "gratuitamente", definindo a medida conforme Equação 2.2, em que $\alpha$ e $\beta$ são parâmetros. Nesses casos, mesmo os vértices que não possuem grau de entrada e, consequentemente, 0 de centralidade de auto-vetor, recebem um valor pequeno de centralidade. Esse valor vai garantir que os vizinhos desses elementos não sejam zerados, garantindo também que os valores de centralidade sejam disseminadas pela 
rede. Os vértices com valores altos ainda se mantém com o melhor desempenho, o que mantém a qualidade da medida.

$$
C_{i}^{\prime}=\alpha \sum_{J} W_{i, j} * C_{j}+\beta
$$

- PageRank - A centralidade de Katz ainda tem um problema: os vértices que possuem muitas conexões sempre terão uma centralidade de Katz muito grande. Esse valor pode não simbolizar o verdadeiro valor de centralidade dessa medida. Portanto, é proposta uma

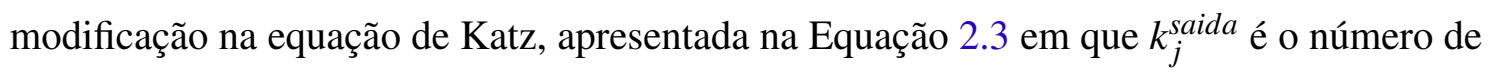
arestas de saída que o vértice $V_{j}$ possui. Nessa medida, a multiplicação é normalizada de acordo com o número de conexões de saídas do vértice, resolvendo o problema de vértices com muitas conexões mas com baixa importância. O nome dessa medida foi registrado pela Google e é utilizada em seu mecanismo de busca (BRIN; PAGE, 1998).

$$
C_{i}^{\prime}=\alpha \sum_{J} \frac{W_{i, j} C_{j}}{k_{j}^{s a i d a}}+\beta
$$

- Centralidade de Proximidade - As medidas apresentadas até agora eram baseadas no grau dos vértices, de acordo com os pesos das conexões. A medida de centralidade por proximidade é uma medida totalmente diferente das outras já apresentadas, pois essa medida considera a distância média de um vértice até outros de acordo com o número de vértices visitados. Essa medida sai do domínio da vizinhança de um determinado vértice para considerar toda a rede no cálculo, considerando a distância geodésica ${ }^{4}$ entre todos os vértices. Na Equação 2.4 é apresentado o cálculo da medida, em que $d_{i, j}$ é a distância geodésica do vértice $i$ até o vértice $j$ considerando o tamanho da distância (quantidade de vértices entre eles), não a soma dos pesos, e $n$ é o total de vértices na rede. Essa medida de centralidade apresenta um conceito diferente, considerando a importância de um vértice de acordo com seu posicionamento na rede, não de acordo com a força de suas conexões.

$$
C_{i}^{\prime}=\frac{1}{n} \sum_{J} d_{i, j}
$$

Essa medida não pode ser aplicada diretamente em redes que não estejam totalmente conectadas, ou seja, quando existem grupos de vértices dentro da rede que não estão conectados entre si. Portanto, foi proposto o uso da média harmônica das distâncias, conforme apresentado na Equação 2.5. Nessa equação, a divisão foi realizada por $n-1$, pois foi desconectado a distância do vértice até ele mesmo na somatória. Essa somatória

\footnotetext{
4 Distância geodésica é a menor distância possível entre 2 pontos.
} 
torna-se interessante pois, caso $d_{i, j}=\infty$, o valor da somatória simplesmente tende a 0 e será desconsiderada da soma.

$$
C_{i}^{\prime}=\frac{1}{n-1} \sum_{j \neq i} \frac{1}{d_{i, j}}
$$

- Centralidade de Betweenness - Segundo Newman (2010), a autoria da centralidade de betweenness foi atribuída a Freeman (1977), porém, o próprio Freeman mesmo teria dito em Freeman (2004) que a autoria da medida veio de um relatório técnico não publicado (ANTHONISSE, 1971). Assim como a medida anterior, a centralidade de betweenness também considera o caminho entre os vértices para calcular a importância de um determinado vértice, porém, nesse caso, o que é considerado é a quantidade de caminhos mínimos entre os vértices da rede e não os tamanhos dos caminhos. Na Equação 2.6 é apresentado o cálculo da medida, sendo $n_{s, t}^{i}$ o número de caminhos mínimos entre $s$ e $t$ que possuem $i$ e $g_{s, t}$ o total de caminhos mínimos entre $s$ e $t$. Ressaltando que a divisão foi feita por $n^{2}$ pois é checado o caminho de todos os n vértices para todos os n vértices, ou seja, $n * n$, e que o número de caminhos mínimos entre 2 pontos pode ser maior que um, ou seja, o caminho mínimo nem sempre é único. Nessa medida um vértice com alta centralidade é um vértice que está posicionado em um local de alto fluxo de informações da rede.

$$
C_{i}^{\prime}=\frac{1}{n^{2}} \sum_{s, t} \frac{n_{s, t}^{i}}{g_{s, t}}
$$

Além das medidas de centralidade apresentadas, existem também alguns outros conceitos interessantes para analisar uma rede. Um desses conceitos é o de hubs e autoridades. Basicamente, um vértice $h u b$ é um elemento que, por si só, não apresenta um conhecimento ou informação importante, mas que aponta para vértices que possuam esse conhecimento. Já vértices autoridades são vértices que representam conhecimento interessante de acordo com a distribuição da rede. Um vértice $h u b$ pode ser também um vértice autoridade e vice-versa, porém, em diferentes "graus". Essa medida de centralidade foi proposta por Kleinberg (1999) e utilizada nesse mesmo trabalho para desenvolver o algoritmo HITS. Nesse algoritmo, todos os vértices possuem valores de $h u b$ e de autoridades, podendo ser consideradas 2 medidas de centralidades interdependentes. $\mathrm{O}$ valor de autoridade de um vértice é a somatória dos valores de hubs que os vértices que apontam para ele possuem. Já o valor de $h u b$ de um vértice é a somatória dos valores de autoridade dos vértices que ele aponta. Dessa maneira, é necessário inicializar os valores de $h u b$ e autoridade dos vértices em 1 e realizar um processo iterativo para cálculo desses valores. Segundo Newman (2010), apesar de teoricamente apresentarem um conhecimento mais completo do que as medidas de similaridades mais simples, os hubs e autoridades são utilizadas nos algoritmos de busca do site ask.com ${ }^{5}$ e Teoma ${ }^{6}$ e não possui outras aplicações descobertas. Porém, é importante ressaltar que 
a informação apresentada pelo conceito é de alta relevância, sendo interessante sua exploração mais aprofundada em busca de aplicações.

Todas essas medidas apresentadas visam encontrar a importância dos vértices na rede de acordo com uma premissa ou realizar alguma análise específica. Essas medidas são utilizadas para apresentar um conjunto inicial de vértices interessantes, que possam conter um conhecimento interessante, ou para levantar alguns pontos a serem considerados em explorações mais complexas, visando adquirir um conhecimento maior sobre a base de dados modelada. Essas técnicas de explorações mais complexas serão apresentadas na próxima seção.

\subsubsection{Técnicas de Processamento de Redes}

As análises apresentadas até esse ponto são focadas em vértices específicos, considerando ou não a vizinhança. Nesta seção são apresentados algoritmos de processamento de redes capazes de realizar análises mais amplas, visando extrair informações mais gerais do domínio. O foco maior será dado em 2 tipos de algoritmos: agrupamento e classificação. Esse foco deve-se ao fato de que esses 2 tipos de algoritmos são utilizados para auxiliar o processo de mineração de regras de associação por alguns autores, conforme apresentado na Seção 2.3. Os algoritmos de agrupamento visam separar o domínio em diversos grupos, de acordo com o peso das conexões e alguma premissa adotada. Essa separação visa encontrar vértices cujo conhecimento são similares, dividindo a rede em grupos para serem explorados. Já os algoritmos de classificação visam aprender o conhecimento contido na base, utilizando esse conhecimento para classificar os vértices ainda não classificados. Ambos os algoritmos serão explicados nas próximas seções.

\subsubsection{Abordagens de Classificação}

As abordagens de classificação utilizando redes utilizam-se da conexão entre os vértices para aprender o conhecimento modelado e classificar corretamente os vértices não classificados. Nessa área temos alguns tipos de aprendizado (ZHU, 2005): não supervisionado, semisupervisionado, supervisionado e por reforço. Aprendizado não supervisionado é quando se tem um conjunto de dados não rotulados e busca-se uma organização dos elementos. Uma técnica bastante conhecida de aprendizado não supervisionado é o agrupamento. Já na classificação supervisionada é quando se tem um conjunto de dados rotulados e deseja-se aprender um modelo, visando classificar novos elementos. As abordagens semi-supervisionadas ficam entre o supervisionado e o não supervisionado, considerando apenas uma pequena parte dos elementos rotulados. $\mathrm{Na}$ abordagem semi-supervisionada parte-se do pressuposto que todos os dados já estão disponíveis na rede e o algoritmo deve classificá-los. Por fim, no aprendizado por reforço o sistema observa o ambiente e sempre que uma ação interessante é realizada é dada uma recompensa ao agente, incentivando a ação tomada. Dentre essas abordagens as não supervisionadas foram bastante utilizadas para exploração de regras de associação (vide Seção 2.2.3.2). Além das não supervisionadas, as semi-supervisionadas também mostram-se interessantes para o uso 
para exploração de regras de associação, uma vez que exigem apenas um pequeno conjunto de elementos avaliados para serem capazes de processar toda uma base de dados.

Uma das abordagens de aprendizado semi-supervisionado em rede é a propagação de rótulos. Seja $L=\left\{\left(x_{1}, y_{1}\right),\left(x_{2}, y_{2}\right), \ldots,\left(x_{l}, y_{l}\right)\right\}$ o conjunto de dados classificados, com $y \in$ $\{1, \ldots, C\}$ e $\mathrm{U}=\left\{x_{l+1}, \ldots, x_{l+u}\right\}$ o conjunto de dados não classificados, em que $l$ denota a quantidade de elementos classificados, $u$ a quantidade de elementos não classificados, $l \ll u$ e $C$ sendo o total de classes definidas no problema, no qual todas estejam presentes nos elementos classificados e $D$ sendo composto por $L+U$ (NEWMAN, 2010). A abordagem de propagação de rótulos consiste em espalhar os rótulos contidos nos elementos classificados por toda a rede, considerando o peso da conexão e otimizando alguma função objetivo. Os algoritmos de propagação de rótulos funcionam, basicamente, otimizando uma função de classificação, responsável por ditar como o algoritmo irá funcionar. Normalmente, essa função possui 2 partes, 1 delas responsável pelos elementos que já possuem classe e outra responsável pelos elementos que ainda não foram classificados. As funções serão explicadas a seguir, conforme os trabalhos que as propõem são apresentados.

Antes de apresentar as funções, é necessário definir os termos utilizados por elas. Para as equações a seguir, $f_{i}$ corresponde a classe atribuída pelo classificador ao vértice $i, y_{i}$ representa a real classe do vértice $i$, ou seja, a classe atribuída previamente por um especialista na área, $\Gamma_{i}$ o conjunto de vértices vizinhos de $i$ e $d_{i}$ o grau do vértice $i$. Tendo essas definições, é possível discutir as equações.

Blum e Chawla (2001) propuseram um algoritmo de propagação de rótulos baseado no corte mínimo de um grafo. Para classificar os elementos, a Equação 2.7 é otimizada. O primeiro termo da equação, que está sendo multiplicada por $\infty$, é responsável por garantir que a classe dada ao elemento pelo especialista não mude, ou seja, caso ela seja diferente da classe real o valor da equação será extremamente alto, o que tornará a configuração inviável. No segundo termo tem-se o peso entre as conexões multiplicando uma equação que penalizará o algoritmo em caso de diferença, ou seja, os vértices com maior valor de similaridade tendem a ficar juntos, uma vez que a penalidade de colocar dois vértices com um peso alto em suas conexões em 2 grupos diferentes é desvantajoso. Esse classificador prevê apenas duas classes, ou seja, apenas trata problemas de classificação binária. Portanto, os valores de $f$ podem ser apenas 0 ou 1.

$$
F=\infty \sum_{v_{i} \in L}\left(f_{i}-y_{i}\right)^{2}+\frac{1}{2} \sum_{v_{i}, v_{j} \in D} w_{i, j} *\left(f_{i}-f_{j}\right)^{2}
$$

Zhou et al. (2003) propôs o GFHF (Gaussian Fields and Harmonic Functions), baseado no algoritmo anterior. A equação otimizada é basicamente a mesma, conforme pode ser visto na Equação 2.8. A grande evolução neste algoritmo está na forma como $f$ é calculado, não sendo mais apenas 0 e 1 , mas sim a média harmônica dos valores dos vizinhos, conforme apresentado na Equação 2.9. Portanto, o algoritmo funciona calculando iterativamente os valores 
de $f$ apresentados na Equação 2.9 até que o valor convirja e então esses valores são aplicados na Equação 2.8 para realizar a propagação de rótulos na base.

$$
\begin{gathered}
F=\infty \sum_{v_{i} \in L}\left(f_{i}-y_{i}\right)^{2}+\frac{1}{2} \sum_{v_{i}, v_{j} \in D} w_{i, j} *\left(f_{i}-f_{j}\right)^{2} \\
f_{i}=\frac{\sum_{v_{j} \in \Gamma\left(v_{i}\right)} w_{i, j} * f_{j}}{\sum_{v_{j} \in \Gamma\left(v_{i}\right)} w_{i, j}}
\end{gathered}
$$

Ambos os algoritmos apresentados acima não permitem que as classes pré-estabelecidas mudem, utilizando um peso "infinito" para penalizar essa mudança. $\mathrm{O}$ algoritmo proposto por Zhou et al. (2003), denominado Learning with Local and Global Consistency (LLGC), permite que os vértices pré-estabelecidos sejam trocados, de acordo com um valor $\mu$ estabelecido por parâmetro. A equação de regularização é apresentada na Equação 2.10, e possui outra diferença em relação às equações anteriores. No LLGC, o valor de $f$ é dividido pela raíz quadrada do grau de saída do vértice com o objetivo de reduzir a dominância de vértices com grau muito alto. Dessa maneira, o peso dos vértices na rede não é extremamente guiado pelo grau de saída, mas sim suavizado equilibrando os pesos.

$$
F=\mu * \sum_{v_{i} \in L}\left(f_{i}-y_{i}\right)^{2}+\frac{1}{2} \sum_{v_{i}, v_{j} \in D} w_{i, j} *\left\|\frac{f_{i}}{\sqrt{d_{i}}}-\frac{f_{j}}{\sqrt{d_{j}}}\right\|^{2}
$$

Os algoritmos apresentados foram propostos para redes homogêneas, ou seja, redes que possuem vértices do mesmo tipo. Para redes bipartidas, que possuem 2 grupos de vértices que só possuem conexões inter-grupos, foram propostas extensões desses algoritmos. No trabalho de Rossi, Lopes e Rezende (2014) foi proposta uma extensão do LLGC proposto por Zhou et al. (2003), denominado Label Propagation using Bipartite Heterogeneous Network (LPBHN), que otimiza a função $F=P * F$, em que $F$ é o vetor que armazena todos os graus dos vértices e $P$ é definido conforme Equação 2.11 para calcular a probabilidade da conexão dos vértices em $G$ com $H$. Foi definida a Equação 2.12 para calcular a probabilidade da conexão dos vértices em $H$ com $G$. Em ambas as equações, $g_{i} \in G$ e $h_{j} \in H$. Relembrando que $G$ é o conjunto dos vértices agrupadores e $H$ são os vértices que representam os itens da base de dados. O algoritmo LPBHN foi proposto originalmente para classificar textos, utilizando os agrupadores como documentos (e, por consequencia, vértices a serem classificados) e os vértices de dados como termos contidos nos textos. Os documentos em $G$ possuem classe definida e os termos em $H$ são utilizados como pontes para classificar os documentos ainda não classificados.

$$
\begin{gathered}
P_{g_{i}, h_{j}}=\frac{w_{g_{i}, h_{j}}}{\sum_{g_{k} \in G ; w_{k j} \in W} w_{k j}} \\
P_{h_{j}, g_{i}}=\frac{w_{g_{i}, h_{j}}}{\sum_{h_{l} \in H ; w_{i k} \in W} w_{i l}}
\end{gathered}
$$


Já Ji et al. (2010) propuseram uma extensão para o algoritmo LLGC, proposto por Zhou et al. (2003), para redes bipartidas denominado GNetMine. A função proposta é apresentada na Equação 2.13, adicionando um novo parâmetro $\alpha$ para considerar a importância da propagação de rótulos entre vértices que não foram previamente rotulados e $\beta$ é o parâmetro que considera a importância dos vértices já previamente classificados.

$$
\begin{aligned}
& F=\sum_{G, H \in D} \alpha_{G, H} * \sum_{g_{i} \in G ; h_{j} \in H} w_{i, j} *\left\|\frac{f_{i}(G)}{\sqrt{d_{i}(G, H)}}-\frac{f_{j}(H)}{\sqrt{d_{j}(G, H)}}\right\|^{2}+ \\
& \sum_{x_{i} \in G_{l}, G_{l} \in \mathscr{L}} \beta_{G_{l}} *\left(\mathbf{f}_{i}\left(G_{l}\right)-\mathbf{y}_{i}\left(G_{l}\right)\right)
\end{aligned}
$$

Todos os algoritmos apresentados nesta seção exigem que uma pequena quantidade dos dados esteja previamente rotulada, ou seja, que a informação de classes por parte dos elementos esteja disponível antes do processo iniciar. Esses métodos possuem qualidade comprovada em suas publicações, sendo capazes de classificar um grande volume de dados com poucos dados rotulados. Porém, nem sempre é possível ter informação prévia de classe, o que torna esses métodos inviáveis em alguns casos. Para esses casos que não se possui informação prévia de classes, são utilizados algoritmos de agrupamento que particionam o domínio. Alguns algoritmos de agrupamento serão explicados na próxima seção.

\subsubsection{Abordagens de Agrupamento}

As abordagens de agrupamento de redes visam dividir a rede em 2 ou mais grupos com o objetivo de separar os conceitos existentes na base modelada. Essa separação é realizada de maneira que a quantidade de conexões entre os grupos seja mínima ${ }^{7}$. Uma possível argumentação seria: "Uma vez que o objetivo é reduzir o número de conexões entre 2 grupos, então é suficiente realizar todos os agrupamentos possíveis e escolher aquele que possui o menor cut-size". O problema, porém, é a complexidade de realizar todos os agrupamentos. Segundo Newman (2010), supondo que a rede possua $n$ vértices, o primeiro grupo possua $n_{1}$ vértices e o segundo grupo possua $n_{2}$ vértices, sendo $n_{1}+n_{2}=n$, o número de possíveis divisões é $\frac{n !}{n_{1} ! * n_{2} !}$, o que torna esse processo exaustivo inviável. Baseado nessa complexidade, vários autores propuseram algoritmos capazes de reduzir a complexidade e agrupar os vértices da rede em tempo factível. Esses algoritmos de agrupamento de redes podem ser chamados de algoritmos de particionamento de grafos ou detecção de comunidades. Alguns desses algoritmos são descritos nesta seção.

Um dos algoritmos de agrupamento mais simples foi proposto por Kernighan e Lin (1970), chamado de Kernighan-lin,e é baseado na redução do cut-size da rede. Para esse algoritmo funcionar, inicialmente é necessário que a rede esteja inicializada com todos os vértices divididos em 2 grupos. Uma abordagem bastante utilizada nesse caso é a inicialização aleatória. Com a rede inicializada aleatoriamente, é calculado o cut-size da rede e inicia-se o processo de trocas de

7 Essa quantidade de conexões entre diferentes grupos é chamada de cut-size. 
vértices. $\mathrm{O}$ algoritmo percorre todos os possíveis pares $(i, j)$ analisando o impacto da alteração dos vértices no cut-size da rede. Depois de explorar todas as possíveis trocas, é selecionada a troca que resulta na maior redução ou, caso não haja redução possível, o menor aumento no valor do cut-size da rede. Importante mencionar que cada vértice só pode mudar de posição uma única vez. Depois que todos os vértices foram trocados, o algoritmo repassa todas as configurações de agrupamento que foram geradas e seleciona aquela com menor valor de cut-size. Todo esse processo é repetido novamente, considerando a melhor configuração da execução passada como rede inicial de processamento. O algoritmo irá executar até que a melhor configuração obtida seja pior que a configuração de entrada, retornando a melhor configuração geral.

Outro algoritmo de agrupamento simples, baseado no algoritmo anterior, proposto por Newman (2010), é a modularidade simples que também trabalha com 2 grupos. Este algoritmo trabalha otimizando uma medida chamada de modularidade, apresentada na Equação 2.14, em que $Q$ é o valor de modularidade da rede, $E_{x, y}$ é o número de conexões que começam no grupo $x$ e terminam no grupo $y$, ou seja, a aresta tem como ponto de origem um vértice no grupo $x \mathrm{e}$ ponto de destino um vértice no grupo $y$. $A_{x}$ é a quantidade de conexões que tem apenas 1 das pontas no grupo $x$ e $n g$ é o total de grupos existentes.

$$
Q=\sum_{p=1 \text { ate } n g} E_{p, p}-A_{p}^{2}
$$

Para realizar a otimização dessa medida, inicialmente os vértices são atribuídos a grupos aleatoriamente e o valor da modularidade é calculado para toda a rede. Depois a rede é percorrida checando vértice a vértice se a troca de grupo melhora o valor de modularidade. Em caso positivo o vértice troca de grupo; caso não mude ou reduza o valor de modularidade o vértice permanece. Cada vértice é analisado apenas uma única vez. Essa abordagem é menos complexa que uma exploração exaustiva, porém, ainda assim exige que toda a rede seja percorrida e que a modularidade seja recalculada $n *(n g-1)$ vezes. Também, como a rede é analisada apenas uma única vez, o resultado nem sempre é satisfatório. Visando melhorar esse resultado, alguns autores utilizam algoritmos de otimização, como algoritmos genéticos, por exemplo, para realizar o agrupamento utilizando a modularidade (NEWMAN, 2010).

Os algoritmos apresentados até agora são algoritmos de agrupamento em redes, que trabalham dividindo a rede em 2 grupos. Caso necessite uma quantidade maior de grupos, então esses algoritmos devem ser executados novamente na base agrupada até que o número de grupos desejado seja obtido (NEWMAN, 2010). Os algoritmos apresentados a seguir são algoritmos de detecção de comunidade, que diferem dos algoritmos de agrupamento por necessitarem de parâmetros para definir um critério de parada. Esses parâmetros podem ser o número de grupos desejado ou até mesmo valores para funcionamento dos algoritmos, que definem indiretamente a quantidade de grupos gerados.

Girvan e Newman (2002) propuseram um algoritmo de detecção de comunidade baseado 
na medida betweenness. $\mathrm{O}$ algoritmo é aplicado nas arestas da rede, ou seja, se um caminho mínimo passa pelos vértices $V_{i}$ e $V_{j}$, então adiciona-se 1 ao valor de betweenness da aresta. $\mathrm{O}$ funcionamento do algoritmo, que é dividido em 4 passos, é apresentado a seguir.

1. Calcular o betweenness de todas as arestas da rede.

2. Pegar o maior valor e remover a aresta.

3. Recalcular o betweenness nas arestas afetadas.

4. Voltar à etapa 2 até que todas as arestas sejam removidas.

O algoritmo é executado até que todas as arestas sejam removidas, ou seja, até que nenhum vértice tenha conexão com nenhum outro vértice. Esse estilo de agrupamento é conhecido como hierárquico, pois é possível construir um dendograma contendo vários níveis de divisão entre os vértices, no qual o usuário (ou uma técnica automática) seleciona a altura mais interessante para realizar o corte para obter os grupos. Na Figura 10 é possível visualizar um exemplo de dendograma de agrupamento hierárquico. Cada divisão na linha da imagem representa a remoção da conexão entre vértices. Por exemplo, a divisão mais baixa da imagem é a divisão entre 33 e 34, nesse caso, essa divisão representa que antes existia uma conexão entre os vértices $V_{33}$ e $V_{34}$ que foi removida e, por ser a mais baixa no dendograma, significa que foi a última conexão a ser removida.

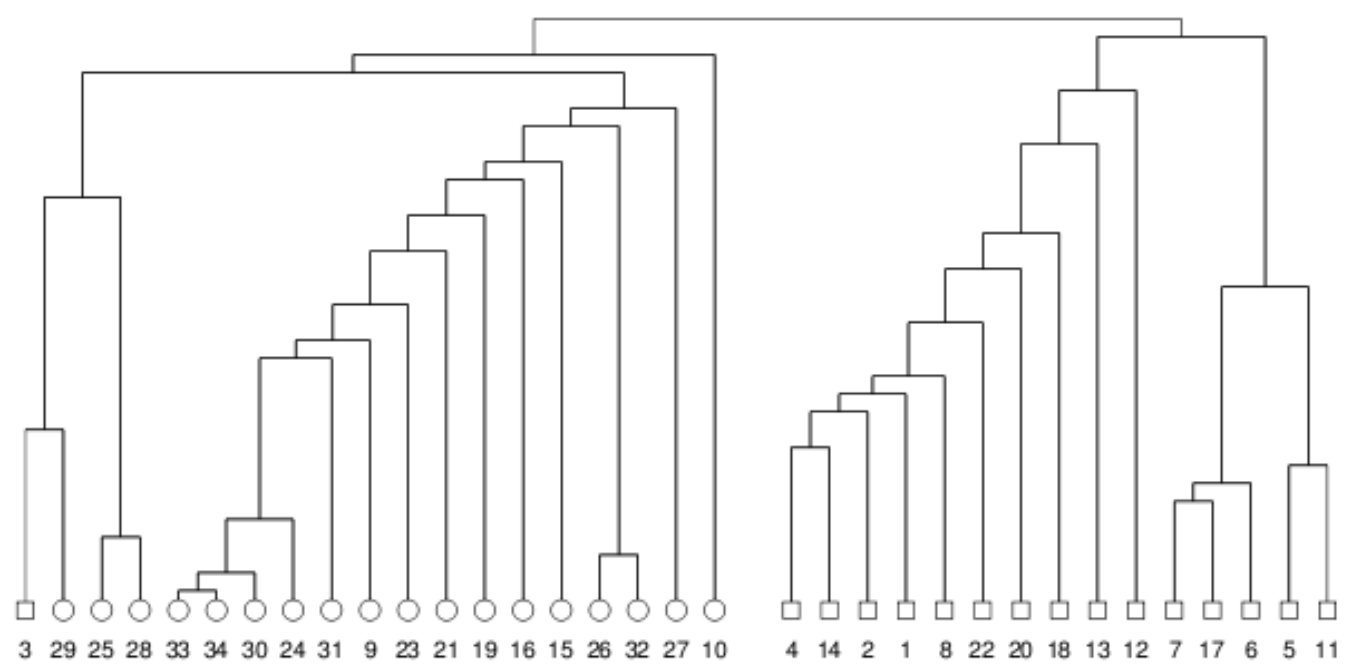

Figura 10 - Exemplo de agrupamento hierárquico retirado de Girvan e Newman (2002).

Reichardt e Bornholdt (2006) propuseram uma abordagem de detecção de comunidades baseada em 4 aspectos: (i) premiar as conexões existentes dentro do mesmo grupo, (ii) penalizar os pares de vértices que não se conectam dentro da mesma comunidade, (iii) penalizar a conexão entre vértices de diferentes grupos, (iv) premiar os pares de vértices de diferentes grupos que 
não se conectam. Essas afirmações levam a Equação 2.15, em que a função $\delta\left(v_{i}, v_{j}\right)$ retorna 1 caso $v_{i}$ e $v_{j}$ estejam no mesmo grupo e 0 caso contrário. É necessário ressaltar que essa equação foi proposta no artigo, focando redes não direcionadas e sem variação de peso (1 caso a conexão exista e 0 caso contrário).

$$
\begin{gathered}
H=-\alpha * \sum_{i \neq j} w_{i, j} * \delta\left(v_{i}, v_{j}\right)+\beta * \sum_{i \neq j}\left(1-w_{i, j}\right) * \delta\left(v_{i}, v_{j}\right)+ \\
\gamma * \sum_{i \neq j} w_{i, j} *\left(1-\delta\left(v_{i}, v_{j}\right)\right)-\omega * \sum_{i \neq j}\left(1-w_{i, j}\right) *\left(1-\delta\left(v_{i}, v_{j}\right)\right)
\end{gathered}
$$

$\mathrm{Na}$ Equação 2.15 a primeira somatória representa as conexões existentes dentro de um mesmo grupo, sendo essas conexões interessantes. A segunda somatória representa as conexões inexistentes dentro do mesmo grupo, ou seja, 2 vértices que se encontram em um mesmo grupo mas que não são conectados entre si. A terceira somatória representa as conexões existentes entre grupos diferentes. Tanto a segunda quanto a terceira somatória não são interessantes, portanto elas são adicionadas ao valor final da equação como punição. A última somatória representa as conexões não existentes entre diferentes grupos, o que é interessante para o agrupamento. $\mathrm{O}$ método proposto trabalha minimizando essa função, tentando maximizar a primeira e a última somatória enquanto reduz a segunda e a terceira.

\subsubsection{Considerações Finais}

Nesta seção foi definido o que é uma rede, apresentado alguns conceitos básicos, medidas para análise de seus vértices e algoritmos para processamento das redes visando extrair conhecimento útil. Toda essa revisão apresentou a capacidade de exploração das redes, sendo capaz de modelar satisfatoriamente diversos domínios diferentes e possuindo diversas abordagens diferentes de exploração para extração de conhecimento.

As medidas apresentadas possuem o mesmo objetivo, encontrar pontos possivelmente interessantes na rede, porém cada uma delas possui um conceito diferente do que é interessante. Algumas utilizam as conexões para definir o que é interessante, outras definem que estar em vários caminhos mínimos da rede torna o vértice interessante. Toda essa variedade de medidas permite que a rede seja explorada com diversos conceitos diferentes, abrindo um grande leque de possibilidades de exploração.

Já os algoritmos de propagação de rótulos e de detecção de comunidades se mostraram eficientes em separar o domínio. A propagação de rótulos realiza o processamento de acordo com classes pré-estabelecidas, dividindo o domínio de acordo com os rótulos atribuídos a alguns vértices. Os algoritmos de detecção de comunidades particionam o domínio considerando apenas a estrutura da rede, visando maximizar o número de conexões dentro de um mesmo grupo e minimizar as conexões entre diferentes grupos. 
No próximo capítulo serão apresentados trabalhos que utilizam redes para minerar regras de associação, dividindo a análise em pré-processamento, extração de regras e pósprocessamento.

\subsection{Redes e Regras de Associação}

Nas seções anteriores, foram apresentadas abordagens de regras de associação e de redes complexas. As abordagens de regras de associação apresentaram diferentes soluções para a exploração de correlações contidas em bases de dados. Entretanto, a quantidade de padrões extraídos normalmente dificulta o processo de exploração como um todo. Também foram apresentadas as redes complexas e sua grande capacidade de modelagem de relações entre itens. Também foram apresentadas diversas técnicas para processamento das redes visando identificar conhecimento potencialmente úteis.

Nesta seção serão apresentadas abordagens que unem a capacidade de extração de padrões das regras de associação com a grande capacidade de modelagem de relações das redes. A seção foi divida para apresentar abordagens em cada uma das etapas da mineração de regras.

\subsubsection{Abordagens de Pré-Processamento}

O trabalho de Vijayalakshmi et al. (2011) utiliza o conceito de pattern growth ou padrão crescente. Nesse conceito, a mineração de padrões frequentes se dá por meio de um padrão de tamanho menor com adição de novos itens. O trabalho visa encontrar subgrafos frequentes em uma base contendo $\mathrm{N}$ grafos. Ou seja, dada uma base de dados $G D=\left\{G_{1}, G_{2}, G_{3}, \ldots, G_{n}\right\}$, em que $G_{x}$ representa o x-ésimo grafo dentro da base de dados, encontre subgrafos que ocorram frequentemente em $G D$. Ressaltando que todos esses grafos modelam o mesmo conjunto de itens, mudando apenas as arestas que os conectam. Esses subgrafos podem ser utilizados como itemsets frequentes para a mineração de regras de associação. O algoritmo proposto (FP-GraphMiner) possui 3 fases.

Na primeira fase a base é totalmente escaneada e a frequência de cada um dos itens é armazenada em uma tabela, chamada tabela de frequência. A construção é realizada lendo todos os grafos de GD e construíndo uma estrutura chamada BitCode para as arestas. Esse BitCode guarda informações referentes a quais grafos suportam a aresta, ou seja, se a aresta que liga os vértices $a$ e $b$ aparecem em $G_{1}, G_{3} e G_{4}$ e não aparece em $G_{2}$ o BitCode dessa aresta é 1011. A soma do BitCode representa a frequência da aresta. Um exemplo de tabela de frequência pode ser visto na Figura 11, em que os outros elementos da figura serão explicados a seguir. Foi utilizada a representação de uma figura para que seja possível apresentar o conjunto de arestas do mesmo grupo e que formam um único vértice.

Usando como base essa tabela de frequência, é iniciada a segunda fase do algoritmo, que é a construção do FP-Graph, no qual cada vértice representa um conjunto de arestas e BitCodes 
que estão presentes em $G D$, ou seja, se existe um conjunto de 4 arestas que estão presentes em $G_{1}, G_{2} e G_{5}$, essas 4 arestas serão representadas pelo mesmo vértice no $F P$-Graph. Ordenando as arestas de acordo com o BitCode, é possível obter subgrafos e detalhes referentes aos grafos que eles pertencem. Com a ordenação realizada, os subgrafos que possuem o mesmo peso no BitCode são agrupados (o peso do BitCode é o número de grafos que possuem aquela determinada aresta). Dessa maneira, é feita uma divisão de subgrafos de acordo com o seu suporte. Na Figura 11 é apresentado um exemplo adaptado de Vijayalakshmi et al. (2011), em que é possível visualizar os grupos (linha tracejada vermelha) e o conjunto de BitCodes que constituem cada vértice (linha contínua azul). A estrutura do BitCode na imagem é <Vértice, Sequencia binária de qual grafo pertence>. Levando como exemplo o ID 1, tem-se uma aresta que conecta os vértices $a$ e $b$ em $G D$, que está contida em todos os grafos da base de dados. Já para o ID 20 tem-se uma aresta que conecta os vértices $f$ e $h$ em $G_{D}$, contida apenas no $G_{3}$.

\begin{tabular}{|c|c|c|c|c|c|}
\hline \multirow{2}{*}{$\begin{array}{l}\text { ID } \\
1 \\
\end{array}$} & \multicolumn{2}{|c|}{$\begin{array}{c}\text { Arestas } \\
<\text { Aresta,BitCode }>\end{array}$} & \multirow{2}{*}{\begin{tabular}{|l|} 
ID \\
11 \\
\end{tabular}} & \multicolumn{2}{|l|}{$\begin{array}{c}\text { Arestas } \\
<\text { Aresta,BitCode }>\end{array}$} \\
\hline & 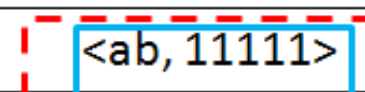 & $=1$ & & i $<\overline{\mathrm{ad}}, \overline{11001>}$ & 1 \\
\hline 2 & $<a c, 11111>$ & 1 & 12 & $<d g, 10101>$ & 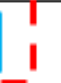 \\
\hline 3 & $<b c, 11111>$ & I & 13 & $\left.\mathrm{I}^{-}<\mathrm{be}, 11000\right\rangle$ & 7 \\
\hline 4 & $<b d, 11111>$ & 1 & 14 & $<$ igh, 10100> & i \\
\hline 5 & $<\mathrm{df}, 11111>$ & $\begin{array}{l}1 \\
1\end{array}$ & 15 & \begin{tabular}{ll|} 
i & $<, 10010>$ \\
\end{tabular} & 1 \\
\hline 6 & $<\mathrm{de}, 11101>$ & $=1$ & 16 & $<\mathrm{dh}, 10010>$ & $\frac{1}{1}$ \\
\hline 7 & <ef, 11101> & 1 & 17 & \begin{tabular}{ll|} 
& $<\mathrm{ce}, 10001>$ \\
\end{tabular} & 1 \\
\hline 8 & <eg, 11101> & i & 18 & $<h i, 10000>$ & 1 \\
\hline 9 & $<f g, 11101>$ & 1 & 19 & \begin{tabular}{ll|} 
& $<e h, 00100>$ \\
\end{tabular} & 1 \\
\hline 10 & $\mathrm{~L} \leq \mathrm{cd}, 11011\rangle$ & $\begin{array}{r}1 \\
-1 \\
\end{array}$ & 20 & \begin{tabular}{|l|l|} 
I & $<\mathrm{fh}, 00100>$ \\
\end{tabular} & 1 \\
\hline ᄂ - & & & & lértice & \\
\hline
\end{tabular}

Figura 11 - Tabela de frequência de uma base de grafos com a separação por grupos e representação em vértices.

Os grupos são ordenados de acordo com o suporte dos subgrafos que eles possuem de maneira crescente, estando o grupo com menor suporte no início da lista e o com maior suporte no fim. Desse modo, é possível analisar 2 grupos sequencialmente, buscando por ligações entre eles considerando o número de grafos que eles aparecem. É possível ver a tabela de frequência apresentada na Figura 11 modelada como um FP-Graph na Figura 12. Considerando a aresta 
“ad", que está presente em $G_{1}, G_{2} e G_{5}$, observa-se que a mesma está ligada à aresta "cd”, que está presente em $G_{1}, G_{2}, G_{4} e G_{5}$, ou seja, todos os grafos que "ad" está presente, "cd" também está; portanto, "cd" é um superconjunto de "ad" e uma aresta não direcionada é adicionada entre eles. Esse exemplo foi retirado do trabalho de Vijayalakshmi et al. (2011).

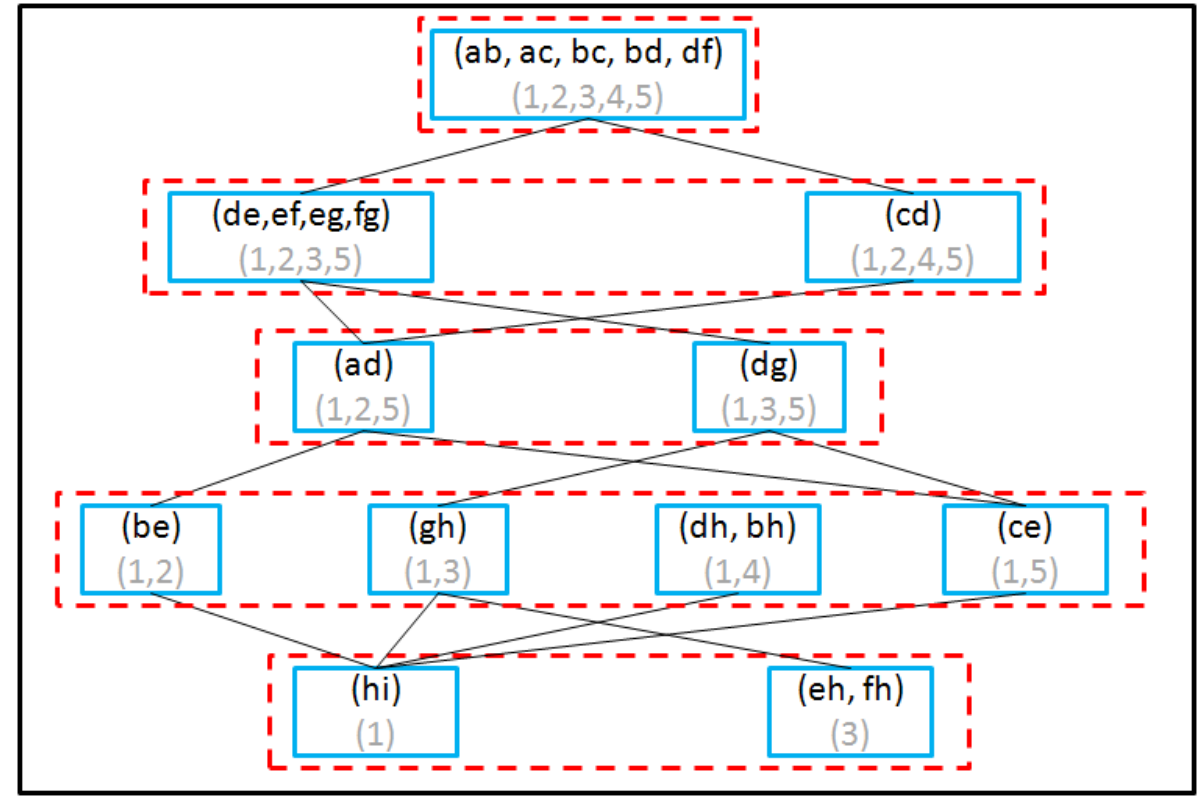

Figura 12 - FPGraph construído de acordo com o exemplo da Figura 11.

Utilizando o FP-Graph os subgrafos são minerados de acordo com um suporte $\sigma$ na terceira fase do processo. Essa mineração é feita utilizando um algoritmo de busca em profundidade, iniciando pelos vértices com menor suporte em direção aos vértices com maior suporte. Conforme é feita a caminhada no grafo, os subgrafos são gerados pelo cálculo do suporte. Além de proporem a geração de subgrafos por busca em profundidade, também foi proposto o uso de um grafo $Q$, definido pelo usuário, como base para geração dos subgrafos. Esse grafo então é utilizado em uma busca em largura, para comparação com o caminho percorrido, visando encontrar subgrafos que possuam esse $Q$.

A ideia de modelar os itens frequentes em grafos e depois percorrê-los para obter os conjuntos de itens frequentes é bastante comum na literatura, conforme pode ser visto em vários trabalhos (ALONSO et al., 2011; WANG; SHANG; LI, 2011; ZHU et al., 2011; ÖZKURAL; UçAR; AYKANAT, 2011; DONG et al., 2012; LIU; ZHAI; PEDRYCZ, 2012; SALAM; KHAYAL, 2012; SILVA; MEIRA JR.; ZAKI, 2012; ARUMUGAM; SABEEN, 2013; ELSEIDY et al., 2014; FLORES-GARRIDO; CARRASCO-OCHOA; TRINIDAD, 2014b; FLORES-GARRIDO; CARRASCO-OCHOA; TRINIDAD, 2014a; LIU et al., 2014; OH; JUNG; JO, 2014; FLORES-GARRIDO; CARRASCO-OCHOA; TRINIDAD, 2015; LEE et al., 2015). Cada um desses trabalhos usa o conceito de padrão crescente para minerar os itemsets frequentes, cada um com sua particularidade. Alguns utilizam um conceito diferente de suporte, outros utilizam DAG (Directed Acyclic Graph) no lugar de um grafo completo. Os resultados variam 
bastante, de acordo com a medida e o grafo escolhidos, dando a possibilidade de realizar diversos tipos de explorações e chegando a resultados diferentes.

Além dos trabalhos que utilizam o conceito de padrão crescente, existem também os que utilizam técnicas de poda ou de detecção de comunidades para obter os itemsets frequentes. Destaca-se o trabalho de Videla-Cavieres, F. e Ríos (2014), que propõem a extensão do processo de análise de cesta de compras, visando processar uma quantidade maior de informação e utiliza poda e detecção de comunidades em seu processo.

A primeira etapa do trabalho consiste em modelar uma rede de produtos (Product Network). Essa rede é construída de maneira que cada um de seus vértices representa um produto e cada aresta representa a interação entre esses produtos. Como definição, foi proposto que o peso dessas arestas fosse a quantidade de compras que os itens aparecem juntos, ou seja, a cada vez que 2 itens são comprados juntos adiciona-se 1 ao peso de sua respectiva aresta. A relação entre os itens é feita entre pares, o que significa que caso uma compra possua os itens "a", "b" e "c" serão adicionados 1 nas arestas "ab", "bc" e "ac". Ressaltando que a ligação é não direcionada, não havendo diferença na ligação saindo de "a" indo para "b" ou "b" indo para "a".

Na etapa 2 é realizada a poda das arestas que não são interessantes. Essa poda é necessária pois, em uma grande base de dados, praticamente todos os itens da base foram comprados em conjunto, mesmo que uma única vez. O fato desses itens terem sido comprados uma única vez juntos não significa que exista uma correlação entre eles. Muitas vezes essas ligações fracas são consideradas correlações espúrias ou ruídos na base e devem ser removidas. O grande problema é definir um limiar, no qual seja possível diferenciar as correlações que são válidas das correlações que são ruídos. Para contornar esse problema, foi proposto o método three heavy edges threshold - thet que consiste em realizar a média dos pesos das 3 maiores arestas. Com esse valor, foram realizados 20 filtros, variando o threshold de $5 \%$ em 5\% (5\%, 10\%, 15\%, ..., 90\%, 95\%, 100\%).

Após a aplicação dos filtros, são aplicados algoritmos de detecção de comunidades que permitem sobreposição. A escolha de permitir sobreposição permite que produtos que estejam fortemente relacionados com outros produtos que estejam em diferentes comunidades ainda sejam considerados em ambas as comunidades, sem perder conexões importantes. Foi utilizado um conjunto de limiares para considerar se um produto pertence a mais de uma comunidade ou não. Esses valores foram $r=0.01,0.05,0.10,0.15, \ldots, 0.45,0.50$. O resultado final do método são os grupos, contendo cada um deles conjuntos de itemsets frequentes de acordo com os limiares utilizados para construção da rede de produtos.

Vários outros trabalhos utilizam detecção de comunidades, conforme pode ser visto em Georgii, Tsuda e Schölkopf (2011), Sikora e Gruca (2011), Anchuri et al. (2012), Berlingerio, Pinelli e Calabrese (2013), Liu, Cheng e Tseng (2013), Park, Han e Lee (2014). Alguns desses trabalhos utilizam técnicas de detecção de comunidades que não permitem sobreposição, outros usam as próprias comunidades como itemsets frequentes. Já na área de poda, tem-se os trabalhos de Takigawa e Mamitsuka (2011), Anchuri et al. (2012), Kim, Kim e Chen (2012), Liu, SHEN e 
ZHU (2013), Prado et al. (2013), Faralli, Stilo e Velardi (2015). Cada um desses trabalhos propõe uma medida diferente para podar os itens da base de dados, visando focar a exploração apenas nos itens mais interessantes para a base de dados. Além dos trabalhos da área de regras de associação, há também alguns artigos que tratam problemas mais especificos, como Besemann, Wu e Denton (2011), que usa correlação de Poisson para gerar os itemsets frequentes, ou Jung (2012) que utiliza sliding windows para extrair padrões frequentes em bases de dados temporais. Todos esses trabalhos utilizam-se das redes para processar a base de dados, porém, essas explorações nem sempre são focadas nos itens e na sua importância na base de dados, focando apenas na geração de grupos ou adaptações para minerar regras de bases não transacionais.

Diversos trabalhos foram propostos no pré-processamento, utilizando diversas técnicas e diferentes medidas. Cada um desses trabalhos visa explorar a base de dados com objetivos diferentes, buscando por itemsets diferentes e apresentando resultados interessantes. Reforçando que alguns dos trabalhos apresentados nesta seção terminam com a geração dos itemsets frequentes, porém, como o maior foco desses trabalhos não é a geração dos itemsets, mas sim o pré-processamento dos itens, eles foram considerados como trabalhos na abordagem de préprocessamento. A característica que todos os trabalhos tem em comum é o que se espera obter de resultado. Todos os trabalhos buscam por algum tipo de redução, seja ela na quantidade de itens que deverão ser minerados ou na quantidade de conexão entre eles. Esses trabalhos visam direcionar a exploração, reduzindo a complexidade do processo de mineração e buscando apenas os itens que realmente interessam para o usuário. Na próxima seção serão explicados os trabalhos que atuam na extração das regras, visando a redução da complexidade na extração das regras e/ou direcionamento no processo de extração.

\subsubsection{Abordagens de Extração de Regras}

Já nas abordagens de extração regras de associação usando redes, podemos destacar o uso de Genetic Network Programming (GNP). As abordanges que utilizam GNP focam em representar a geração das regras de associação em uma sequencia de etapas. Essas etapas fazem parte de um algoritmo de otimização, que tem como objetivo aumentar a qualidade das regras geradas de acordo com uma função pré-definida.

Dos trabalhos que utilizam GNP, é possível destacar o trabalho de Yang et al. (2011b), que utiliza GNP para extrair as regras de associação utilizando como base palavras-chave. GNP é uma extensão da programação genética, que usa grafos direcionados para computação evolutiva. A modelagem convencional de uma GNP é apresentada na Figura 13. A rede é constituída de 3 tipos diferentes de vértices, cada um com sua funcionalidade específica, sendo eles: Start Node ou vértice inicial, Judgement Nodes ou vértices de avaliação e Processing Nodes ou vértices de processamento. O vértice inicial é o ponto de início da exploração, onde a abordagem vai começar a processar a rede para gerar as regras. Os vértices de avaliação são responsáveis por avaliar a informação do domínio e decidir se a regra será gerada com os itens atuais ou se mais 
itens serão inseridos na regra. Já os vértices de processamento representam algumas ações que podem ser tomadas, de acordo com o objetivo do trabalho.

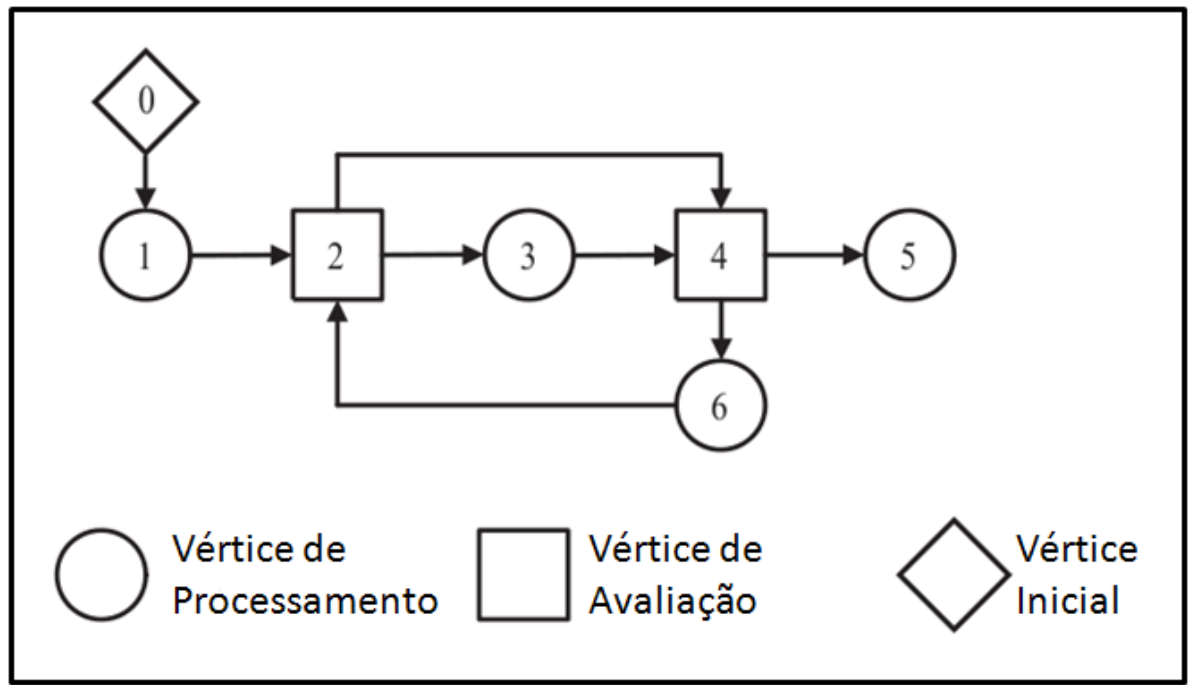

Figura 13 - Estrutura básica de uma GNP, adaptada de Yang et al. (2011b).

Para construir a GNP e minerar regras de associação, primeiro o usuário define as palavras-chave que deseja utilizar como critério de interesse. Essas palavras são então utilizadas para calcular a similaridade com todos os itens da base. Esse valor de similaridade é utilizado como a probabilidade de um item ser selecionado para construir um indivíduo que é composto pelos itens sequenciados. O GNP funciona como um algoritmo genético, gerando diversos indivíduos (onde cada indivíduo é uma regra) aleatoriamente, calculando o fitness como meio de validar os indivíduos. Após a geração das regras, é criado um ranking de acordo com os valores de suporte, confiança e o valor de fitness. Esse ranking é apresentado para o usuário como resultado final. Há outros trabalhos que utilizam GNP para extrair regras: (MABU et al., 2011; YANG et al., 2011a; SIVAKRITHIKA; MERLIN; SUGIRTHA, 2012; ZHOU; HIRASAWA, 2014). Esses trabalhos variam a função de fitness para extração das regras, extraindo-as com diferentes objetivos e também diferentes meios de contrução de indivíduos. Alguns trabalhos utilizam técnicas de pós-processamento em conjunto, que serão explicadas na próxima seção.

Além da GNP, existe outra abordagem que utiliza grafos para gerar regras de associação, que foi proposto por Sheng Huijuan Hou e Chen (2018). Esse algoritmo funciona em 3 etapas: i) extração dos itemsets de tamanho 2, ii) criação de grafo de probabilidades e iii) extração das regras de tamanho 2. Esse trabalho funciona com regras de tamanho 2, pois é uma restrição necessária para a construção do grafo de probalidade. A extração dos itemsets de tamanho 2 é padrão, considerando a medida suporte.

Então, para cada itemset frequente extraído, calcula-se a medida de interesse, dada pela 
Equação 2.16. Essa medida pode ser interpretada da seguinte maneira:

$$
\text { interest }(X, Y)=\frac{\operatorname{support}(X \cup Y)}{\operatorname{support}(X) * \operatorname{support}(Y)}-1
$$

- Se Interest $(X, Y)==0$, então os itens são independetes.

- Se Interest $(X, Y)<0$, então os itens são negativamente correlacionados, o que significa que a ocorrência de $\mathrm{X}$ reduz as chances de $\mathrm{Y}$ ocorrer.

- Se Interest $(X, Y)>0$, entáo os itens são positivamente correlacionados, o que significa que a ocorrência de $\mathrm{X}$ aumenta as chances de $\mathrm{Y}$ ocorrer.

Para extração de regras de associacão, apenas são interessantes os itens positivamente correlacionados. O grafo é modelado com cada item sendo uma aresta e o vértice direcionado entre eles sendo o valor da medida de interesse. Todas as relações de itens com a medida de interesse $<=0$ não são modelados no grafo. Um exemplo desse grafo modelado pode ser visto na Figura 14

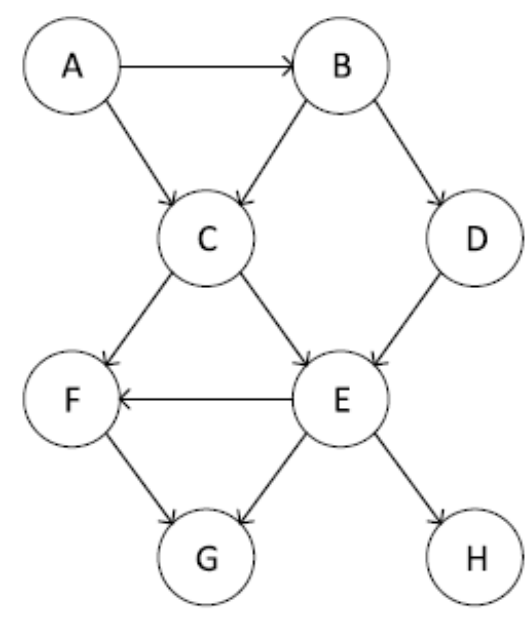

Figura 14 - Grafo de relações entre itens extraído de Sheng Huijuan Hou e Chen (2018).

Por fim, a partir do grafo construído, são extraídas as regras de associação. Para cada item modelado no grafo, busca-se todos os outros itens que possuem vértices direcionados para extrair a regra. Usando como exemplo a Figura 14, considerando que o item selecionado se "C", os ítens que possuem um vértice ligando até ele são "A"e "B", portanto a regra extraída é $A, B \rightarrow C$. Caso a regra selecionada seja "A", então nenhuma regra será extraída e o algoritmo continuará.

Além das abordagens apresentadas, existem outros trabalhos que utilizam outras técnicas para extrair regras. Os trabalhos de Liu, Zhai e Pedrycz (2012), Nguyen et al. (2013), Nirmala e Palanisamy (2013), Pears et al. (2013), Petelin et al. (2013), Li e Wu (2014), Fariha et al. (2015) utilizam uma modelagem de grafos na qual a extração de regras consiste em uma caminhada no 
grafo. As contribuições se diferenciam na construção dos grafos e nos meios de caminhar no grafo, que tendem a gerar diferentes regras. Também tem algumas outras abordagens como o trabalho de Besemann, Wu e Denton (2011), que utiliza uma variação do Apriori aplicado em redes, e o trabalho de Hong et al. (2012), que utiliza um sistema de otimização de formigueiro para geração de regras. Os trabalhos propostos na extração de regras de associação visam uma modelagem otimizada com técnicas que já direcionam a geração das regras para as regras mais interessantes. Porém, os trabalhos apresentados ainda possuem uma complexidade bastante alta, por exemplo a GNP necessita de um algoritmo genético para otimizar a sua mineração. Na próxima seção são apresentados os trabalhos que utilizam o pós-processamento para encontrar as regras mais interessantes.

\subsubsection{Abordagens de Pós-Processamento}

Existem 2 abordagens distintas para encontrar as regras interessantes: mapeamento e medidas objetivas. Nos trabalhos que utilizam medidas objetivas para criar um ranking, é possível destacar o trabalho de Yang et al. (2011a), que utiliza o ranking das regras para melhorar a acurácia de um classificador associativo. A ideia por trás desse classificador associativo é definir um consequente (a classe da base de dados) para selecionar a regras a serem utilizadas. As regras que possuem a classe como consequente são colocadas em um ranking para realizar a classificação de novos elementos da base de dados.

Para decidir qual a medida que será utilizada, os autores desenvolveram uma GNP que tem como função de fitness a acurária de classificação e como indivíduos uma fórmula que contém diferentes medidas objetivas com diferentes pesos. Tendo como base a equação, as regras com valores muito baixos e com correlação negativa são podadas, sobrando assim um conjunto menor. Esse conjunto podado é analisado de acordo com a quantidade de registros que cada uma cobre e um feedback individual é dado, de acordo com a acurácia da regra, realizando algumas modificações no ranking com o objetivo de aumentar a acurácia de classificação. Além desse trabalho há outros que também utilizam medidas objetivas para criar um ranking, conforme podem ser visto em Kim et al. (2011), Kliegr et al. (2011), que variam as medidas objetivas visando obter diferentes análises e diferentes rankings de regras de associação.

Já nas abordagens que utilizam mapeamento, é possível destacar alguns trabalhos, entre eles o de Karimi-Majd e Mahootchi (2015), que faz o pós-processamento das regras de associação utilizando agrupamento e depois o mapeamento das regras. Inicialmente, é definida uma medida de similaridade, capaz de considerar o antecedente e o consequente das regras separadamente, assim como também considera as regras espelhadas ( $A \Rightarrow B$ e $B \Rightarrow A$ com $100 \%$ de similaridade). Após definir a medida de similaridade, é realizado um agrupamento nas regras de associação. Dentre as diversas técnicas disponível de agrupamento, os autores optaram por utilizar o $k$ medoids. Essa escolha foi feita pois o centróide de cada grupo é um elemento que está sendo agrupado, nesse caso uma regra de associação. Um algoritmo cujo centro do grupo é um ponto 
no espaço, como k-means por exemplo, não é adequado para agrupar regras, uma vez que um ponto no espaço de similaridades de regras não possui uma representação válida.

Com as regras divididas em grupos, foi realizado então o mapeamento usando redes para facilitar a exploração por parte do usuário. Cada grupo é então modelado usando uma rede direcionada, em que o antecedente aponta para o consequente. É possível ver um exemplo de modelagem na Figura 15, no qual " $A$ " e "B" são antecedentes de "C". Como a similaridade entre as regras é calculada utilizando os itens e as regras com menos similaridade estão em grupos distintos, os autores garantem que a representação das regras em redes tende a usar poucos atributos, deixando a exploração bastante limpa e fácil de entender. Outros trabalhos também usam a estratégia de modelagem, como visto em Petelin et al. (2013), MartínezBallesteros, Nepomuceno-Chamorro e Riquelme (2014), que variam a modelagem com o objetivo de apresentar diferentes maneiras de visualizar as regras.

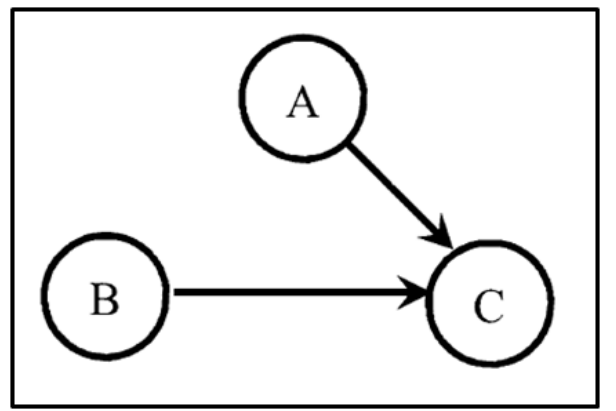

Figura 15 - Exemplo da rede direcionada utilizada por Karimi-Majd e Mahootchi (2015).

Também na mesma área do mapeamento, temos as redes de regras de associação (ARN Association Rule Network), proposto por Chawla, Arunasalam e Davis (2003) e extendido por Pandey et al. (2009) e Chawla (2010). A ARN tem como objetivo explorar uma base de regras de associação de acordo com um item objetivo definido.

Inicialmente, é definido qual o item que se deseja entender. Usando como exemplo a base Contact-Lens, disponível na $\mathrm{UCI}^{8}$, suponha que seja definida a classe "Lens=Hard"como objetivo de exploração. Ao realizar essa definição, a abordagem explorará as regras geradas em busca de outros itens que expliquem a ocorrência da prescrição de uma lente dura. Após a definição do item objetivo, essa abordagem funciona em 2 etapas: (i) modelagem da rede e (ii) remoção de regras que não cumprem as premissas da abordagem e, portanto, são consideradas não interessantes.

Na etapa (i) a rede é construída considerando o item objetivo definido, denotado pela letra z. Primeiro, z é modelado na rede, denotamos o nível de hierarquia 0 para esse item. Então, todas as regras que possuem z como RHS são modeladas. Todos os itens dessas regras são modelados no nível 1, ou seja, 1 conexão de distância do item z. Modela-se então todas as regras que possuem o RHS no nível 1. Os $L H S$ dessas regras são modelados no nível 2, ou seja, 2 8 https://archive.ics.uci.edu/ml/datasets/lenses 
conexões de distância do item z. Esse processo é repetido até que não haja mais regras a serem modeladas.

Na etapa (ii) é realizada a poda das regras consideradas não interessantes para o processo. Para realizar essa poda, 2 restrições foram adicionadas: (1) não é permitido repetir um item na rede, mantendo sempre a ocorrência no menor nível e (2) as regras modeladas necessitam, obrigatoriamente, ter o LHS modelado no nível $x$ e o RHS no nível $x-1$, por exemplo, para uma regra modelada com o LHS no nível 2 ser mantida, o RHS precisa obrigatoriamente estar no modelado no nível 1. Essas restrições existem para garantir que, dado um item modelo, todos os caminhos possíveis levam a z, sem ciclos.

Na Figura 16 é possível visualizar um exemplo de uma $A R N$ constrída sobre a base Contact Lens, com o atributo $\mathrm{z}=$ Lenses $=$ Hard . Nesse exemplo, temos Lens=Hard no nível 0 , Temos 7 itens no nível 1 e 4 itens no nível 2. Todas as outras regras que possuem esses itens foram podadas, por não seguir a restrição (1) ou restrição (2).

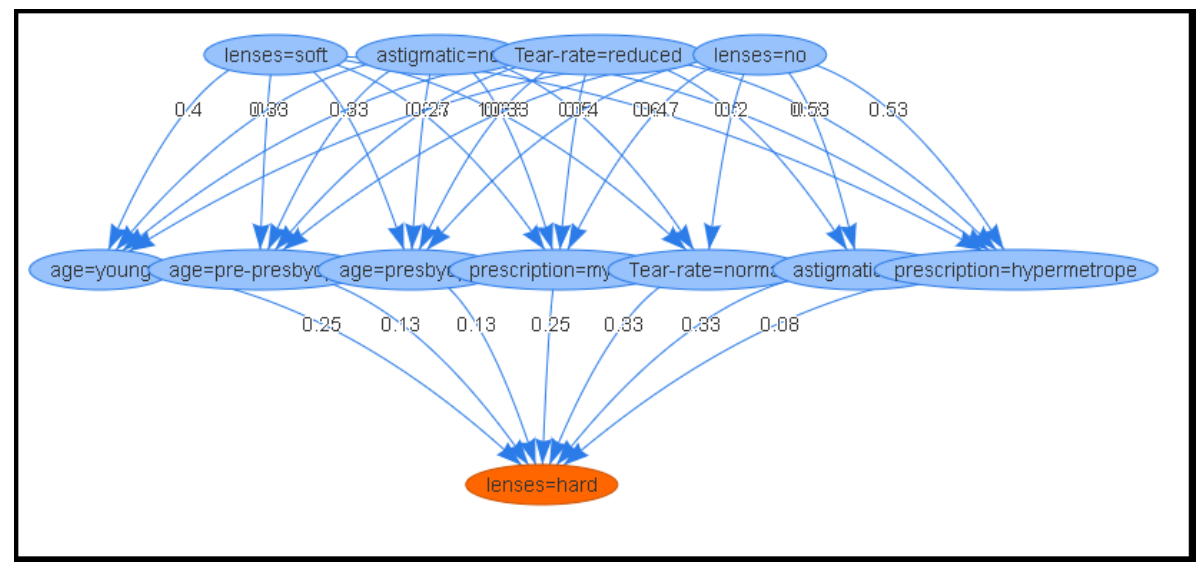

Figura $16-$ Exemplo de ARN gerada com $\mathrm{z}=$ Lens $=$ Hard .

Todos esses trabalhos focam na exploração baseada em um único objetivo, ou seja, é uma abordagem extremamente focada em uma medida desconsiderando outras possibilidades.

\subsubsection{Considerações Finais}

Nesta seção foram apresentados os principais trabalhos relacionados com esse projeto de doutorado. Esses trabalhos utilizam-se de redes para auxiliar o processo de mineração de regras de associação, sendo esse auxílio no pré-processamento, na extração ou no pós-processamento, podendo cada trabalho contribuir com mais de uma área. Esse tipo de auxílio é necessário, pois o processo de mineração de regras de associação é extremamente complexo, sendo necessárias diversas varreduras na base de dados para encontrar os itemsets frequentes, além de diversas comparações entre itens, para extrair as regras. Além da complexidade computacional, o número de regras geradas também é um grande desafio, sendo inviável a exploração manual por parte dos especialistas. 
A etapa que recebe o maior interesse da comunidade é o pré-processamento, que visa reduzir o tamanho da base de dados, seja no número de itens ou nas ligações entre os itens, reduzindo assim a gama de combinações para a etapa de extração. Essas abordagens normalmente param na extração de itemsets frequentes, não atuando diretamente na extração das regras de associação. Porém, conforme discutido na Seção 2.1, a geração dos itemsets frequentes é responsável pela maior complexidade computacional. Dessa maneira, reduzindo a quantidade de elementos ou padrões possíveis, é reduzida drasticamente a complexidade do processo de geração de regras.

Já na etapa de extração de regras os trabalhos propostos visam direcionar a extração dos padrões. Alguns desses métodos utilizam a modelagem em rede como meio de realizar esse direcionamento, utilizando métodos de caminhadas para extrair as regras. Outros trabalhos utilizam GNP para gerar as regras, utilizando algoritmos evolutivos para criar novas regras não encontradas durante as primeiras gerações. Esses métodos tendem a buscar por regras mais interessantes de acordo com algumas medidas ou até mesmo utilizando informações prévias que foram dadas pelo usuário.

$\mathrm{Na}$ etapa de pós-processamento os trabalhos propostos visam modelar e descrever as regras de associação de modo que seja possível ter um entendimento mais completo do todo. Algumas abordagens aproveitam-se de medidas objetivas, que visam calcular um valor de qualidade para cada regra gerada. Essas abordagens tendem a criar um ranking de qualidade, apresentando sempre as melhores regras, de acordo com a medida selecionada, no topo da lista.

Outras abordagens buscam utilizar os benefícios de se modelar as regras em um grafo. As abordagens apresentadas nesta seção tem como objetivo facilitar a exploração das regras usando os grafos. A representação gráfica das regras tendem a facilitar o entendimento da base de regras, facilitando a exploração por parte do usuário

Apesar das abordagens de pós-processamento serem interessantes e apresentarem resultados bastante promissores, essas abordagens não são capazes de apresentar uma exploração das regras de acordo com um conjunto de itens de interesse. A $A R N$ possibilita a exploração da base utilizando 1 item objetivo, permitindo que o usuário direcione a exploração. Entretanto, se o usuário deseja entender como um conjunto de itens de interesse se relaciona com o resto da base e como os itens da base podem se relacionar com 2 ou mais itens interesse, então a $A R N$ não é capaz de apresentar o resultado. Por exemplo, em uma análise de uma base de dados médica, deseja-se entender a relação entre diferentes sintomas e um conjunto específico de doenças. Nessa análise, é bastante importante entender se um determinado sintoma se relaciona com apenas uma doença, o que faria esse sintoma extremamente importante no momento de diagnosticar um paciente, ou se um determinado sintoma ocorre em todo o conjunto de doenças, fazendo com que aquele sintoma não seja tão importante no diagnóstico. Na $A R N$ seria necessário gerar 1 grafo para cada item de doença que se deseja e explorar e, após a geração, o usuário precisaria manualmente identificar os sintomas em comum considerando todas os grafos gerados. 
Com o objetivo de preencher essa lacuna, foram apresentadas duas abordagens capazes de explorar as regras de associação de acordo com um conjunto de itens de interesse. Essas abordagens são capazes de apresentar a correlação entre um determinado item da base com todo o conjunto de itens de interesse. As abordagens também são capazes de apresentar os itens dominantes e determinantes, facilitando a interpretação do usuário da base de dados. As soluções propostas foram a exARN convencional e a exARN gulosa. Ambas as abordagens são descritas em detalhes no próximo capítulo, junto com o resultado esperado. 


\section{3}

\section{EXARN CONVENCIONAL E GULOSA}

A mineração de regras de associação é capaz de encontrar padrões em um conjunto de dados. Em geral, esses padrões representam conhecimento que pode ser utilizado para auxiliar o processo de tomada de decisão, apoiando o especialista do domínio. Porém, o processo de mineração de regras de associação é extremamente custoso e, normalmente, a quantidade de regras extraídas supera a capacidade humana de processamento

Por esse motivo é seguro afirmar que após a extração das regras de associação, uma nova etapa é importante e necessária. O objetivo é explorar as regras, buscando por regras que possuem um conhecimento novo e interessante, ou até mesmo por relações importantes entre itens da base de dados, mesmo que não sejam necessariamente uma novidade.

Assim, neste doutorado foram propostas 2 novas abordagens de pós-processamento de regras de associação: ConexARN e Greedy exARN. Ambas as abordagens têm os mesmos objetivos: modelar mais de um item objetivo e maximizar a qualidade das regras modeladas. Entretanto, as abordagens possuem estratégias de modelagem que levam a resultados bastante diferentes. A ConexARN modela as regras assim que possível, focando nos menores níveis da rede. Essa abordagem foca na modelagem mais próxima possível dos itens objetivos. Já a Greedy exARN modela a melhor regra, de acordo com uma medida objetivo. Essa modelagem foca na maximização de uma medida objetivo, buscando uma maior qualidade nas regras modeladas.

\subsection{Motivação e Problemas em Aberto}

A mineração de regras de associação é extremamente interessante para descoberta de coocorrências e correlações entre atributos ou itens de umas bases de dados. Por muitas vezes, a quantidade de regras obtidas é maior que o conjunto de dados original, sendo necessários processos automáticos de preparo, de extração de conhecimento ou direcionamento de exploração. Com essa dificuldade, diferentes abordagens podem ser utilizadas para minerar regras de 
associação e explorar as regras geradas. Uma das abordagens que se mostrou promissora é o uso de grafos para auxiliar na exploração das regras, por exemplo, a $A R N$, apresentada no capítulo anterior, em que um item de interesse é definido pelo usuário e as regras são modeladas no grafo, apresentando visualmente as correlações.

Os grafos modelam os dados de acordo com a similaridade existente entre eles, sendo essa uma característica extremamente interessante para mineração de regras de associação, que visam buscar coocorrências e correlações entre itens de uma base de dados. As modelagens possíveis usando grafos são vastas, possibilitando que os grafos auxiliem na exploração das regras de associação.

Os trabalhos apresentados no Capítulo 2 buscam as regras interessantes utilizando-se de medidas objetivas. Essas medidas, geralmente, visam ranquear as regras de maneira que as mais interessantes fiquem no topo do ranking e as menos interessantes no fim. A grande limitação dessa área é que a exploração acaba sendo enviesada e focada em apenas uma medida, desconsiderando regras que poderiam ser interessantes mas não possuem um bom valor de acordo com uma determinada medida.

Um dos trabalhos que se diferenciam desse padrão é a Association Rule Network, apresentado em Pandey et al. (2009). Essa abordagem foca em modelar a base de acordo com um atributo objetivo, ou seja, foca na explicação de um atributo pré-selecionado de acordo com as regras de associação geradas na base de dados.

Entretanto, como a abordagem aceita um único item como objetivo de exploração, o conhecimento apresentado pode estar incompleto. Ao modelar apenas um item objetivo, algumas relações podem não aparecer para o usuário, portanto, faz-se necessário a modelagem de diversos itens objetivos em uma mesma visualização (Hipótese 1). Itens dominantes na base de dados podem aparecer como fortemente correlacionado a determinado item objetivo. Porém, sua correlação pode não explicar a ocorrência do item objetivo, uma vez que ele é dominante e aparece na maioria das transações (Hipótese 2). Como a $A R N$ modela as regras assim que possível, focada em um único item objetivo, não há qualquer processamento para aumentar ou verificar a qualidade das regras ((Hipótese 3)). Por fim, por ser necessário gerar diversas $A R N s$ para explorar diversos itens objetivos, não há nenhum processamento ou foco em reduzir a quantidade de regras modeladas (Hipótese 4).

Visando solucionar essa limitação, duas abordagens foram propostas nesse doutorado; a ConexARNe a Greedy exARN. Em ambas as abordagens é possível escolher N itens objetivos, para serem explicados em conjunto, utilizando um único grafo. Essa característica atende a Hipótese 1 A ConexARN visa modelar as regras assim que elas acontecem, focando em apresentar ao usuário as correlações mais próximas do conjunto de itens objetivos. Essa abordagem visa atender a Hipótese 4. Já a Greedy exARN visa modelar as regras otimizando uma medida de interesse de regras de associação. Ao maximizar a medida, a abordagem visa encontrar o conjunto de regras mais interessantes e apresentar ao usuário. Já essa abordagem visa atender as Hipóteses 3 e 4. 
Ao modelar mais de um item objetivo em uma mesma rede, ambas as abordagens apresentam os itens dominantes e determinantes para o usuário final. Essa característica visa atender a Hipótese 2. Ambas as abordagens são explicadas na próxima seção.

\subsection{ARN e Redes de Regras de Associação Extendidas}

Neste doutorado foram propostas 2 abordagens, essas abordagens possuem uma ideia central, aqui denominada Extended Association Rule Network (exARN), permitindo que o usuário explore a base de dados de acordo com um conjunto de itens objetivos, atendendo a Hipótese 1. Esses itens objetivos são os itens da base de dados que se deseja obter o conhecimento. Por exemplo, em uma base contendo músicas e estilos musicais, pode-se ter como objetivo entender quais são os padrões mais comuns de cada estilo e quais padrões em comum entre mais de um estilo. Nesse caso, os itens objetivos da base de dados seriam os estilos musicais.

Uma visão geral de como a exARN funciona pode ser visto a seguir, dividido em 4 passos. As abordagens serão apresentadas em detalhes no decorrer do capítulo.

1. O usuário define qual o conjunto de itens de seu interesse, que gostaria de aprender a respeito.

2. Os itens objetivos são modelados no grafo.

3. As regras que possuem esses itens objetivos são modeladas no grafo.

4. Siga modelando as regras até que não haja mais regras a serem modeladas.

Esses passos descrevem a construção do grafo baseado nas regras de associações extraídas. Como resultado, é obtido um grafo, onde cada vértice é um item e cada aresta representa graficamente uma regra. Entretanto, seguindo esses passos, a quantidade de regras modeladas seria muito grande, fazendo com que a capacidade de se interpretar o grafo fosse drasticamente reduzida. Para facilitar a interpretação do grafo gerado, as restrições da ARN foram mantidas, sem a restrição de escolher apenas 1 item objetivo. Essas restrições visam atender a Hipótese 4.

1. A modelagem das exARNs é feita em níveis, ou seja, os itens objetivos são modelados no nível 0 , o antecedente das regras que possuem os itens de nível 0 são modelados no nível 1, os antecedentes das regras que possuem os itens no nível 1 como $\boldsymbol{R H S}$ são modeladas no nível 2. Uma explicação visual dessa restrição pode ser vista na Figura 17.

2. O item é sempre modelado no nível mais baixo possível, de acordo com a regra ou heurística empregada. Se um item já foi modelado no grafo, então esse item não mais será adicionado ao grafo, somente serão adicionados novas regras que sejam no nível já modelado. 


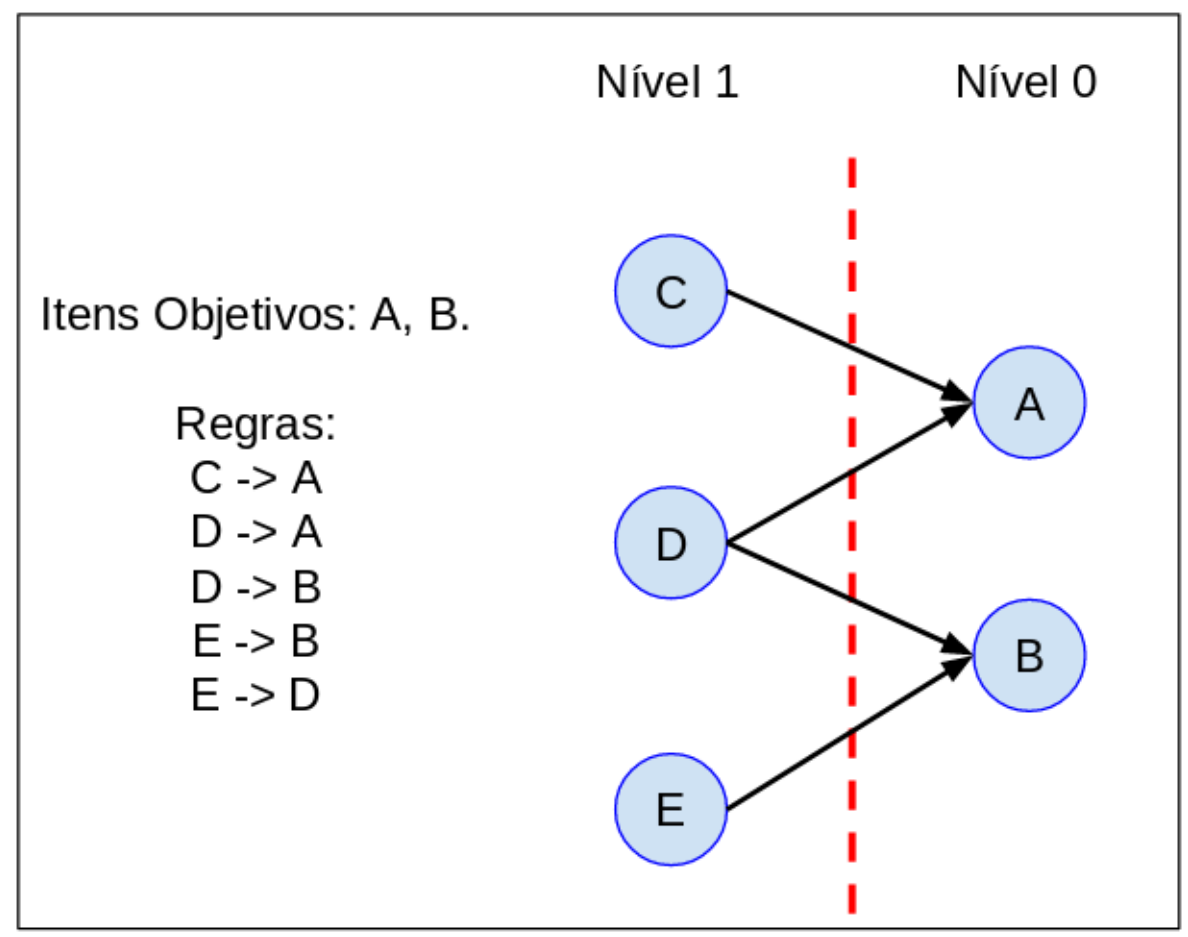

Figura 17 - Restrição - Modelagem de itens.

Na Figura 17 é apresentado um exemplo de exARN modelada. Nesse exemplo, os itens objetivos escolhidos foram A e B. Dado que temos 5 regras, apenas 4 foram modeladas. A regra $E \rightarrow D$ foi descartada. Isso acontece por que tanto $E$ como $D$ estão no mesmo nível, que é o nível 1, então a Restrição 1, de apenas modelar regras com o $\boldsymbol{R} \boldsymbol{H} \boldsymbol{S}$ no nível inferior, é quebrada.

Também é importante notar que o item E não é adicionado no nível 2. Isso ocorre por causa da Restrição 2, que força os itens sejam sempre modelados nos níveis mais baixos de acordo com alguma heurística. Nesse exemplo, as regras foram modeladas assim que fossem possíveis, então todas as 4 regras modeladas foram selecionadas assim que A e B foram definidos como itens objetivos. A Restrição 2 também impede um item de ser duplicado no grafo, portanto, a última regra é descartada por violar ambas as restrições.

Essas 2 restrições existem para que a visualização seja mais limpa, evitando a criação de ciclos. Além disso, essas restrições visam garantir o foco da modelagem, garantindo que todo o nó adicionado no grafo tenha um caminho direto, sem desvios, para os itens objetivos. Dessa maneira, buscamos direcionar o usuário ao conhecimento potencialmente útil, considerando seu input como guia de exploração. Esse direcionamento visa atender a Hipótese 2.

Neste doutorado foram desenvolvidas duas modelagens para a exARN: Convencional e Gulosa. Ambas as abordagens propostas atendem as Hipótese 1, 2 e 4 pela definição geral. A exARN Convencional visa adicionar a possibilidade de se modelar um grafo considerando um conjunto de itens objetivos. Essa abordagem é capaz de diferenciar itens dominantes, ou seja, itens que se relacionam com mais de 1 item objetivo, de itens que se relacionam apenas com um único item objetivo. Já a exARN Gulosa, além de modelar mais de um item objetivo, visa 
reduzir a quantidade de regras modeladas pela versão convencional, focando em otimizar uma medida selecionada pelo usuário. Essa abordagem visa, por fim, atender a Hipótese 3. Ambas as abordagens, com suas particularidades, são explicadas a seguir.

\subsubsection{ConexARN}

Visando aumentar a capacidade da $A R N$, foi proposta e implementada a abordagem chamada "convencional" da exARN (chamada ConexARN). A ConexARN apresenta uma extensão importante a $A R N$, que é a capacidade de modelar mais de um item objetivo em um grafo. Essa extensão permite que o usuário seja capaz de identificar itens dominantes, que se relacionam com vários itens objetivos. Esse processo não é trivial na $A R N$, uma vez que cada grafo poderia ter um único item objetivo e o usuário precisa identificar esse comportamento considerando todos os grafos gerados. Além dessa característica, os itens que se relacionam com apenas um único

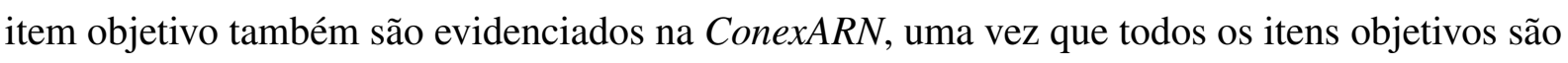
apresentados em um único grafo.

A ConexARN atende as Hipótese 1, 2 e 4, sendo elas: 1) modelar mais de um item objetivo, 2) visualizar itens dominantes e determinantes e 4) reduzir o número de regras a serem exploradas.

As principais diferenças entre a $A R N$ e a $\operatorname{ConexARN}$ são:

1. Número de itens objetivos. Na ConexARN é possível definir $\mathrm{N}>=1$ itens objetivos para serem explorados, enquanto na $A R N$ o número de itens objetivos é $\mathrm{N}=1$.

2. Identificação de itens dominantes. $\mathrm{Na}$ ConexARN a modelagem é feita para vários itens objetivos, o que permite ao usuário identificar quais itens são dominantes na base, ou seja, quais itens se relacionam basicamente com todos os objetivos.

3. Identificação de itens determinantes. Por modelar vários itens objetivos na mesma rede é possível identificar quais itens tem relação com apenas 1 único item objetivo e não se relacionam com nenhum outro. Essa informação pode ser determinante para descobrir quais itens tem maior chance de ter uma causalidade.

Assim como a $A R N$, a ConexARN manteve a restrição de regras terem tamanho 2, ou seja, 1 item no antecedente e 1 item no consequente. No caso da ConexARN e da $A R N$ essas restrições são bastante importantes, pois como não há restrições para modelagem, elas facilmente ficam sobrecarregadas de informação. A construção da ConexARN é apresentada no Algoritmo 1

Nesse algoritmo as operações de '+' e '-' representam operações de conjuntos. No caso da operação $\{A, B, C\}+\{D, E\}$ o resultado seria $\{A, B, C, D, E\}$. Já na operação $\{A, B, C, D, E\}$ - $\{D, E\}$ o resultado seria $\{A, B, C\}$. Além dessas operações, temos algumas funções definidas. Essas funções são explicadas abaixo: 


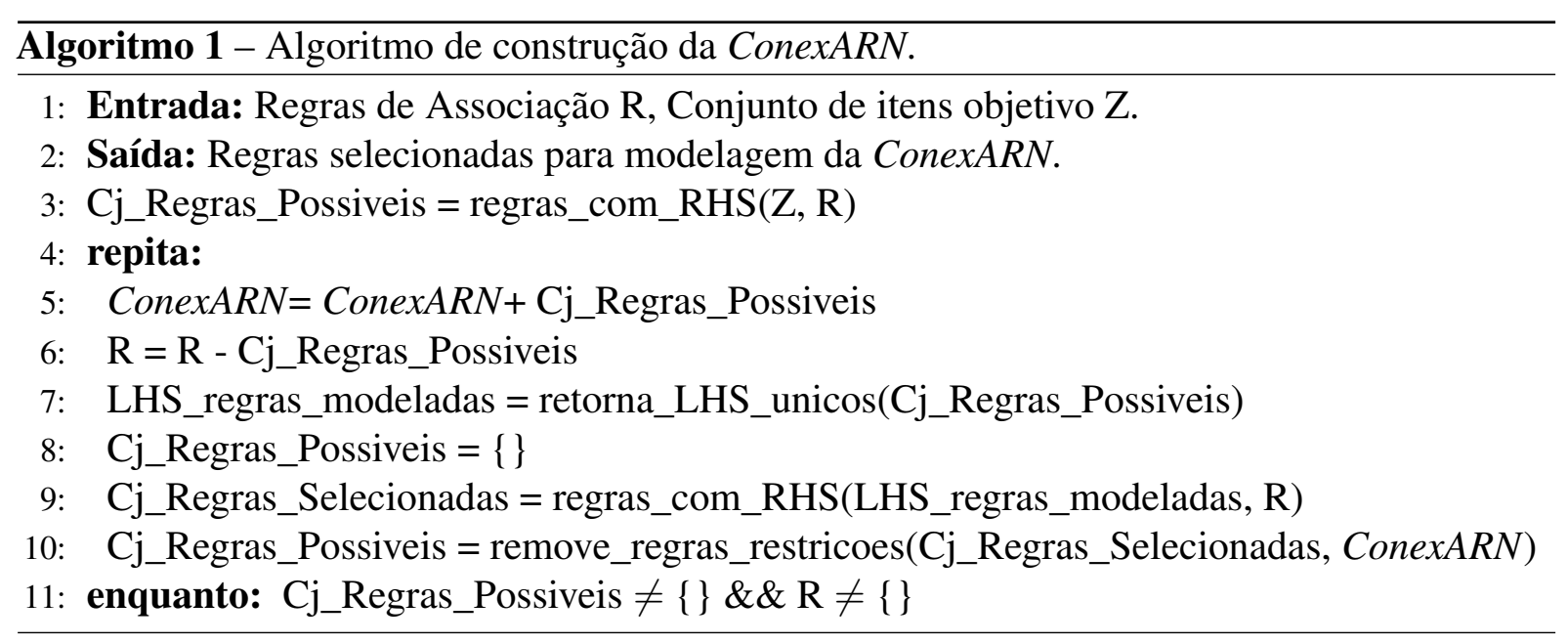

- regras_com_RHS (itensObjetivos, Regras): Essa função retorna um conjunto de regras baseado no conjunto itensObjetivos. Basicamente, toda a regra cuja condição $R H S \in$ itensObjetivos seja satisfeita é retornada.

- retorna_LHS_unicos (Regras): Retorna todos os itens únicos dos LHS das regras. Essa função primeiro pega todos os itens no $L H S$, depois remove todos os itens duplicados que podem ter sido selecionados e então retorna o resultado final.

- remove_regras_restricoes (Regras, ConexARN): Aplica as restrições apresentadas na Seção 3.2 ao conjunto de regras informado, de acordo com o que já foi modelado na ConexARN. O retorno dessa função é um subconjunto de Regras, mantendo apenas as regras que passam pelas restrições.

$\mathrm{Na}$ linha 5 do algoritmo são selecionadas todas as regras que possuam o $R H S$ definido nos itens objetivos. Dessa forma, todas essas regras que levam diretamente aos itens objetivos são modeladas. Após essa primeira modelagem é realizado um laço nas regras restantes, sempre modelando o nível imediatamente superior. Por exemplo, assim que todas as regras com o $L H S$ no nível 1 e o RHS no nível 0 forem modeladas, os itens recém modelados no nível 1 são considerados como RHS e novas regras com LHS no nível 2 são modeladas. Essa modelagem contínua até que não haja mais regras disponíveis para modelar ou nenhuma regra disponível passe pelas restrições.

A seguir são apresentadas algumas imagens para ilustrar a diferença entre as abordagens. A $A R N$ foi gerada nas Figuras 18 e Figura 19. Já a ConexARN foi gerada na Figura 20. Nesse exemplo foi utilizada a base contact-lens, disponível no $\mathrm{UCI}^{1}$. A base modela pacientes com suas características e qual o tipo de lente de contato que foi prescrita. O objetivo é predizer o tipo da lente baseado nas características de cada paciente. Por ser uma base pequena, nenhuma conclusão tirada nesse conjunto deve ser considerada como real, é uma base de dados apenas

\footnotetext{
1 https://archive.ics.uci.edu/ml/datasets/Lenses
} 
para testes. Nesse exemplo, foram consideradas 2 classes: lentes rígidas e macias ("Lens=hard"e "Lens=Soft", respectivamente).

Como a $A R N$ permite apenas a seleção de 1 único item objetivo, foram construídas $2 A R N$ s, uma para cada classe. Na Figura 18 é apresentada a ARN construída para o item objetivo "Lens=Hard". Nessa $A R N$ há 7 itens no nível 1, que representam regras que possuem "Lens=Hard"no consequente. No nível 2 há mais 4 itens, sendo que 2 deles são classes ("Lens=no"e "Lens=Soft"). Os números apresentados nas arestas representam a confiança da regra. Nessa $A R N$ é possível ver algumas correlações que não são interessantes, por exemplo: "Lens=no"se relaciona com "prescription=hypermetrope"que se relaciona com "Lens=Hard". Essa relação indireta entre "Lens=no"e "Lens=hard"não faz muito sentido para a base de dados, uma vez que um paciente não poder usar lentes não deveria ser explicação para que ele possa usar lentes rígidas.

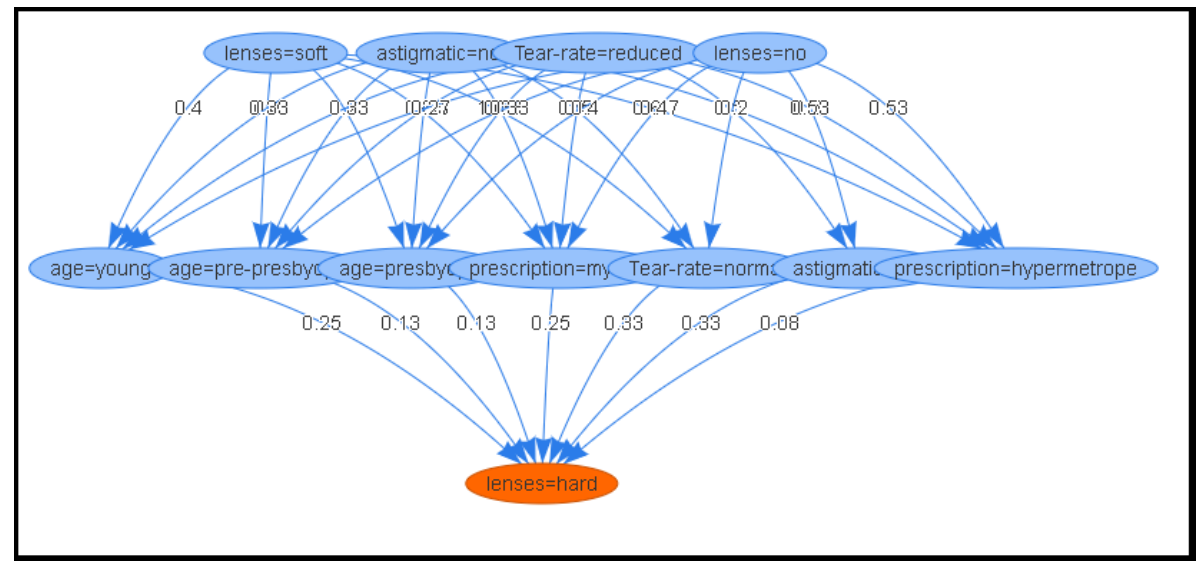

Figura $18-A R N$ construída na base Contact Lens, com "lens=Hard"como item objetivo

Na Figura 19 é apresentada a $A R N$ construída para "Lens=Soft". Essa $A R N$ possui a mesma estrutura de 7 itens no nível 1 e 4 itens no nível 2, sendo 2 deles no nível 2 as outras classes da base de dados. O que é importante ressaltar são as semelhanças e diferenças entre essas $2 A R N s$, que não são visíveis em uma primeira exploração. Os atributos "age=young", "tear-rate=normal", "prescription=hypermetrope", "prescription=myope", "age=presbyopic" e "age=pre-presbyopic" estão presentes em ambas as $A R N s$ no nível 1. Ou seja, de 7 atributos, 6 são compartilhados por ambos os tipos de lente. O único atributo diferente é "astigmatic=no" para "lens=soft" e "astigmatic=yes" para "lens=hard". Essa visualização não é tão óbvia olhado as redes separadamente.

Na Figura 20 é apresentada a ConexARN construída na mesma base de regras, considerando ambos os tipos de lente como itens objetivo. É possível visualizar 8 itens no nível $1 \mathrm{e}$ apenas 2 itens no nível 2. Essa construção apresenta uma visão mais completa da relação entre os 2 tipos de lentes e os outros atributos da base de dados. Por exemplo, é possível visualizar que vários itens no nível 1 se relacionam com ambos os itens objetivos. É possível também visualizar as exceções, como, por exemplo o item "astigmatic=no", no canto direito da figura. A percepção 


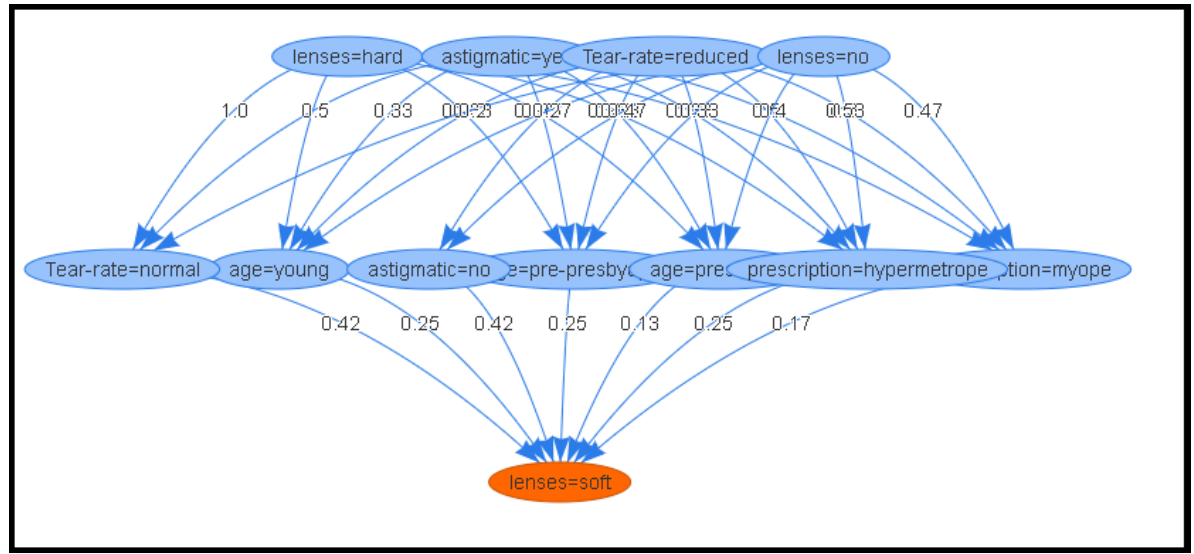

Figura $19-A R N$ construída na base Contact Lens, com "lens=Soft"como item objetivo

dessas relações é muito mais trivial na ConexARN se comparado a $A R N$, que força a exploração de todos os grafos. Nesse exemplo, "lens=no" manteve-se na rede no nível 2. Aconselha-se utilizar todos os valores possíveis do fenômeno que se deseja explicação quando for construir a ConexARN.

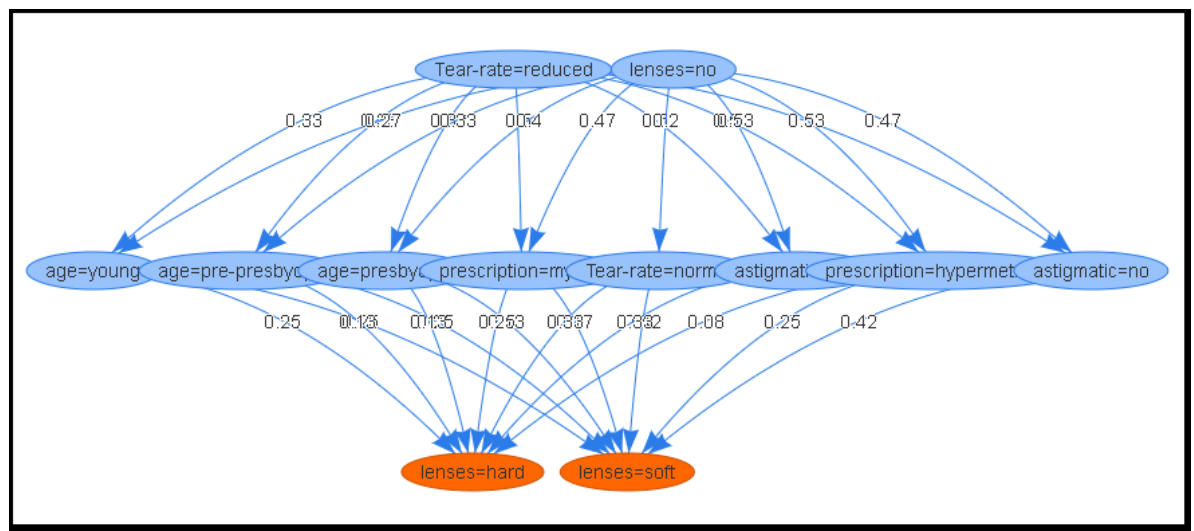

Figura 20 - ConexARN construída na base Contact Lens, com "lens=Soft"+ "lens=Hard"como itens objetivo

Dependendo da configuração utilizada para se gerar as regras de associação ou das características da base de dados, os níveis podem se tornar bastante populosos. Além dessa característica, como a modelagem é feita de acordo com a disponibilidade das regras, sem considerar nenhuma otimização, pode-se obter uma ConexARN com baixos níveis de confiança no nível 1, o que também é um problema para a $A R N$. Foi então desenvolvida a versão gulosa da exARN, que será detalhada a seguir.

\subsubsection{Greedy exARN}

Visando reduzir a superpopulação de itens nos níveis mais baixos, foi proposta a versão gulosa da exARN (chamada Greedy exARN). A Greedy exARN recebe esse nome pois é construída utilizando uma heurística gulosa, que visa maximizar o valor de determinada medida objetivo. 
Essa otimização é feita de forma gulosa, ou seja, sempre será escolhida a opção com o maior valor da medida que está sendo utilizada.

A Greedy exARN atende a todas as 4 Hipóteses de pesquisa, sendo elas: 1) modelar mais de 1 item objetivo, 2) visualizar itens dominantes e determinantes, 3) maximizar a qualidade das regras e 4) reduzir o número de regras a serem visualizadas.

As principais diferenças entre a Greedy exARN e a ConexARN são:

1. Regras com tamanho $\geq \mathbf{2}$. Ao utilizar uma heurística para selecionar as regras que serão modeladas, se torna possível modelar regras de tamanhos variados. Isso é possível por que uma nova restrição foi adicionado a construção da rede.

2. Nova Restrição. Caso um subconjunto de uma regra selecionada já tenha sido modelado na rede, então essa regra é descartada. Exemplo: Se foi selecionada a regra $R_{1}=A, B \rightarrow C$ e a regra $R_{2}=A \rightarrow C$ ou a regra $R_{3}=B \rightarrow C$ já estejam modeladas, então a regra $R_{1}$ é descartada.

3. Redução de itens nos níveis mais baixos. Como sempre é buscada a regra com maior valor possível, a Greedy exARN tende a modelar mais níveis, distribuindo a relação dos itens ao longo da rede. Essa redução na super população dos níveis mais baixos gera uma visualização muito mais limpa e fácil de interpretar.

4. Possibilidade de otimizar medidas objetivas. Como a Greedy exARN é construída utilizando um algoritmo guloso, as regras selecionadas para modelagem terão um maior valor em uma medida objetivo. Essa otimização permite que o usuário escolha qual medida faz mais sentido para o seu contexto de exploração.

5. Redução da quantidade total de regras modeladas. A heurística utilizada na construção da rede tende a distribuir as regras em diversos níveis. Ao considerar essa distribuição em conjunto com as restrições de modelagem, o número de regras possíveis é reduzido drasticamente.

O algoritmo de construção da Greedy exARN é apresentado no Algoritmo 2.

Ao comparar a construção da Greedy exARN com a construção da ConexARN, apresentado no Algoritmo 1, é possível identificar 3 grandes diferenças. A primeira grande diferença é que, antes de entrar no laço, a melhor regra de cada item do conjunto objetivo já é modelada na rede. Isso acontece pois como otimizamos uma medida objetivo, pode ser que algum item objetivo fique sem nenhuma regra modelada. Essa modelagem inicial força que todos os itens objetivos estejam presente na rede. A segunda diferença é que no Greedy exARN a modelagem é feita regra a regra, unitariamente. Isso é apresentado na linha rModel = seleciona_Melhor_Regra $\left(C j \_R e g r a s \_P o s s i v e i s, M\right)$, na qual $r M o d e l$ recebe a melhor regra possível de modelagem de acordo com a medida objetivo selecionada. A última grande 


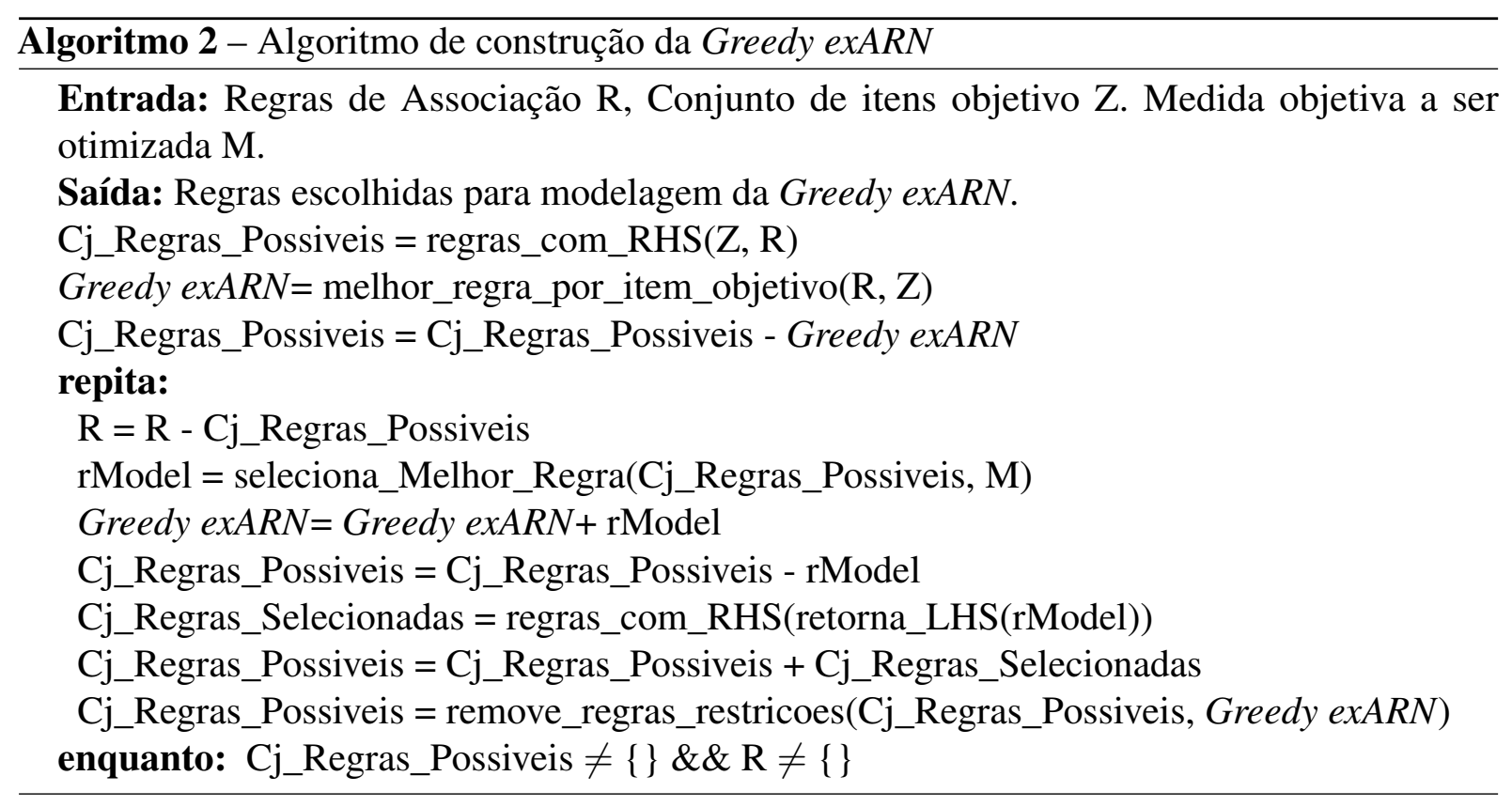

diferença é que, ao modelar o grafo regra a regra, escolhendo sempre a regra com maior valor da medida objetivo para adicionar a rede, a tendência é que as regras sejam modeladas em níveis maiores se comparando com a ConexARN e a $A R N$. Por causa disso, existirá uma mistura de regras de diferentes níveis no conjunto de regras possíveis de modelagem, uma vez que a regra que maximiza a medida objetivo pode estar longe do conjunto de itens objetivos. Por esse motivo, é necessário reavaliar todo o conjunto de regras possíveis a cada regra modelada, pois a cada nova regra inserida na rede um conjunto de regras que eram possíveis agora precisam ser descartas.

Na Figura 21 é apresentada a modelagem feita para a Greedy exARNtambém na base contact-lens. Nesse exemplo, foi mantido o tamanho das regras fixo em 2, para que seja possível visualizar a diferença entre as abordagens sem alterar os dados de entrada. Nesse exemplo a medida otimizada foi a confiança.

Na Greedy exARN foram modeladas 15 regras, se comparado com 29 da ConexARN. Esse número de regras também é inferior a quantidade de regras modeladas por cada $A R N$ com item objetivo único. Além disso, 2 novos níveis surgiram, distribuindo melhor a visualização e a exploração dos dados. Na Greedy exARN é mais simples visualizar que "astigmatic=no"tem um vínculo único com "lens=soft". Entretanto, "astigmatic=yes" não ficou vinculado com "lens=hard". Isso acontece por que uma regra com maior confiança foi modelada em um nível superior, sendo a regra "astigmatic=yes" $\rightarrow$ "Tear-rate=normal", com 50\% de confiança. Se olharmos nas outras redes, podemos ver que a regra "astigmatic=yes" $\rightarrow$ "lenses=hard" possui uma confiança de $33 \%$. Outro ponto importante é que a regra com menor confiança na Greedy exARN tem o valor de $27 \%$, enquanto nas outras redes foram modeladas regras com confiança de $8 \%$, conforme pode ser visto nas figuras apresentadas. 


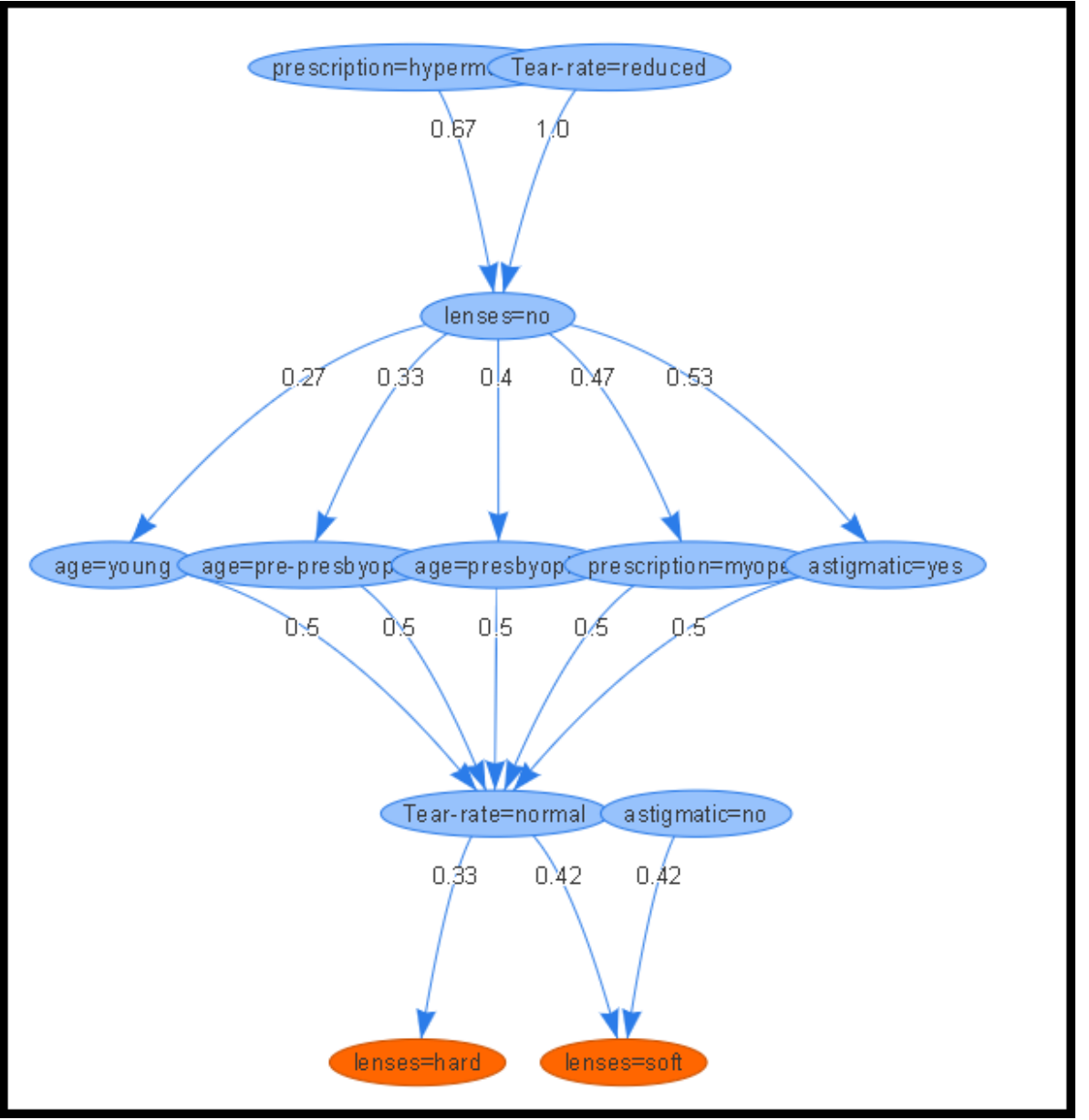

Figura 21 - Greedy exARN construída na base Contact Lens, com "lens=Soft"+ "lens=Hard"como itens objetivo

\subsection{Considerações Finais}

Neste capítulo foi apresentada a motivação por trás das abordagens propostas e quais os problemas em aberto elas focam resolver (Seção 3.1). Depois disso as abordagens foram apresentadas na Seção 3.2.

Conforme visto na literatura, há diversas maneiras de se explorar o conhecimento extraído por meio de regras de associação. Entretanto, nenhuma dessas abordagens se mostrou capaz de direcionar a exploração de acordo com um conjunto de itens predefinidos. Ao realizar a exploração guiada por um conjunto de itens, é possível analisar a correlação entre diversos itens da base de dados e o conjunto definido. Analisando essa correlação, é possível construir um entendimento mais completo dos relacionamentos na base, possibilitando o entendimento da ocorrência dos itens predefinidos de acordo com a ocorrência de outros itens na base.

Visando proporcionar essa possibilidade de exploração, foram propostas duas soluções: a ConexARN e a Greedy exARN. A ConexARN apresentou uma nova modelagem, permitindo a exploração das regras geradas de acordo com um conjunto de itens objetivos de tamanho $\geq 2$. Essa inovação, se comparada com a ARN, visa apresentar uma exploração mais completa da 
base de dados, identificando itens dominantes e itens que se correlacionam com apenas 1 único item objetivo.

Porém, percebeu-se que apesar de a ConexARN ser bem-sucedida em apresentar esse relacionamento, ela apresentava uma rede super populosa. Essa aglomeração de itens dificultava o entendimento do conhecimento modelado, uma vez que a rede por vezes ficava confusa. Para resolver esse problema foi proposta a Greedy exARN, que utiliza um algoritmo guloso para construir a rede final.

Essa abordagem gulosa reduziu a quantidade de regras modeladas e permitiu o uso de regras de associação com tamanho $\geq 2$, desde que $|R H S|=1$. A Greedy exARN visa maximizar o valor de uma medida objetiva pré-selecionada; no caso deste doutorado utilizamos a confiança. Essa medida pré-selecionada representa a qualidade das regras extraídas.

No próximo capítulo as abordagens foram submetidas a experimentos para validação das características descritas. Além delas, aplicamos outras abordagens nas mesmas bases de dados, sob mesmas condições, para compararmos os pontos fortes e fracos das abordagens propostas. 


\section{EXPERIMENTOS E RESULTADOS}

Com o objetivo de analisar a qualidade das abordagens propostas e validar suas características, foram executados alguns experimentos visando 2 análises: qualitativas e quantitativas. As análises qualitativas focam na qualidade visual e nas diferenças de resultados apresentados. Neste capítulo o foco está em apresentar como a abordagem proposta melhora a exploração das regras e facilita a extração de conhecimento. A análise quantitativa visa avaliar outras características da abordagem, tais como: redução do número de regras exibido e diferença em valores de medida objetivo.

Neste capítulo os experimentos são descritos, apresentando quais foram as bases utilizadas e como as abordagens foram aplicadas. Também apresentamos os baselines utilizados para comparação. Em todos os casos, as bases de dados estão disponíveis em <https://bit.ly/30gBlv3>.

\subsection{Experimentos}

Os experimentos foram desenhados para validar as 2 abordagens propostas: ConexARN e Greedy exARN. Além da análise das abordagens propostas, os resultados obtidos foram comparados com a ARN convencional, proposta por (PANDEY et al., 2009) e também com uma rede Bayesina, devido as caracterísiticas probabilísticas das conexões das arestas.

Para validar as abordagens propostas, foram utilizadas 10 bases de dados, sendo que 8 delas estão disponíveis no UCI ${ }^{1}$. Foram utilizadas as bases: balance-scale $(<\mathrm{http} / / /$ archive. ics.uci.edu/ml/datasets/balance+scale $>$ ), breast-cancer (<https://archive.ics.uci.edu/ml/datasets/ Breast+Cancer+Wisconsin+(Diagnostic) $>)$, $\operatorname{car}(<\mathrm{http}: / /$ archive.ics.uci.edu/ml/datasets/Car+ Evaluation $>$ ), ecoli (<https://archive.ics.uci.edu/ml/datasets/ecoli $>)$, Haberman $(<\mathrm{https} / / /$ archive. ics.uci.edu/ml/datasets/Haberman' s+Survival $>$ ), iris (<http://archive.ics.uci.edu/ml/datasets/ Iris $>$ ), tic-tac-toe (<https://archive.ics.uci.edu/ml/datasets/Tic-Tac-Toe+Endgame $>$ ) e zoo (<https:

$\overline{1 \quad \text { http://archive.ics.uci.edu/ml/index.php }>~}$ 
//archive.ics.uci.edu/ml/datasets/zoo $>$ ).

Para gerar as regras de associação é necessário processar as bases de dados, transformando essas bases de dados em um formato "atributo=valor". Os atributos contínuos foram discretizados, utilizando intervalos iguais. Todas as bases de dados processadas, prontas para a extração das regras de associação, podem ser baixadas no link <https://bit.ly/30gBlv3>.

Além das bases do UCI, as abordagens propostas foram testadas em base de dados musical. Uma das bases utilizadas é uma base de classificação de gêneros musicais; para tanto, utilizamos a base GTZAN (TZANETAKIS; COOK, 2002). Essa base contém 1000 arquivos de 30 segundos, perfeitamente balanceados em 10 gêneros musicais.

Também foi utilizada uma base de classificação de artista, ou seja, dada uma música a variável resposta é o artista (ou banda) que a gravou. A base é conhecida como Artist20 (ELLIS, 2007). Essa base contém 1413 músicas gravadas por 20 artistas diferentes, em sua maioria músicos de POP ou ROCK. O número de músicas não está balanceado por artistas.

Um resumo de todas as bases de dados utilizadas é apresentado na Tabela 7. Na coluna atributos, cada elemento único "atributo=valor" é contado como 1, ou seja, se na base original um determinado atributo possui 3 valores distintos, então é contabilizado 3 para aquele atributo. No caso da base zoo, o primeiro atributo representa o animal descrito, possuindo 100 valores diferentes. Todas essas bases estão disponíveis para download no link <https://bit.ly/30gBlv3 $>$. Toda a configuração para reexecutar os experimentos, junto com um README, pode ser encontrado em <https://bit.ly/2NFJVjz>.

Tabela 7 - Bases de dados utilizadas nos experimentos e suas características.

\begin{tabular}{cccc}
\hline Nome & \# Transac & \# Atributos & \# Classes \\
\hline balance-scale & 625 & 12 & 3 \\
\hline breast-cancer & 277 & 41 & 2 \\
\hline car & 1728 & 21 & 4 \\
\hline ecoli & 336 & 19 & 8 \\
\hline haberman & 306 & 18 & 2 \\
\hline iris & 150 & 12 & 3 \\
\hline artist20 & 1413 & 25 & 20 \\
\hline gtzan & 1000 & 25 & 10 \\
\hline tic tac toe & 958 & 27 & 2 \\
\hline zoo & 101 & 135 & 7 \\
\hline
\end{tabular}

Com todas as bases preparadas e disponíveis no formato transacional, que é utilizado para entrada do algoritmo de regras de associação, foi construído um pipeline de experimentos, apresentado na Figura 22. O Pipeline consiste em processar os dados por 2 caminhos: geração de regras de associação e construção da rede Bayesiana. A rede Bayesiana é um dos resultados finais, então seu output é enviado diretamente para os processos de análise. Já as regras de associação são submetidas ao processamento da ARN, ConexARN e Greedy exARN. No final, 
esses 3 grafos também são submetidos aos processos de análise.

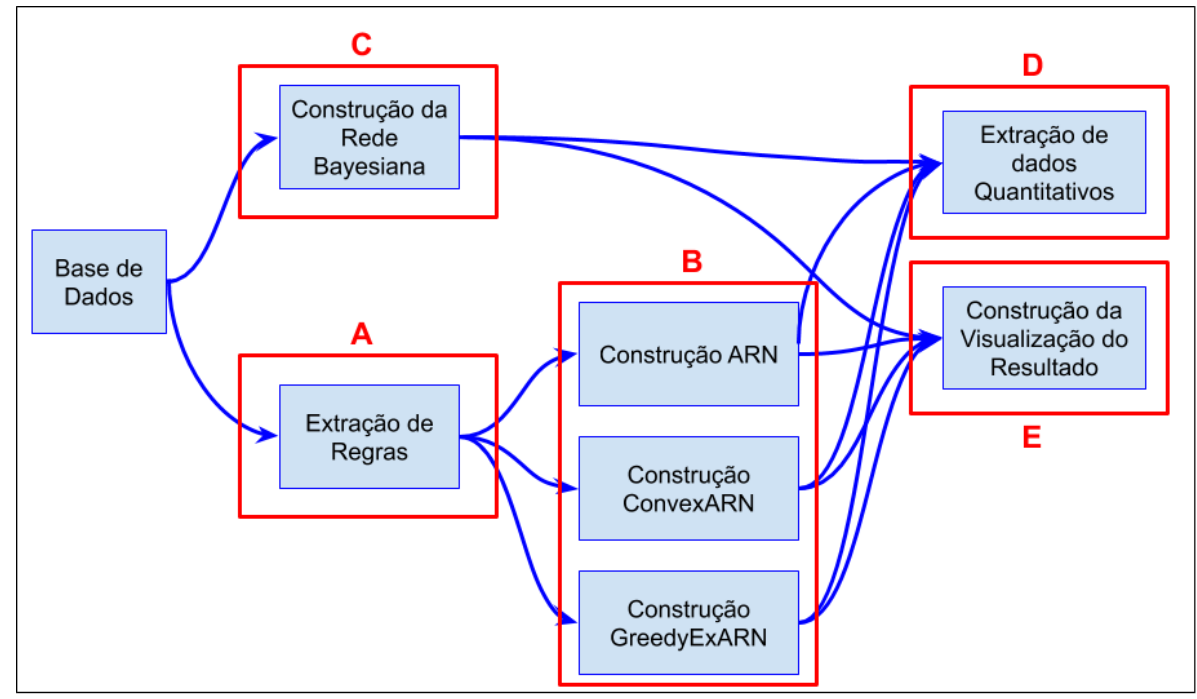

Figura 22 - Pipeline de experimentos realizado para validação das abordagens propostas.

Para fins didáticos, a estrutura do projeto proposto foi dividida em 5 etapas: A - Extração de regras de associação; B - Geração da ARN e das abordagens propostas; C - Geração da rede Bayesiana, considerando as mesmas configurações utilizadas para extrair as regras; D - Extração dos dados quantitativos para validação e comparação das abordagens e E - Construção visual dos resultados para análise quantitativa. As etapas A, B e C são abordadas nesta seção. A etapa D será abordada na Seção 4.1.1 e a etapa E será abordada na Seção 4.1.2.

As Hipóteses 1 e 2, que referem-se a modelar mais de 1 item objetivo e visualizar itens dominantes e determinantes são validadas na etapa E. Já as Hipóteses 3 e 4, que referem-se a qualidade das regras modeladas e redução do número de regras a serem visualizadas são validadas na etapa $\mathrm{D}$.

Com as bases já pré-processadas, conforme descrito anteriormente, as regras de associação foram extraídas na etapa A. Para isso, 2 restrições foram adicionadas: 1) a regra pode ter, no máximo, tamanho 4 e 2) o RHS sempre terá tamanho 1. Para uma maior variabilidade de possibilidades, visando explorar cenários mais amplos de tamanhos de conjuntos de regras, as regras de associação foram extraídas utilizando um conjunto de valores de parâmetros, apresentados na Tabela 8

A extração iniciou com o suporte mínimo em 0\%, assim nenhum itemset é removido da base de dados, independentemente da sua frequência. O suporte varia até até $10 \%$, ou seja, o item precisa aparecer em pelo menos 1 transação a cada 10. A confiança também foi variada a partir de $0 \%$, para mais uma vez não remover regras mesmo que sejam ao acaso. $\mathrm{O}$ valor máximo de confiança foi definido em $25 \%$, ou seja, para cada 4 transações que o LHS ocorrer, RHS precisa ocorrer em pelo menos 1 .

O caso mais permissivo da configuração é $0 \%$ de suporte e confiança, que executa 
Tabela 8 - Lista de parâmetros utilizado nos experimentos de Regras de Associação.

\begin{tabular}{cc}
\hline Suporte & Confiança \\
\hline $0 \%$ & $0 \%$ \\
\hline $0 \%$ & $5 \%$ \\
\hline $0 \%$ & $10 \%$ \\
\hline $0 \%$ & $15 \%$ \\
\hline $0 \%$ & $25 \%$ \\
\hline $1 \%$ & $0 \%$ \\
\hline $1 \%$ & $5 \%$ \\
\hline $1 \%$ & $10 \%$ \\
\hline $1 \%$ & $15 \%$ \\
\hline $1 \%$ & $25 \%$ \\
\hline $5 \%$ & $0 \%$ \\
\hline $5 \%$ & $5 \%$ \\
\hline $5 \%$ & $10 \%$ \\
\hline $5 \%$ & $15 \%$ \\
\hline $5 \%$ & $25 \%$ \\
\hline $10 \%$ & $0 \%$ \\
\hline $10 \%$ & $5 \%$ \\
\hline $10 \%$ & $10 \%$ \\
\hline $10 \%$ & $15 \%$ \\
\hline $10 \%$ & $25 \%$ \\
\hline &
\end{tabular}

basicamente uma análise combinatória de todos os itens que coocorrem pelo menos 1 vez na base. $\mathrm{O}$ caso menos permissivo considera que todos os itens ocorrem ao menos em $10 \%$ das transações e só considera regras que acontecem em, pelo menos, $25 \%$ da ocorrência do $L H S$. Na Tabela 8 todas as combinações de configuração de suporte e confiança são apresentadas.

Após a extração de todas as regras, a etapa B é iniciada. Nessa etapa, todas as regras foram processadas pelas 3 abordagens de ARN: ARN convencional (PANDEY et al., 2009), ConexARN e Greedy exARN. A definição dos itens objetivos foi feita considerando as classes de cada database como conjunto objetivo.

No caso da ARN, foi criada uma ARN para cada classe. Nos casos da ConexARN e Greedy exARN, todas as classes foram consideradas como itens objetivo. Todas as informações extraídas foram enviadas para as etapas D e E, que serão explicadas nas próximas seções.

Na etapa C uma rede Bayesiana foi gerada para cada base de dados (PEARL, 1988). Para fins de comparação, os parâmetros de suporte e confiança utilizados nas regras de associação foram estendidos para as redes bayesianas. $\mathrm{O}$ suporte foi estendido como um filtro prévio, removendo da base todo o item que não possui aquela ocorrência mínima. Por exemplo, no caso do suporte $=5 \%$, remove-se da base de dados todos os itens que ocorrem em menos de $5 \%$ das transações. Para emular a confiança, foram mantidas na rede apenas as conexões com probabilidade $\geq \operatorname{minConf}$, realizando todas as variações explicadas na Tabela 8 . 
Após todo esse processo realizado, todos os resultados foram analisados qualitativa e quantitativamente. Nas próximas seções são descritos esses processos e são apresentados os resultados obtidos.

\subsubsection{Análise quantitativa}

O objetivo da análise quantitativa é comparar os métodos seguindo alguns critérios objetivos, mensuráveis, e debater qual abordagem apresenta melhor resultado de acordo com essas medidas.

Este projeto teve 4 hipóteses: 1) modelar múltiplos itens objetivos; 2) apresentar itens dominantes e determinantes; 3) maximizar uma determinada medida de interesse e 4) modelar um baixo número de regras. Nesta seção serão analisadas as hipóteses 3 e 4, que visam maximizar a medida de interesse mantendo um baixo número de regras.

Para tanto, foram definidas 2 medidas de análise, apresentadas na Equação 4.1 e 4.2 respectivamente. A análise de item dominante e determinante será discutida na próxima seção.

$$
\begin{gathered}
\text { Medida } 1=\text { contagem }(\text { regrasModeladas }) \\
\text { Medida } 2=\frac{\sum_{i=1}^{n} \text { peso }_{\left(\text {Conexao }_{i}\right)}}{n}
\end{gathered}
$$

Na Equação 4.1 foi calculada a quantidade de regras modeladas por cada abordagem testada. Quanto menor for o valor dessa medida, melhor o resultado, uma vez que um alto número de regras modelada dificulta a exploração por parte do usuário. Essa medida visa validar a Hipótese 4.

$\mathrm{Na}$ Equação 4.2 foi calculada a qualidade das regras modeladas. Para isso, foi considerado o peso da conexão como qualidade, ou seja, quanto maior o peso das regras modeladas, maior a probabilidade daquela conexão efetivamente acontecer, portanto, melhor é a conexão apresentada. Essa medida visa validar a Hipótese 3.

A Tabela 9 apresenta os principais resultados obtidos, por base, analisando quantitativamente as abordagens. Nessa tabela foram apresentados os resultados obtidos para suporte mínimo $=1 \%$ e confiança mínima $=15 \%$. Essa configuração foi escolhida por apresentar grandes diferenças entre as abordagens analisadas. Entretanto, a listagem completa dos resultados se encontra no Apêndice A.

Para a ARN múltiplos valores foram adicionados para a Medida1 e Medida2. Isso se deve ao fato de ser necessário gerar uma ARN para cada item objetivo. Ao analisar a quantidade de regras geradas para cada item objetivo e a necessidade de se explorar todas, nota-se que a ARN não se sai bem sob essas condições. Em um cenário no qual se deseja explorar apenas um 
único item, a ARN torna-se interessante; entretanto, para a análise conjunta de diversos itens objetivos, a ARN apresenta diversas dificuldades e alto nível de complexidade.

Já a rede Bayesiana não considera o conjunto de itens objetivos em sua construção, logo, é capaz de modelar todos os itens objetivos em uma única estrutura. Essa é a abordagem que apresenta a maior quantidade de regras. As maiores diferenças podem ser visualizadas nas bases não sintéticas, que são a artist20 e a genre. Na artist 20 a rede Bayesiana modela 454 regras, com uma probabilidade condicional mínima de 50.8\%, contra 112 da ConexARN e 15 da Greedy exARN. Entretanto, em algumas bases sintéticas a rede Bayesiana se saiu bem. Por exemplo, na base iris, a rede Bayesiana superou a ConexARN, modelando 1 regra a menos e obtendo um valor médio da Medida2 quase $4 \%$ superior.

Uma das abordagens propostas, a ConexARN, obteve resultados bastante interessantes. Comparando com a ARN, a ConexARN provou ser mais interessante para uma modelagem possuindo diversos itens objetivos. Por exemplo, considerando a base artist20, a ConexARNmodelou menos de $25 \%$ do número de regras modeladas pela rede Bayesiana, apesar de ter obtido um valor da medida 2 inferior. Nesse caso, o alto número de regras modeladas pela rede Bayesiana torna o resultado extremamente complexo de se analisar. Comparada com a Greedy exARN, a ConexARN conseguiu um bom resultado nessa base, tendo quase o dobro do valor da Medida2.

Por fim, a Greedy exARN apresentou resultados bastante promissores. Considerando a base genre, é possível notar a diferença da qualidade do resultado obtido pela Greedy exARN se comparado com todas as outras abordagens. Nessa base, a Greedy exARN modelou apenas 10 regras, $\frac{1}{6}$ da quantidade de regras modeladas pela ConexARN. Já no valor da Medida2, a Greedy exARN conseguiu quase o dobro do valor comparado com as outras abordagens, o que a faz despontar como extremamente interessante nesta base de dados.

Ao analisar todo o resultado obtido, considerando a Tabela 9, há bons indícios que as abordagens propostas, ConexARN e Greedy exARN, são capazes de adicionar mais de um item objetivo e aumentar a qualidade do resultado apresentado. Cada uma das abordagens propostas possui suas características que as tornam interessantes. A ConexARN apresentou uma boa capacidade para modelar os itens objetivos mantendo uma quantidade razoável de regras e mantendo um bom nível de qualidade dessas regras, se comparado com a ARN e a rede Bayesiana. Essa abordagem pode ser usada em contextos nos quais não há uma vasta quantidade de atributos disponíveis. Já a Greedy exARN apresentou uma boa capacidade exatamente nas condições em que a ConexARN possui deficiências, que são as bases com alta quantidade de regras geradas. Ao realizar a otimização de uma medida objetiva, a Greedy exARN tende a reduzir a quantidade de regras modeladas, focando na qualidade das regras que serão selecionadas. Essa otimização permite uma melhor performance em bases com maior diversidade de atributos, na qual se deseja entender um conjunto de itens dentro de uma vasta quantidade de possibilidades.

Na próxima seção é realizada a análise qualitativa, visando discutir aspectos da visualização dos resultados e interpretabilidade dos resultados. 
Tabela 9 - Resultados obtidos por base de dados.

\begin{tabular}{|c|c|c|c|c|c|}
\hline Base & Abordagem & Suporte & Confianca & Medida1 & Medida2 \\
\hline \multirow[t]{4}{*}{ balance-scale } & ARN & $1 \%$ & $15 \%$ & {$[36,36]$} & {$[37.6 \%, 37.6 \%]$} \\
\hline & Bayes & $1 \%$ & $15 \%$ & 36 & 33.3 \\
\hline & ConexARN & $1 \%$ & $15 \%$ & 24 & $46.1 \%$ \\
\hline & Greedy exARN & $1 \%$ & $15 \%$ & 5 & $82.5 \%$ \\
\hline \multirow[t]{4}{*}{ breast-cancer } & ARN & $1 \%$ & $15 \%$ & {$[101,71]$} & {$[52.6 \%, 59.9 \%]$} \\
\hline & Bayes & $1 \%$ & $15 \%$ & 41 & $38.9 \%$ \\
\hline & ConexARN & $1 \%$ & $15 \%$ & 70 & $56.3 \%$ \\
\hline & Greedy exARN & $1 \%$ & $15 \%$ & 7 & $100 \%$ \\
\hline \multirow[t]{4}{*}{ car } & ARN & $1 \%$ & $15 \%$ & {$[97,65]$} & {$[31.1 \%, 49.0 \%]$} \\
\hline & Bayes & $1 \%$ & $15 \%$ & 69 & $34.7 \%$ \\
\hline & ConexARN & $1 \%$ & $15 \%$ & 40 & $48.4 \%$ \\
\hline & Greedy exARN & $1 \%$ & $15 \%$ & 6 & $74.3 \%$ \\
\hline \multirow[t]{4}{*}{ ecoli } & ARN & $1 \%$ & $15 \%$ & $\begin{array}{l}{[1,81,49,} \\
71,95,85]\end{array}$ & $\begin{array}{c}{[50.0 \%, 65.4 \%, 42.6 \%,} \\
52.7 \%, 65.7 \%, 67.0 \%]\end{array}$ \\
\hline & Bayes & $1 \%$ & $15 \%$ & 59 & $68.6 \%$ \\
\hline & ConexARN & $1 \%$ & $15 \%$ & 39 & $37.9 \%$ \\
\hline & Greedy exARN & $1 \%$ & $15 \%$ & 6 & $94.4 \%$ \\
\hline \multirow[t]{4}{*}{ haberman } & ARN & $1 \%$ & $15 \%$ & [26.21] & {$[45.1 \%, 67.2 \%]$} \\
\hline & Bayes & $1 \%$ & $15 \%$ & 7 & $53.2 \%$ \\
\hline & ConexARN & $1 \%$ & $15 \%$ & 31 & $53.2 \%$ \\
\hline & Greedy exARN & $1 \%$ & $15 \%$ & 3 & $88.3 \%$ \\
\hline \multirow[t]{4}{*}{ iris } & ARN & $1 \%$ & $15 \%$ & {$[27,21,17]$} & {$[56.2 \%, 58.5 \%, 55.0 \%]$} \\
\hline & Bayes & $1 \%$ & $15 \%$ & 17 & $67.7 \%$ \\
\hline & ConexARN & $1 \%$ & $15 \%$ & 18 & $63.9 \%$ \\
\hline & Greedy exARN & $1 \%$ & $15 \%$ & 7 & $100 \%$ \\
\hline \multirow[t]{4}{*}{ artist20 } & ARN & $1 \%$ & $15 \%$ & {$[310,310,306]$} & {$[50.9 \%, 51.0 \%, 47.9 \%]$} \\
\hline & Bayes & $1 \%$ & $15 \%$ & 454 & $50.8 \%$ \\
\hline & ConexARN & $1 \%$ & $15 \%$ & 112 & $43.9 \%$ \\
\hline & Greedy exARN & $1 \%$ & $15 \%$ & 15 & $22.6 \%$ \\
\hline \multirow[t]{4}{*}{ genre } & ARN & $1 \%$ & $15 \%$ & $\begin{array}{c}{[71,76,79,} \\
71,69,82, \\
76,78,69,70]\end{array}$ & $\begin{array}{c}{[29.3 \%, 28.7 \%, 29.0 \%} \\
30.9 \%, 28.2 \%, 30.6 \% \\
32 \%, 30 \%, 28.1 \%, 30 \%]\end{array}$ \\
\hline & Bayes & $1 \%$ & $15 \%$ & 71 & $26.5 \%$ \\
\hline & ConexARN & $1 \%$ & $15 \%$ & 60 & $27.3 \%$ \\
\hline & Greedy exARN & $1 \%$ & $15 \%$ & 10 & $47.5 \%$ \\
\hline \multirow[t]{4}{*}{ tic tac toe } & ARN & $1 \%$ & $15 \%$ & {$[54,53]$} & {$[33.9 \%, 50 \%]$} \\
\hline & Bayes & $1 \%$ & $15 \%$ & 53 & $33.6 \%$ \\
\hline & ConexARN & $1 \%$ & $15 \%$ & 54 & $49.9 \%$ \\
\hline & Greedy exARN & $1 \%$ & $15 \%$ & 4 & $100 \%$ \\
\hline \multirow[t]{4}{*}{ zOo } & ARN & $1 \%$ & $15 \%$ & $\begin{array}{c}{[245,1,113,195,} \\
287,304,278]\end{array}$ & $\begin{array}{c}{[57.2 \%, 100 \%, 38.6 \%, 51.7 \%} \\
65.4 \%, 68.4 \%, 68 \%]\end{array}$ \\
\hline & Bayes & $1 \%$ & $15 \%$ & 144 & $77.2 \%$ \\
\hline & ConexARN & $1 \%$ & $15 \%$ & 76 & $37.1 \%$ \\
\hline & Greedy exARN & $1 \%$ & $15 \%$ & 7 & $100 \%$ \\
\hline
\end{tabular}




\subsubsection{Análise qualitativa}

O objetivo da análise qualitativa é avaliar os resultados obtidos, visando analisar a capacidade de modelar mais de um item objetivo. A análise também foca validar a capacidade das abordagens apresentarem itens dominantes e itens determinantes. Essas análises visam validar as Hipóteses 1 e 2. Para que essas características sejam medidas, modelamos todas as regras em um grafo visualmente, utilizando a biblioteca visjs ${ }^{2}$.

Serão analisadas as 2 bases não sintéticas, artist20 e genre. Serão apresentadas as modelagens gráficas referentes a configuração apresentada na seção anterior, ou seja, suporte mínimo em $1 \%$ e confiança mínima em 15\%. Essa configuração será mantida para comparação dos resultados na seção anterior. A mesma adaptação de suporte e confiança feita para a rede Bayesiana se mantém nesta análise.

Na Figura 23 é possível visualizar uma $A R N$ construída na base artist20, com o item objetivo class-metallica utilizando suporte mínimo $=1 \%$ e confiança mínima $=15 \%$. O vértice elíptico de cor laranja, marcado com uma seta, representa o item objetivo, ou seja, classmetallica, enquanto os vértices circulares azuis representam os outros atributos da base de dados. A visualização é extremamente densa, o que impossibilita a extração de conhecimento útil por essa imagem. Esse grafo representa apenas 1 item objetivo, o que significa que o usuário precisaria analisar outros grafos, igualmente carregados, para encontrar quais os conjuntos de itens interessantes para os itens objetivos.

Já a Figura 24 apresenta a rede Bayesiana construída com a base artist20, considerando a ocorrência mínima dos itens em $1 \%$ das transações e o valor mínimo de probabilidade condicional em $15 \%$. Cada elíptico vértice laranja representa um item objetivo, ou seja, um artista. Esse grafo é ainda mais denso que o grafo anterior, tornando o processo de se extrair conhecimento ainda mais complexo.

A Figura 25 apresenta a ConexARN construída na base artist20 com suporte mínimo em $1 \%$ e confiança mínima em 15\%. Comparado com os grafos apresentados anteriormente, a ConexARN apresenta menos regras. Entretanto, a visualização ainda não é trivial, sendo relativamente densa. Há uma grande redução na densidade da visualização, comparada com a $A R N$ e com a rede Bayesiana. Novamente, os vértices elípticos laranja representam os itens objetivos e os vértices circulares azuis os itens da base. Nesse caso, a ConexARN ainda não é uma boa solução para o problema.

Por fim, na Figura 26 é apresentada a Greedy exARN construída na base artist20, utilizando as mesmas consigurações de suporte mínimo e confiança mínima. O grafo apresentado pela Greedy exARN é bem menos denso, possibilitando uma exploração do conhecimento gerado. Por exemplo, é possível visualizar que o item 18 está relacionado tanto com a banda Creedence quanto com a banda Beatles. Já o item 15 se relaciona tanto com Credence quanto com Led

2 https://visjs.org/ 


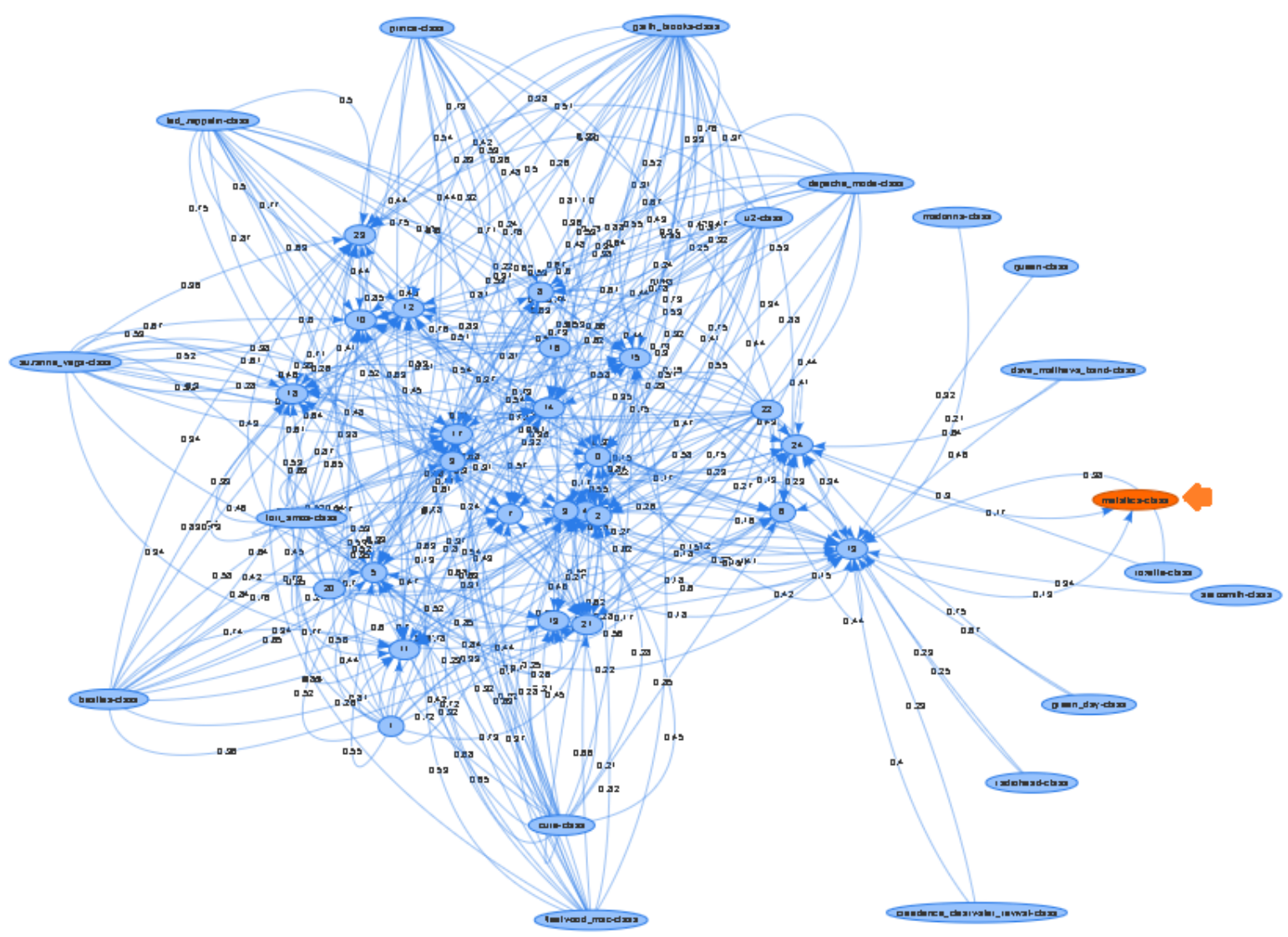

Figura 23 - ARN construída na base artist20 com o item objetivo class-metallica.

Zeppelin. Por fim, o item 6 se relaciona apenas com a banda Credence, em conjunto com o item 18.

Também foram aplicadas as mesmas abordagens, com as mesmas configurações, na base gender, para classificar gêneros musicais. Na Figura 27 é apresentada a ARN construída na base genre com o item objetivo class-country. Essa visualização da ARN é bem menos densa se comparado a ARN apresentada na base artist20. Nessa ARN há a presença de outros gêneros musicais, o que torna o conhecimento gerado pelo grafo não confiável. Por exemplo, o gênero reggae gera o item 22 que gera o gênero musical country.

Já na Figura 28 é apresentada a rede Bayesiana construída na base genre. A rede Bayesiana apresentou resultados interessantes, distribuindo os gêneros musicais pelo grafo. É possível visualizar os itens que se relacionam com mais de um item objetivo e quais itens se relacionam apenas com um único item objetivo.

Na Figura 29 é apresentada a ConexARN construída na base genre. A quantidade de itens modelados foi reduzida se comparado com a rede Bayesiana, o que torna o processo de extração de conhecimento mais simples. Nessa visualização os itens que se correlacionam com mais de um item objetivo são mais simples de identificar, assim como também é mais simples identificar os itens que se correlacionam com um único item objetivo. Ao reduzir o número de 


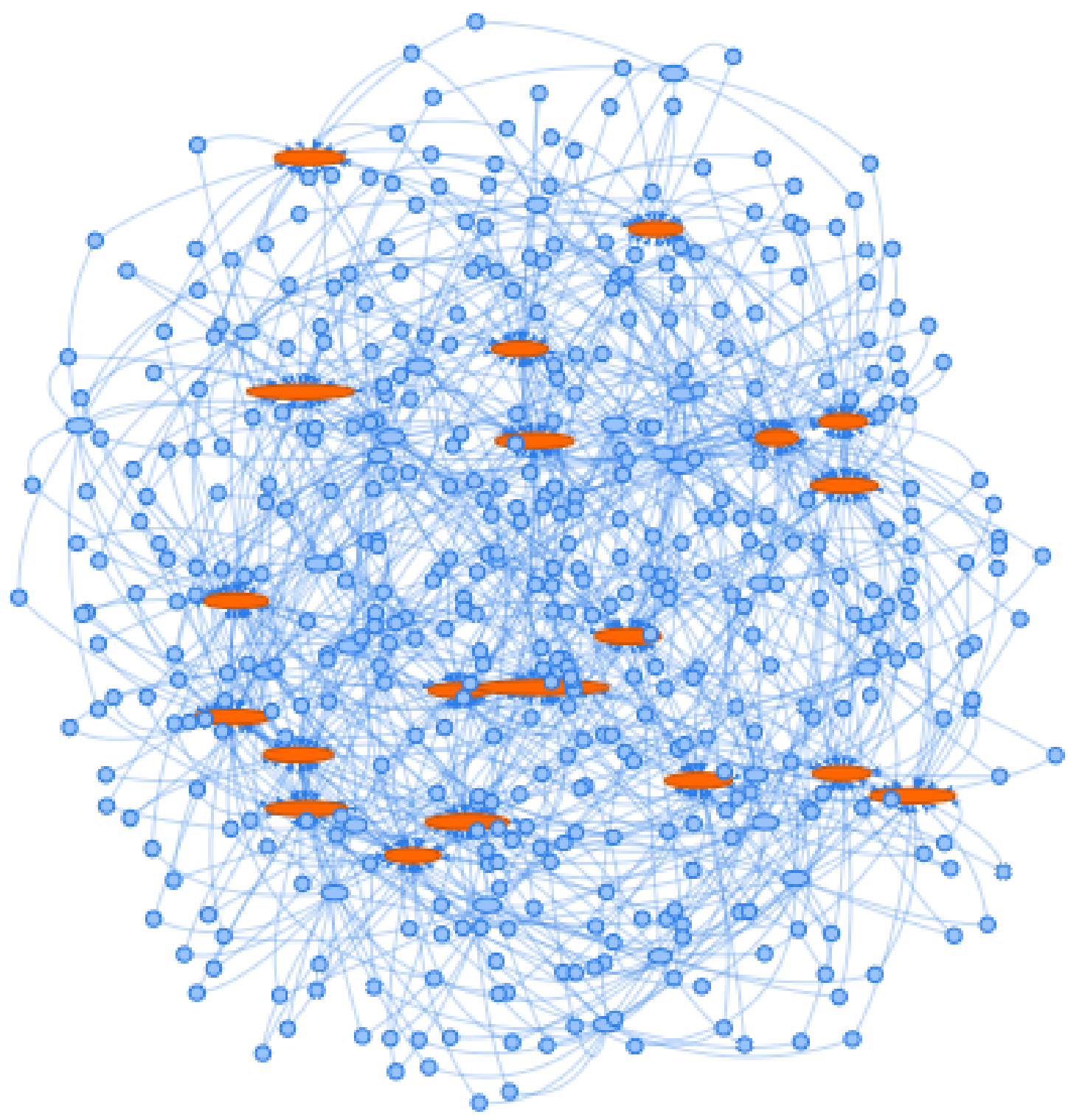

Figura 24 - Rede Bayesiana construída na base artist20.

regras comparado a rede Bayesiana, a ConexARN apresenta uma visualização mais simplificada, facilitando a extração do conhecimento modelado.

Por fim, na Figura 30 é apresentada a Greedy exARN construída na base genre. Ao otimizar uma medida objetivo, a quantidade de regras modeladas é drasticamente reduzida. Nesse caso, é possível visualizar os itens objetivos que possuem itens em comuns e os itens objetivos que não possuem intersecção nos itens com outros itens objetivos. A Greedy exARNapresenta a visualização menos densa; entretanto, é necessário analisar esse resultado com cuidado. Ao realizar uma poda mais agressiva, em bases com itens menos frequentes, existe o risco de remover itens interessantes.

Considerando a base artist20, foram apresentadas visualizações utilizando as 4 abordagens comparadas. A $A R N$, a rede Bayesiana e a ConexARN apresentaram visualizações bastante 


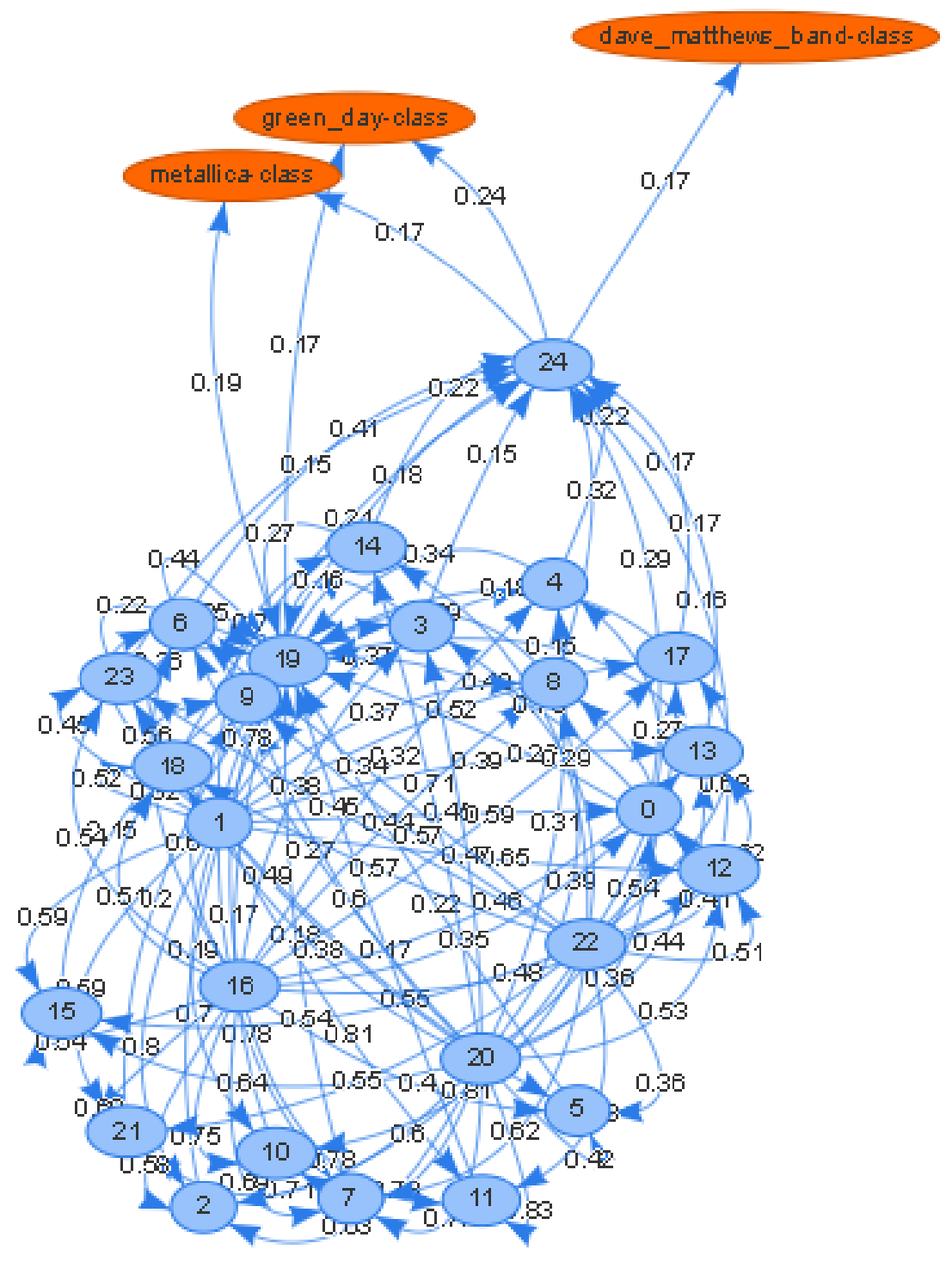

Figura 25 - ConexARN construída na base artist20.

densas, impossibilitando a extração de conhecimento útil. A ConexARN apresentou uma grande quantidade no número de regras modeladas, o que torna o processo de exploração do conhecimento modelado não trivial. Já a Greedy exARN apresentou uma visualização mais simples de interpretar. A quantidade de regras apresentada é bem menor comparada com as outras abordagens e a extração do conhecimento é bem mais trivial. Nesse cenário, no qual há muitos itens frequentes e muitas relações, a Greedy exARN apresentou melhores resultados. Isso se deve ao fato da Greedy exARNutilizar uma abordagem gulosa, direciona a construção do grafo para o maior valor da medida objetivo a cada nova iteração.

Já a base genre apresenta outro cenário, possui menos itens frequentes. A $A R N$ apresentou uma visualização menos densa e possível de se explorar. Entretanto, ao modelar apenas um único item objetivo, existe a dificuldade de se analisar uma $A R N$ para cada item objetivo existente. Além 


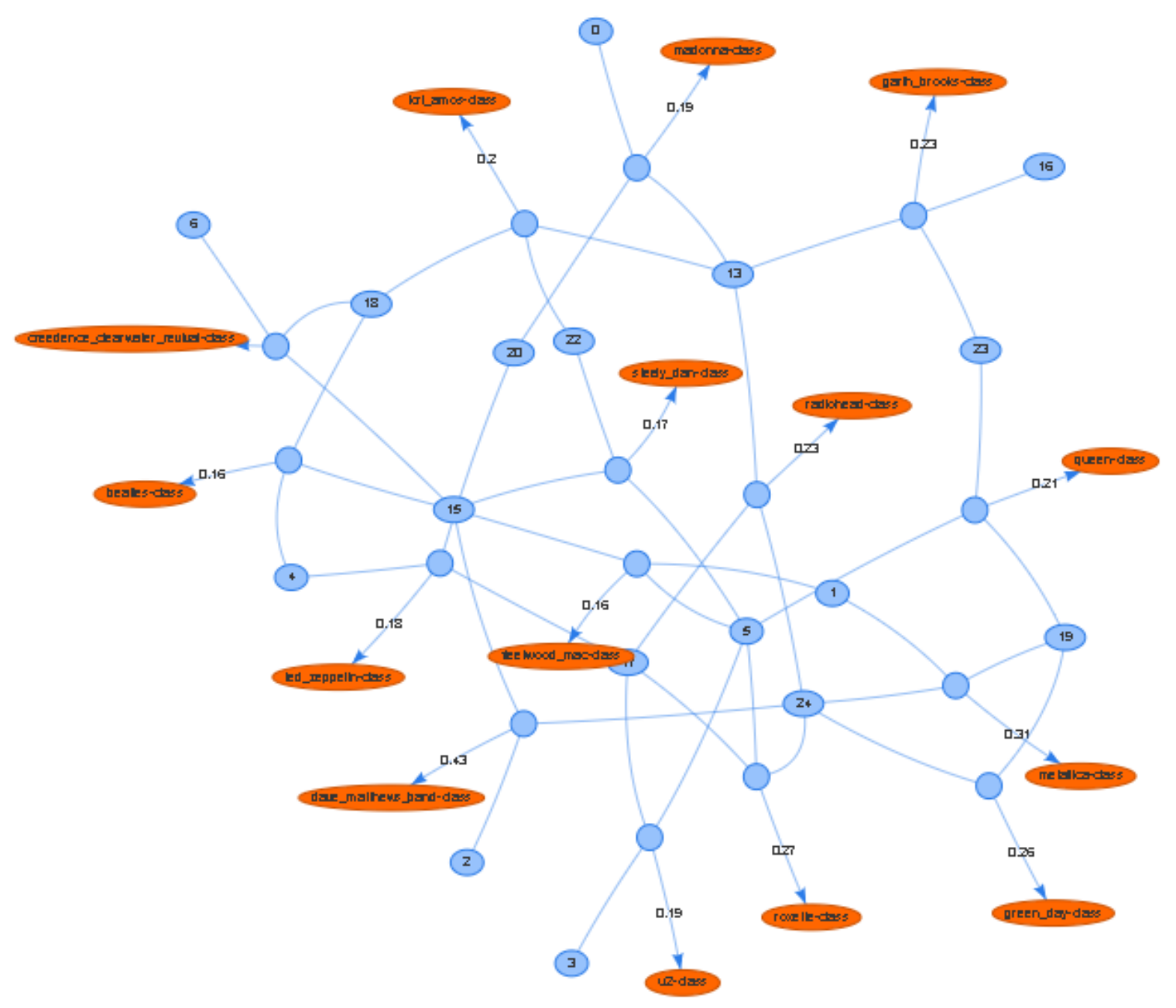

Figura 26 - Greedy exARN construída na base artist20.

dessa dificuldade, também há a construção de correlações não tão corretas, conforme o exemplo: o gênero musical reggae leva a ocorrência do padrão musical 22 que leva a classificação da música como country. Já a rede Bayesiana apresentou um bom resultado, modelando as relações em um grafo que correlaciona todos os itens objetivos. Há um alto número de regras modeladas nessa abordagem; entretanto, não é um número de regras que torne a exploração extremamente complexa. A ConexARN apresentou uma visualização bastante interessante, correlacionando todos os itens objetivos. A principal diferença entre a ConexARN e a rede Bayesiana é que a ConexARN modelou menos regras, tornando a exploração mais simples. Essa redução no número de regras não resultou em uma alteração na estrutura, mantendo o grafo resultante totalmente conexo. Por fim, a Greedy exARN novamente apresenta a modelagem com menos regras entre as abordagens. Nesse caso, a Greedy exARN apresentou mais de um grafo como resultado, quebrando diferentes itens objetivos em diferentes grafos. Ao realizar essa divisão, a abordagem sugere que não há relações entre esses itens. Na base genre, a ConexARN apresentou os melhores resultados. A quantidade de regras modelada foi baixo sem remover a conexão entre os itens objetivos. A Greedy exARN apresentou o menor número de regras, entretanto é necessário cuidado ao analisar esse resultado. Como a base possui poucos itens frequentes, a Greedy exARN 


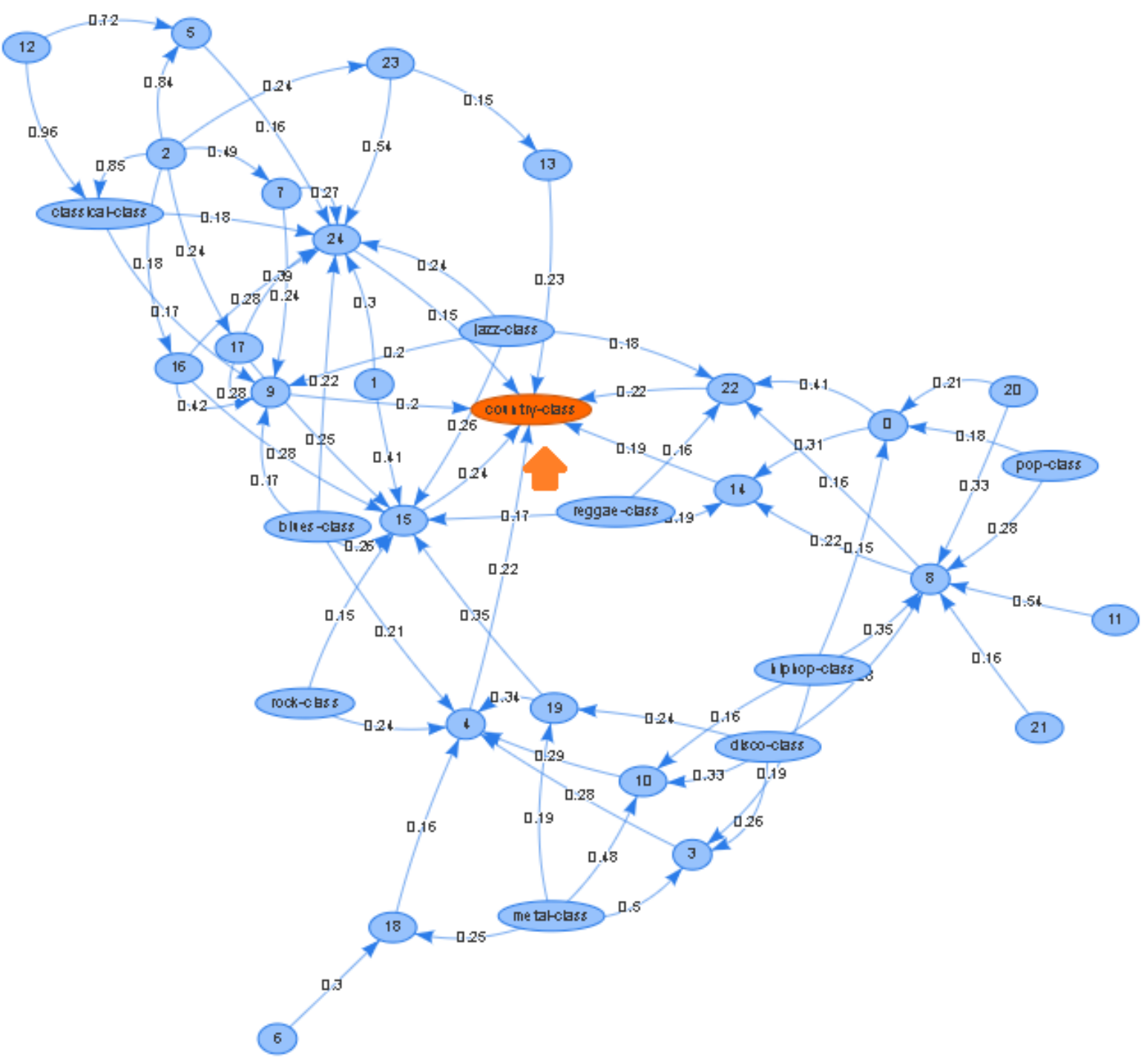

Figura $27-A R N$ construída na base genre com o item objetivo country-class.

tende a podar mais itens que o necessário, perdendo conhecimento potencialmente interessante.

\subsection{Considerações Finais}

Neste capítulo foi apresentada a configuração experimental utilizada para validar a ConexARN e a Greedy exARN. Também foram relembradas as hipóteses que foram validados, sendo elas 1) modelar múltiplos itens objetivos; 2) possibilitar a visualização de itens dominantes e determinantes; 3) aumentar a qualidade das regras apresentadas para o usuário e 4) reduzir a quantidade de regras modeladas.

$\mathrm{Na}$ Seção 4.1 foram apresentadas as bases de dados utilizadas nos experimentos, bem como todo o processamento necessário para prepará-las.

Depois de descrever as bases, foi apresentado a construção dos experimentos. Para gerar a ARN, ConexARN e Greedy exARN, foram geradas regras de associação. Toda a configuração dos 


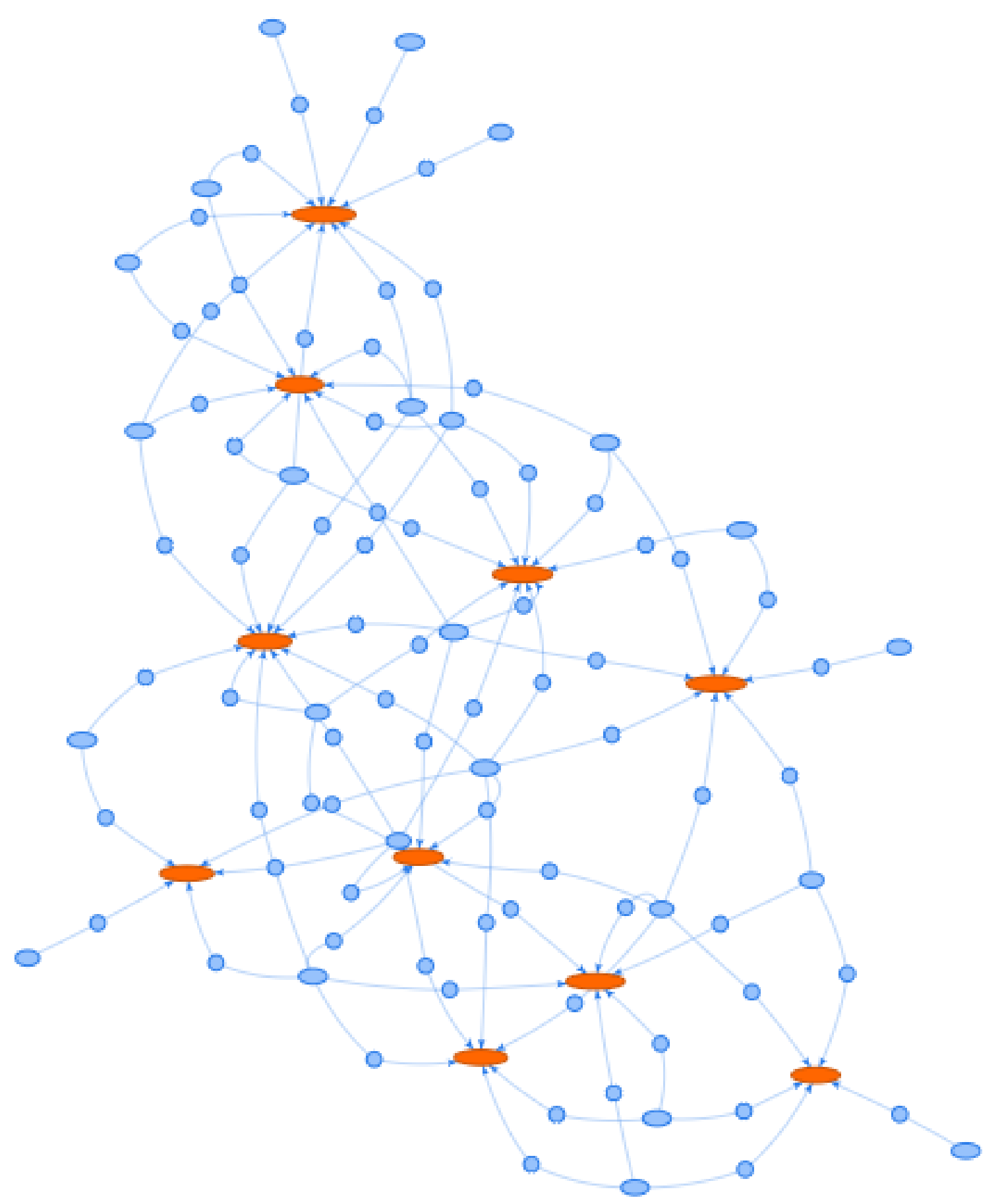

Figura 28 - Rede Bayesiana construída na base genre.

parâmetros para geração dessas regras foi apresentada, assim como os passos necessários para se gerar as redes a partir dos dados originais. O baseline utilizado, que são as redes Bayesianas, são geradas considerando uma adaptação de suporte e confiança das regras de associação, para que a comparação pudesse ser justa.

A análise quantitativa apresentou diversas características interessantes das abordagens propostas. A ConexARN apresentou resultados interessantes em bases de dados com poucos 


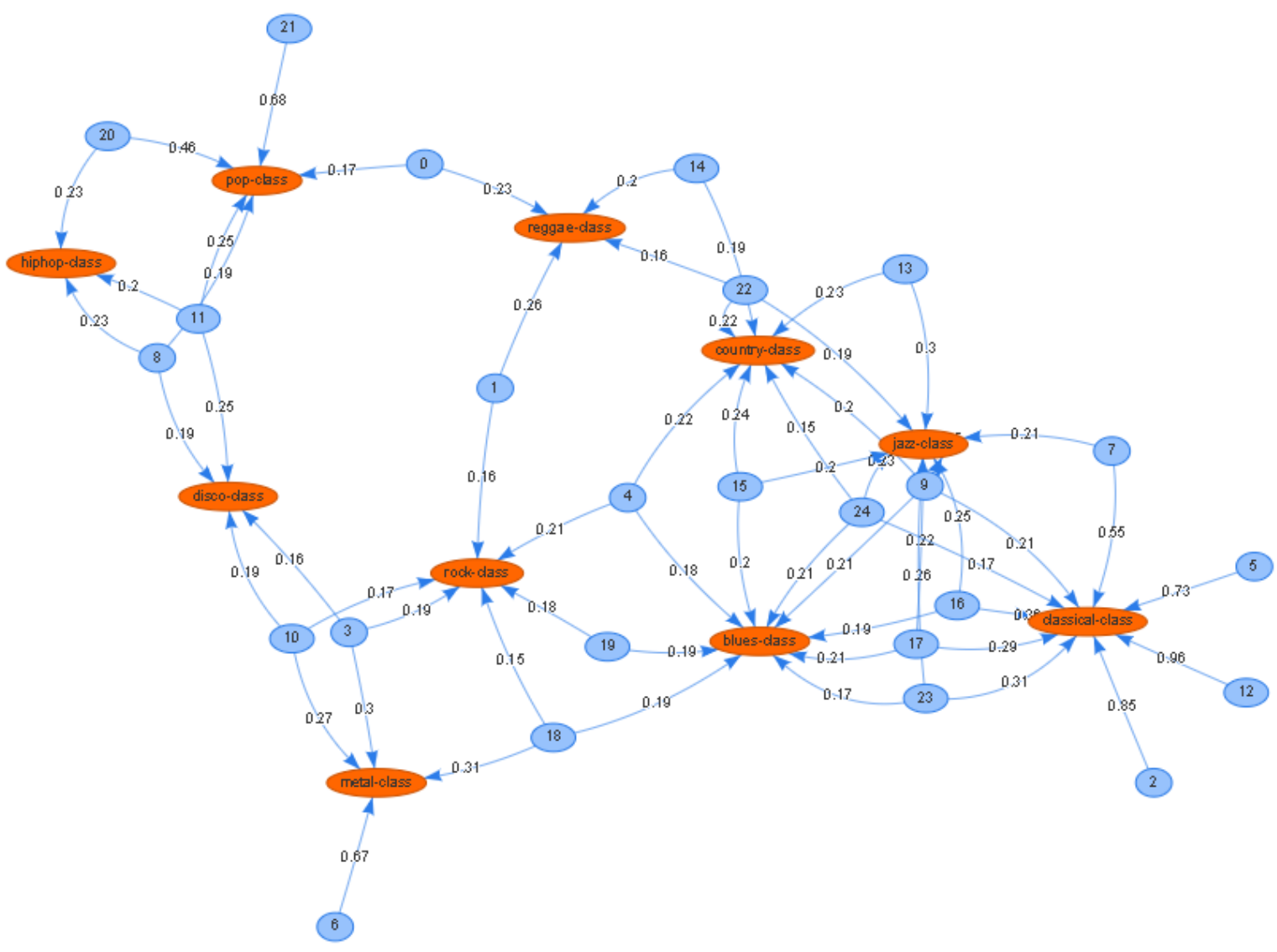

Figura 29 - ConexARN construída na base genre.

atributos disponíveis ou com poucos atributos frequentes. Isso aconteceu pois a modelagem da ConexARN é realizada escolhendo todas as regras possíveis a cada iteração. Dessa maneira, há uma maior tendência a sobrecarregar os níveis mais baixos da rede, apresentando uma quantidade razoável de regras. Já a Greedy exARN apresentou resultados promissores exatamente nas condições em que a ConexARN não apresenta bons resultados. Ao otimizar uma medida objetivo, a Greedy exARN prioriza a qualidade em detrimento da quantidade de regras modeladas. Essa escolha permite que mesmo em condições com muitos atributos frequentes, a Greedy exARN seja capaz de reduzir a quantidade de regras a ser modelada, reduzindo também o impacto na qualidade das regras modeladas. A Greedy exARN apresenta resultados menos interessantes nos casos em que há uma baixa quantidade de atributos frequentes, modelando uma quantidade insuficiente de regras.

Já na análise qualitativa foi apresentada a visualização do resultado e a capacidade de se extrair informações relevantes. Foram apresentadas 2 visualizações para cada abordagem: uma gerada na base artist 20 e outra gerada na base genre. Em ambas as visualizações a $A R N$ apresentou um alto número de regras modeladas. Além da quantidade de regras, a $A R N$ não foi capaz de apresentar correlação entre diferentes itens objetivos da base, sendo necessário gerar mais de uma $A R N$ para explorar esses itens objetivos individualmente. A rede Bayesiana não apresentou bons resultados na base artist20, gerando uma modelagem extremamente densa que 


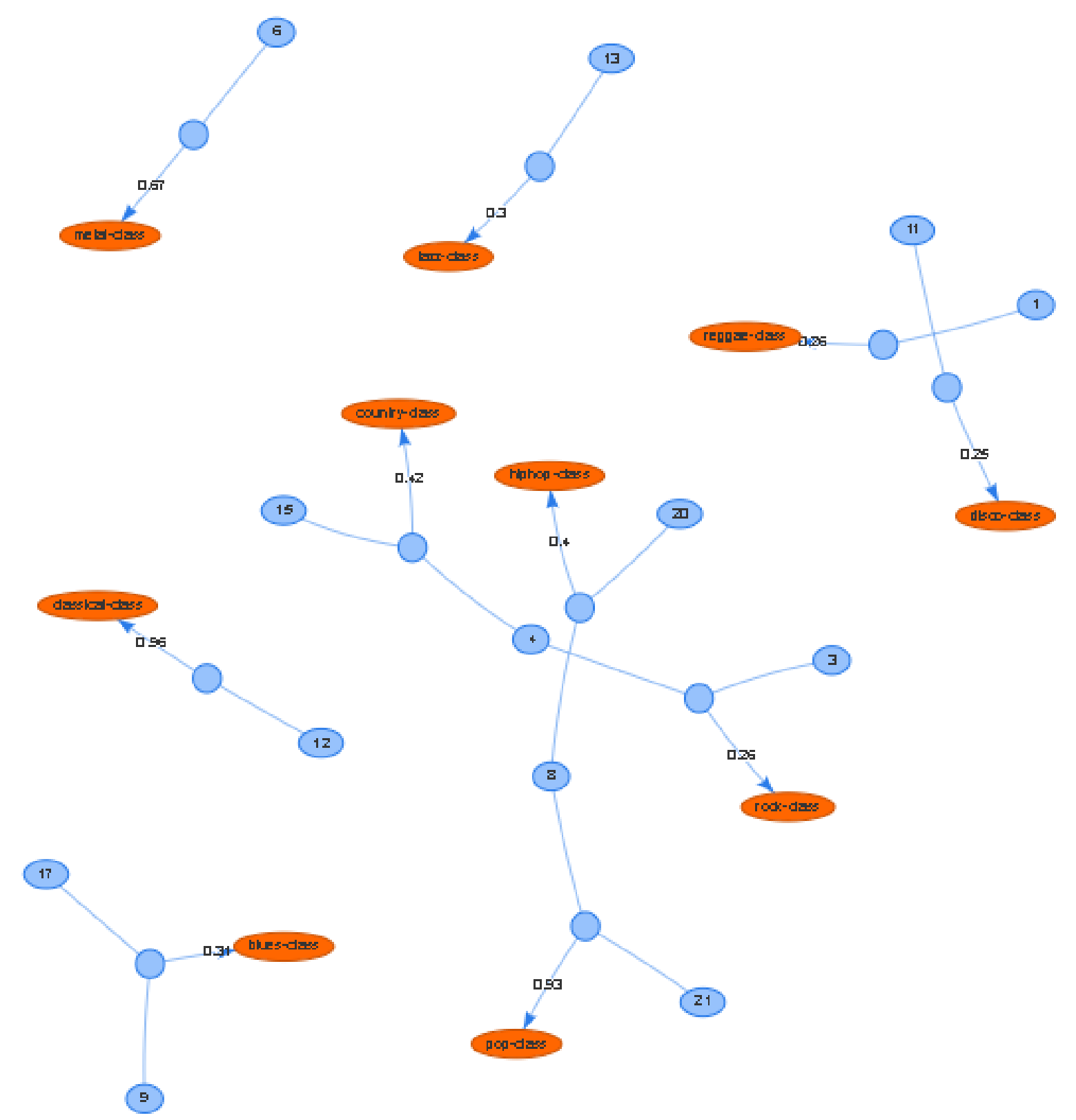

Figura 30 - Greedy exARN construída na base genre.

impossibilita a exploração do conhecimento. Já na base gender a rede Bayesiana apresentou bons resultados, sendo possível identificar a correlação entre itens da base e diferentes itens objetivos. A ConexARN também não apresentou bons resultados na base artist20, gerando uma visualização muito densa, tornando o processo de extrair conhecimento útil bastante complexo. Já na base genre a ConexARN apresentou resultados bastante promissores. A quantidade de regras modeladas é baixa, menor que a quantidade modelada pela rede Bayesiana, o que torna o processo de exploração mais simples. Por fim, a Greedy exARN apresentou resultados bastante promissores na artist20, que é a base mais densa. Esse bom resultado é obtido devido a capacidade de otimizar uma medida de qualidade, o que acaba gerando uma poda mais agressiva. Já na base genre a Greedy exARN não apresentou bons resultados, falhando em apresentgar as correlações entre 
diferentes itens objetivos.

Os resultados obtidos qualitativamente e quantitativamente direcionam para as mesmas conclusões: em bases mais densas, com mais itens frequentes, a Greedy exARN tende a obter uma melhor performance devido a sua capacidade de poda. Já em bases menos densas, a ConexARN apresentou os melhores resultados, sendo capaz de reduzir a quantidade de regras modeladas sem perder muito conhecimento no processo. 

CAPÍTULO

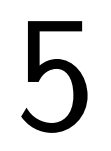

5

\section{CONCLUSÕES}

Neste capítulo são apresentadas as conclusões deste doutorado. Primeiramente, apresentaremos as inovações e as contribuições científicas geradas em decorrência deste trabalho, referentes aos objetivos listados na introdução. Uma lista das publicações resultantes das contribuições científicas deste trabalho também é apresentada. Por fim, apresentamos as limitações presentes nas abordagens propostas, bem como apresentamos o caminho dos trabalhos futuros a serem realizados.

\subsection{Inovações e Contribuições Científicas}

Neste projeto de doutorado foram propostas 2 abordagens para o processamento e representação de regras de associação. Essas abordagens têm como objetivo modelar as regras de associação de acordo com as hipóteses deste trabalho, a saber: 1) modelar múltiplos itens objetivos; 2) facilitar a identificação de itens dominantes e determinantes na base; 3) aumentar a qualidade das regras apresentadas para o usuário e 4) reduzir a quantidade de regras modeladas. Destaca-se que foram realizadas avaliações quantitativas, visando extrair numericamente o valor da contribuição apresentada, mas também foram feitas análises qualitativas, visando entender mais a fundo os benefícios das abordagens propostas e como elas facilitam a exploração das regras e identificação de possíveis hipóteses de pesquisa.

- Hipótese 1 - É possível modelar mais de um item objetivo: Conforme apresentado no capítulo anterior, as abordagens ConexARN e Greedy exARNsão capazes de modelar mais de um item objetivo em uma mesma estrutura. As abordagens propostas apresentam um grafo capaz de apresentar, visualmente, as relações entre os itens de uma base de dados com um conjunto de itens objetivos selecionados pelo usuário.

- Hipótese 2 - Abordagens com vários itens objetivos possibilitam visualização de itens dominantes e determinantes: Ambas as abordagens propostas destacam visualmente os 
itens dominantes, que são os itens que se relacionam com vários itens objetivos, e os itens determinantes, que são itens que se relacionam com apenas um único item objetivo. Dessa maneira, o usuário final é capaz de identificar as relações de interesse dentro da base de dados.

- Hipótese 3 - Abordagens com vários itens objetivos possibilitam maximizar a qualidade das regras a serem visualizadas: A abordagem Greedy exARN apresentou excelentes resultados ao maximizar uma determinada medida objetiva. Conforme apresentado no capítulo anterior, a Greedy exARN foi capaz de maximizar a medida objetivo selecionada, utilizando um algoritmo guloso para escolher as regras que são modeladas no grafo. Em alguns casos, como na base balance-scale por exemplo, a Greedy exARN conseguiu um valor médio da medida objetivo 36 pontos maior que a ConexARN, que já possui um ganho se comparado com a $A R N$ e a rede Bayesiana.

- Hipótese 4 - Abordagens com vários itens objetivos possibilitam uma redução no número de regars a serem visualizadas: Conforme apresentado no capítulo anterior, a ConexARN e a Greedy exARN apresentaram resultados bastante promissores em modelar as regras de associação, permitindo extrair o conhecimento com menos complexidade. A Greedy exARN obteve melhores resultados em bases mais densas, com mais itens frequentes. A abordagem foi capaz de reduzir a quantidade de regras a ser explorada pelo usuário drasticamente, apresentando apenas um pequeno conjunto. Já a ConexARN obteve melhores resultados em bases menos densas, com menos itens frequentes. A abordagem foi rapaz de reduzir a quantidade de regras a ser explorada pelo usuário mas sem perder muito conhecimento. A ConexARNfoca nas regras que apresentam a relação entre os itens objetivos, podando regras em níveis maiores que teriam uma relação mais distante com os itens objetivos.

Além dos resultados obtidos, também foi gerado um Framework de processamento de regras de associação baseado em itens objetivos. Disponível em $<$ https://bit.ly/2NFJVjz>, as abordagens desenvolvidas estão disponíveis para download e utilização. Esse framework pode ser utilizado em uma grande gama de problemas, desde que o objetivo final seja entender a correlação entre um conjunto de itens da base com um outro conjunto de itens pré-selecionados.

\subsection{Publicações}

As contribuições obtidas com o desenvolvimento desta tese de doutorado foram divulgadas por meio de publicações em conferências (3 diretamente relacionadas com os resultados obtidos neste doutorado) e periódico (1 - submetido).

\section{Periódico}


de Padua, R.; Carvalho, V. O.; Ramos, Fabio; Rezende, S. O. . Extended Association Rule Network: Exploring the data focusing on predetermined items. Knowledge and Information Systems, submetido.

\section{Conferências - Resultados diretos da tese}

de Padua, R.; Calcada, D. B. ; Carvalho, V. O. ; Rezende, S. O. . Exploring the Data Using Extended Association Rule Network. In: 2018 7th Brazilian Conference on Intelligent Systems (BRACIS), 2018, Sao Paulo. 2018 7th Brazilian Conference on Intelligent Systems (BRACIS), 2018. p. 330.

de Padua, R.; Carvalho, V. O. ; Rezende, S. O. ; SILVA, D. F. . Exploring Musical Relations Using Association Rule Networks. In: International Society for Music Information Retrieval Conference (ISMIR 2018), 2018. Proceedings of the 19th International Society for Music Information Retrieval Conference, 2018. p. 400-406.

Calcada, D. B. ; de Padua, R. ; Rezende, S. O. . Asymmetric objective measures applied to filter Association Rules Networks. In: XLIV Latin American Computing Conference, 2018. XLIV Latin American Computing Conference, 2018. p. 1-10.

Além das publicações diretas deste doutorado, também foram geradas outras publicações em parceria com outros pesquisadores do laboratório, relacionados com o tema deste doutorado.

\section{Conferências - Relacionadas com o tema do doutorado}

Sundermann, C. V.; de Padua, R.; Tonon, V. R.; Domingues, M. A.; Rezende, S. O. A Context-Aware Recommender Method Based on Text Mining. In: 2019 EPIA Conference on Artificial Inteligence, 2019, Vila Real. Lecture Notes in Computer Science. p. 385-396.

de Padua, R.; Carmo, L. P. ; Rezende, S. O. ; Carvalho, V. O. An Analysis on Community Detection and Clustering Algorithms on the Post-Processing of Association Rules. In: 2018 International Joint Conference on Neural Networks (IJCNN), 2018, Rio de Janeiro. 2018 International Joint Conference on Neural Networks (IJCNN), 2018. p. 1.

Carvalho, V. O.; de Padua, R.; Rezende, S. O. Solving the Problem of Selecting Suitable Objective Measures by Clustering Association Rules Through the Measures Themselves. In: International Conference on Current Trends in Theory and Practice of Computer Science, 2016, Harrachov. SOFSEM 2016: Theory and Practice of Computer Science, 2016. v. 9587. p. 505-517.

de Padua, R.; Carvalho, V. O. ; Rezende, S. O. Post-processing Association Rules: A Network Based Label Propagation Approach. In: International Conference on Current Trends in Theory and Practice of Computer Science, 2016, Harrachov. SOFSEM 2016: Theory and Practice of Computer Science, 2016. v. 9587. p. 580-591.

de Padua, R.; Silva Junior, E. L. ; Carmo, L. P. ; Carvalho, V. O. ; Rezende, S. O. . Preprocessing data sets for association rules using community detection and clustering: a comparative study. In: XIII Encontro Nacional de Inteligência Artificial e Computacional (ENIAC 
2016), 2016, Recife. XIII Encontro Nacional de Inteligência Artificial e Computacional (ENIAC 2016), 2016.

\subsection{Limitações e Trabalhos Futuros}

Durante o desenvolvimento do doutorado, consideramos uma rede direcionada para representação das regras de associação. Essa rede direcionada foi construída de maneira backward, ou seja, considerando o elemento final da rede e encontrando elementos que se conectavam a ele. Entretanto, outras abordagens são possíveis que poderiam apresentar resultados interessantes. Uma delas seria a utilização de uma rede bidirecional, na qual apresentaríamos as mesmas informações que apresentamos nas abordagens propostas, porém, acrescidas das relações inversas. Por exemplo, se a regra $A \rightarrow B$ está modelada em uma exARN, então teríamos também o peso de $B \rightarrow A$, para entendermos de maneira mais completa como a relação funciona.

Já com relação ao algoritmo de construção da Greedy exARN, foi utilizada a construção Hill Climbing. Esse algoritmo considera sempre a situação local para decisão do próximo passo, escolhendo a melhor opção disponível a cada iteração nova. Como o algoritmo realiza uma otimização local, não há garantias de ótimo global. Há diversos algoritmos capazes de garantir o ótimo global, entretanto, ao custo de uma alta complexidade computacional.

$\mathrm{Na}$ abordagem ConexARN a modelagem das regras é realizada sempre nos menores níveis. Por mais que essa abordagem tenha sido bem-sucedida em reduzir a quantidade de regras, ela não apresenta uma redução suficiente para ser viável em bases densas. A ConexARN consegue bons resultados nas condições em que a Greedy exARN apresenta resultados ruins, assim como a Greedy exARN apresenta bons resultados onde a ConexARN falha em reduzir a quantidade de regras a serem modeladas.

Apresentadas essas limitações, há algumas linhas de trabalhos futuros traçadas para serem realizadas. A primeira delas é a exploração de outros métodos de otimização para a construção da rede, de modo que seja possível atingir um máximo global. Essa abordagem maximizará o valor das medidas sendo otimizada, apresentando a melhor configuração possível dado um conjunto de regras e de itens objetivos.

Além da otimização, outros algoritmos devem ser estudados para identificação de pontos importantes nessas redes. Por exemplo, um algoritmo que detecta itens dominantes ou um algoritmo que detecta caminhos mais comuns na rede. Esses algoritmos podem apresentar insights interessantes para o usuário explorando a rede, facilitando o entendimento das correlações e como os itens interagem entre eles. 


\section{REFERÊNCIAS}

AGGARWAL, C.; PROCOPIUC, C.; YU, P. Finding localized associations in market basket data. IEEE Transactions on Knowledge and Data Engineering, IEEE Computer Society, v. 14, n. 1, p. 51-62, 2002. ISSN 1041-4347. Citado nas páginas 33 e 34.

AGRAWAL, R.; IMIELINSKI, T.; SWAMI, A. Mining association rules between sets of items in large databases. Special Interest Group on Management of Data, v. 22, n. 2, p. 207-216, jun. 1994. Citado nas páginas 25, 31, 32, 33, 34, 35 e 37.

AGRAWAL, R.; MANNILA, H.; SRIKANT, R.; TOIVONEN, H.; VERKAMO, A. I. Fast discovery of association rules. Advances in Knowledge Discovery and Data Mining, American Association for Artificial Intelligence, Menlo Park, CA, USA, p. 307-328, 1996. Citado nas páginas 35,36 e 37.

ALONSO, A. G.; CARRASCO-OCHOA, J. A.; MEDINA-PAGOLA, J. E.; TRINIDAD, J. F. M. Reducing the number of canonical form tests for frequent subgraph mining. Computación $\mathbf{y}$ Sistemas, v. 15, p. 251-265, 2011. Citado na página 61.

AN, A.; KHAN, S.; HUANG, X. Objective and subjective algorithms for grouping association rules. In: In proceedings of the 3rd IEEE International Conference on Data Mining. [S.1.: s.n.], 2003. p. 477-480. Citado na página 42.

ANCHURI, P.; ZAKI, M. J.; BARKOL, O.; BERGMAN, R.; FELDER, Y.; GOLAN, S.; SITYON, A. Graph mining for discovering infrastructure patterns in configuration management databases. Knowledge Information Systems., v. 33, p. 491-522, 2012. Citado nas páginas 62 e 63.

ANTHONISSE, J. M. The rush in a directed graph. Amsterdam, 1971. Citado na página 51.

ARUMUGAM, S.; SABEEN, S. Association rule mining using path systems in directed graphs. International Journal of Computers Communications \& Control, v. 8, p. 791-799, 2013. Citado na página 61.

BAESENS, B.; VIAENE, S.; VANTHIENEN, J. Post-processing of association rules. In: In proceedings of the International Conference on Knowledge Discovery and Data Mining. [S.1.: s.n.], 2000. p. 2-8. Citado na página 38.

BERLINGERIO, M.; PINELLI, F.; CALABRESE, F. Abacus: frequent pattern mining-based community discovery in multidimensional networks. Data Mining and Knowledge Discovery, v. 27, p. 294-320, 2013. Citado na página 62.

BERRADO, A.; RUNGER, G. C. Using metarules to organize and group discovered association rules. Data Mining and Knowledge Discovery, v. 14, n. 3, p. 409-431, 2007. Citado nas páginas 41 e 42.

BESEMANN, C.; WU, J.; DENTON, A. M. A log-linear approach to mining significant graphrelational patterns. Data Knowledge Engineering, v. 70, p. 527-554, 2011. Citado nas páginas 63 e 66. 
BLANCHARD, J.; GUILLET, F.; BRIAND, H. Interactive visual exploration of association rules with rule-focusing methodology. Knowledge and Information Systems, v. 13, p. 43-75, 2007. Citado na página 42.

BLUM, A.; CHAWLA, S. Learning from labeled and unlabeled data using graph mincuts. In: In proceedings of the 18th International Conference on Machine Learning. [S.1.]: Morgan Kaufmann Publishers Inc., 2001. p. 19-26. Citado na página 53.

BRIN, S.; PAGE, L. The anatomy of a large-scale hypertextual web search engine. In: In proceedings of Computer Networks and ISDN Systems. [S.1.: s.n.], 1998. p. 107-117. Citado na página 50.

CARVALHO, V. O.; BIONDI, D. S.; SANTOS, F. F.; REZENDE, S. O. Labeling methods for association rule clustering. In: 14th International Conference on Enterprise Information Systems. [S.1.: s.n.], 2012. p. 105-111. Citado na página 42.

CARVALHO, V. O.; PADUA, R.; REZENDE, S. O. Solving the problem of selecting suitable objective measures by clustering association rules through the measures themselves. In: In proceedings of 42nd International Conference on Current Trends in Theory and Practice of Computer Science. [s.n.], 2016. p. 505-517. Disponível em: <http://dx.doi.org/10.1007/ 978-3-662-49192-8_41>. Citado na página 40.

CARVALHO, V. O.; REZENDE, S. O.; CASTRO, M. Obtaining and evaluating generalized association rules. In: In proceedings of the 9th International Conference on Enterprise Information Systems. [S.1.: s.n.], 2007. v. 2 - Artificial Intelligence and Decision Support Systems, p. 310-315. Citado na página 41.

CARVALHO, V. O.; SANTOS, F. F.; REZENDE, S. O. Post-processing association rules with clustering and objective measures. In: In proceedings of the 13th International Conference on Enterprise Information Systems. [S.1.: s.n.], 2011. p. 54-63. Citado na página 42.

CHANGGUO, Y.; NIANZHONG, W.; TAILEI, W.; QIN, Z.; XIAORONG, Z. The research on the application of association rules mining algorithm in network intrusion detection. In: HU, Z.; LIU, Q. (Ed.). In proceedings of the International Workshop on Education Technology and Computer Science. [S.1.: s.n.], 2009. v. 2, p. 849-852. Citado na página 31.

CHAWLA, S. Feature selection, association rules network and theory building. In: In proceedings of the 4th International Workshop on Feature Selection in Data Mining. [S.1.]: PMLR, 2010. (Proceedings of Machine Learning Research, v. 10), p. 14-21. Citado na página 67.

CHAWLA, S.; ARUNASALAM, B.; DAVIS, J. Mining open source software(oss) data using association rules network. In: In proceedings of Pacific Asia Conference on Knowledge Discovery and Data Mining. [S.1.: s.n.], 2003. p. 461-466. Citado na página 67.

CHEN, P.; VERMA, R. M.; MEININGER, J. C.; CHAN, W. Semantic analysis of association rules. In: In proceedings of the 25th International Florida Artificial Intelligence Research Society Conference. [S.1.: s.n.], 2008. p. 270-275. Citado na página 42.

CHOI, Y. K.; KIM, S. K. An auxiliary recommendation system for repetitively purchasing items in e-commerce. In: In proceedings of the Big Data and Smart Computing. [S.1.: s.n.], 2014. p. 96-98. Citado na página 31. 
DADASER-CELIK, F.; CELIK, M.; DOKUZ, A. S. Associations between stream flow and climatic variables at kizilirmak river basin in turkey. In: In proceedings of the International Conference on Environmental Science and Technology. [S.1.: s.n.], 2012. v. 14, n. 3, p. 354361. Citado na página 31.

DONG, J.; CHEN, S.; CHEN, J.; HUANG, G.; REN, J. A dag-based algorithm of mining frequent closed itemsets in high dimensional datasets. International Journal of Advancements in Computing Technology, v. 4, p. 213-222, 2012. Citado na página 61.

ELLIS, D. P. W. Classifying music audio with timbral and chroma features. In: In proceedings of the 8th International Conference on Music Information Retrieval. [S.1.: s.n.], 2007. p. 339-340. Citado na página 84.

ELSEIDY, M.; ABDELHAMID, E.; SKIADOPOULOS, S.; KALNIS, P. Grami: Frequent subgraph and pattern mining in a single large graph. In: Proceedings of the VLDB Endowment. [S.1.: s.n.], 2014. p. 517-528. Citado na página 61.

FARALLI, S.; STILO, G.; VELARDI, P. Recommendation of microblog users based on hierarchical interest profiles. Social Network Analysis and Mining, v. 5, p. 25:1-25:23, 2015. Citado nas páginas 62 e 63.

FARIHA, A.; AHMED, C. F.; LEUNG, C. K.; SAMIULLAH, M.; PERVIN, S.; CAO, L. A new framework for mining frequent interaction patterns from meeting databases. Engineering Applications of Artificial Intelligence, v. 45, p. 103-118, 2015. Citado na página 65.

FERRAZ, I. N.; GARCIA, A. C. B. Ontology in association rules pre-processing and postprocessing. In: In proceedings of European Conference on Data Mining. [S.1.: s.n.], 2008. p. 87-91. Citado na página 42.

FLORES-GARRIDO, M.; CARRASCO-OCHOA, J. A.; TRINIDAD, J. F. M. Agrap: an algorithm for mining frequent patterns in a single graph using inexact matching. Knowledge Information Systems., v. 44, p. 385-406, 2014. Citado na página 61.

. Mining maximal frequent patterns in a single graph using inexact matching. Knowledge Based Systems, v. 66, p. 166-177, 2014. Citado na página 61.

Agrap: an algorithm for mining frequent patterns in a single graph using inexact matching. Knowledge Information Systems., v. 44, p. 385-406, 2015. Citado na página 61.

FREEMAN, L. C. A Set of Measures of Centrality Based upon Betweenness. Sociometry, v. 40, p. 35-41, 1977. Citado na página 51.

The Development of Social Network Analysis: A Study in the Sociology of Science. [S.1.]: Empirical Press, 2004. Citado na página 51.

FUJIMOTO, M. L.; CARVALHO, V. O.; REZENDE, S. O. Evaluating generalized association rules combining objective and subjective measures and visualization. In: In proceedings of the International Conference on Enterprise Information Systems. [S.1.: s.n.], 2009. p. 285-288. Citado na página 42.

GEORGII, E.; TSUDA, K.; SCHöLKOPF, B. Multi-way set enumeration in weight tensors. Machine Learning, v. 82, p. 123-155, 2011. Citado na página 62. 
GIRVAN, M.; NEWMAN, M. E. J. Community structure in social and biological networks. Proceedings of the National Academy of Sciences, National Academy of Sciences, v. 99, n. 12, p. 7821-7826, jun. 2002. Citado nas páginas 15, 56 e 57.

HAN, J.; PEI, J.; YIN, Y.; MAO, R. Mining frequent patterns without candidate generation: A frequent-pattern tree approach. Data Mining and Knowledge Discovery, Kluwer Academic Publishers, v. 8, n. 1, p. 53-87, jan. 2004. ISSN 1384-5810. Citado nas páginas 35 e 37.

HONG, T.-P.; TUNG, Y.-F.; WANG, S.-L.; WU, Y.-L.; WU, M.-T. A multi-level ant-colony mining algorithm for membership functions. Information Sciences, v. 182, p. 3-14, 2012. Citado na página 66.

JADHAV, R. D.; DESHPANDE, A. An efficient and interactive approach for association rules generation by integrating ontology and filtering technique. In: In proceedings of International Conference on ICT for Sustainable Development. [S.1.: s.n.], 2016. p. 233-241. Citado na página 31 .

JI, M.; SUN, Y.; DANILEVSKY, M.; HAN, J.; GAO, J. Graph regularized transductive classification on heterogeneous information networks. In: In proceedings of the European Conference on Machine Learning and Knowledge Discovery in Databases. [S.1.]: Springer-Verlag, 2010. p. 570-586. Citado na página 55.

JUNG, J. J. Constraint graph-based frequent pattern updating from temporal databases. Expert Systems with Application, v. 39, p. 3169-3173, 2012. Citado na página 63.

KARIMI-MAJD, A.-M.; MAHOOTCHI, M. A new data mining methodology for generating new service ideas. Information Systems and e-Business Management, v. 13, p. 421-443, 2015. Citado nas páginas 15, 66 e 67.

KERNIGHAN, B.; LIN, S. An Efficient Heuristic Procedure for Partitioning Graphs. The Bell Systems Technical Journal, v. 49, p. 291-307, 1970. Citado na página 55.

KIM, C.; LEE, H.; SEOL, H.; LEE, C. Identifying core technologies based on technological cross-impacts: An association rule mining (arm) and analytic network process (anp) approach. Expert Systems with Application, v. 38, p. 12559-12564, 2011. C Citado na página 66.

KIM, H. K.; KIM, J. K.; CHEN, Q. Y. A product network analysis for extending the market basket analysis. Expert Systems with Application, v. 39, p. 7403-7410, 2012. Citado nas páginas 62 e 63.

KLEINBERG, J. M. Authoritative sources in a hyperlinked environment. Journal of ACM, p. 604-632, 1999. Citado na página 51.

KLEMETTINEN, M.; MANNILA, H.; RONKAINEN, P.; TOIVONEN, H.; VERKAMO, A. I. Finding interesting rules from large sets of discovered association rules. In: ADAM, N. R.; BHARGAVA, B. K.; YESHA, Y. (Ed.). In proceedings of the 3rd International Conference on Information and Knowledge Management. [S.1.]: ACM Press, 1994. p. 401-407. Citado na página 43.

KLIEGR, T.; SVáTEK, V.; RALBOVSKý, M.; SIMUNEK, M. Sewebar-cms: semantic analytical report authoring for data mining results. Journal of Intelligent Information Systems, v. 37, p. 371-395, 2011. Citado nas páginas 42 e 66. 
LEE, G.; YUN, U.; RYANG, H.; KIM, D. Multiple minimum support-based rare graph pattern mining considering symmetry feature-based growth technique and the differing importance of graph elements. Symmetry, v. 7, p. 1151-1163, 2015. Citado na página 61.

LI, Y.; WU, J. Interpretation of association rules in multi-tier structures. International Journal of Approximate Reasoning, v. 55, p. 1439-1457, 2014. Citado na página 65.

LIU, B.; HSU, W.; MA, Y. Pruning and summarizing the discovered associations. In: In proceedings of the 5th ACM SIGKDD International Conference on Knowledge Discovery and Data Mining. [S.1.: s.n.], 1999. p. 125-134. Citado na página 41.

LIU, L.; SHEN, J.; ZHU, Q. Mining tribe based on the frequent pattern. Journal of Theoretical and Applied Information Technology, v. 48, p. 1558-1564, 2013. Citado nas páginas 62 e 63.

LIU, W.; YUE, K.; LIU, H.; ZHANG, P.; LIU, S.; WANG, Q. Associative categorization of frequent patterns based on the probabilistic graphical model. Frontiers of Computer Science, v. 8, p. 265-278, 2014. Citado na página 61.

LIU, X.; ZHAI, K.; PEDRYCZ, W. An improved association rules mining method. Expert Systems with Application, v. 39, p. 1362-1374, 2012. Citado nas páginas 61 e 65.

LIU, Y.-C.; CHENG, C.-P.; TSENG, V. S. Mining differential top-k co-expression patterns from time course comparative gene expression datasets. BMC Bioinformatics, v. 14, p. 1:13, 2013. Citado na página 62.

MABU, S.; CHEN, C.; LU, N.; SHIMADA, K.; HIRASAWA, K. An intrusion-detection model based on fuzzy class-association-rule mining using genetic network programming. IEEE Transactions on Systems, Man, and Cybernetics, Part C., v. 41, p. 130-139, 2011. Citado na página 64.

MANSINGH, G.; OSEI-BRYSON, K.-M.; REICHGELT, H. Using ontologies to facilitate post-processing of association rules by domain experts. Information Sciences, v. 181, n. 3, p. 419-434, 2011. Citado na página 42.

MARINICA, C.; GUILLET, F. Knowledge-based interactive postmining of association rules using ontologies. IEEE Transactions on Knowledge and Data Engineering, v. 22, n. 6, p. 784-797, 2010. Citado na página 42.

MARTíNEZ-BALLESTEROS, M.; NEPOMUCENO-CHAMORRO, I.; RIQUELME, J. Discovering gene association networks by multi-objective evolutionary quantitative association rules. Journal of Computer and System Sciences, v. 80, p. 118-136, 2014. Citado na página 67.

NATARAJAN, R.; SHEKAR, B. Interestingness of association rules in data mining: Issues relevant to e-commerce. SĀDHANĀ - Academy Proceedings in Engineering Sciences (The Indian Academy of Sciences), v. 30, n. Parts 2\&3, p. 291-310, 2005. Citado na página 40.

NEWMAN, M. E. J. Networks: An Introduction. [S.1.]: Oxford University Press, 2010. Citado nas páginas $15,44,45,48,49,51,53,55$ e 56.

NGUYEN, K.-N.; CERF, L.; PLANTEVIT, M.; BOULICAUT, J.-F. Discovering descriptive rules in relational dynamic graphs. Intelligent Data Analysis, v. 17, p. 49-69, 2013. Citado na página 65. 
NIRMALA, M.; PALANISAMY, V. An efficient prediction of missing itemset in shopping cart. Journal of Computer Science, v. 9, p. 55-62, 2013. Citado na página 65.

NUWANGI, S. M.; ORUTHOTAARACHCHI, C. R.; TILAKARATNA, J. M. P. P.; CALDERA, $\mathrm{H}$. A. Usage of association rules and classification techniques in knowledge extraction of diabetes. In: In proceedings of the International Conference on Advanced Information Management and Service. [S.1.: s.n.], 2010. p. 372-377. Citado na página 31.

OELLRICH, A.; JACOBSEN, J.; PAPATHEODOROU, I.; PROJECT, T. S. M. G.; SMEDLEY, D. Using association rule mining to determine promising secondary phenotyping hypotheses. Bioinformatics, Oxford University Press, v. 30, n. 12, p. i52-i59, jun. 2014. Citado na página 31.

OH, K.-J.; JUNG, J.-G.; JO, G.-S. Discovering frequent patterns by constructing frequent pattern network over data streams in e-marketplaces. Wireless Personal Communications, v. 79, p. 2655-2670, 2014. Citado na página 61.

PADUA, R. de; CALçADA, D. B.; CARVALHO, V. O. de; REZENDE, S. O. Exploring the data using extended association rule network. In: In proceedings of the 7th Brazilian Conference on Intelligent Systems (BRACIS). [S.1.: s.n.], 2018. p. 330-335. Citado na página 28.

PADUA, R. de; CARVALHO, V. O. de; REZENDE, S.; SILVA, D. F. Exploring Musical Relations Using Association Rule Networks. In: In proceedings of the 19th International Society for Music Information Retrieval Conference. [S.1.]: ISMIR, 2018. p. 400-406. Citado na página 28.

PANDEY, G.; CHAWLA, S.; POON, S.; ARUNASALAM, B.; DAVIS, J. G. Association rules network: Definition and applications. Statistical Analysis and Data Mining, Wiley Subscription Services, Inc., A Wiley Company, v. 1, n. 4, p. 260-279, 2009. Citado nas páginas 26, 67, 72, 83 e 86.

PARK, K.; HAN, Y.; LEE, Y.-K. Activity graph feature selection for activity pattern classification. International Journal of Distributed Sensor Networks, v. 2014, p. 1-10, 2014. Citado na página 62.

PEARL, J. Probabilistic Reasoning in Intelligent Systems: Networks of Plausible Inference. [S.l.: s.n.], 1988. Citado na página 86.

PEARS, R.; KOH, Y. S.; DOBBIE, G.; YEAP, W. K. Weighted association rule mining via a graph based connectivity model. Information Sciences, v. 218, p. 61-84, 2013. Citado na página 65.

PETELIN, B.; KONONENKO, I.; MALACIC, V.; KUKAR, M. Multi-level association rules and directed graphs for spatial data analysis. Expert Systems with Application, v. 40, p. 4957-4970, 2013. Citado nas páginas 65 e 67.

PLASSE, M.; NIANG, N.; SAPORTA, G.; VILLEMINOT, A.; LEBLOND, L. Combined use of association rules mining and clustering methods to find relevant links between binary rare attributes in a large data set. Computational Statistics \& Data Analysis, v. 52, n. 1, p. 596-613, 2007. Citado nas páginas 33 e 34.

PRADO, A.; PLANTEVIT, M.; ROBARDET, C.; BOULICAUT, J.-F. Mining graph topological patterns: Finding covariations among vertex descriptors. IEEE Transactions on Knowledge and Data Engineering, v. 25, p. 2090-2104, 2013. Citado nas páginas 62 e 63. 
REICHARDT, J.; BORNHOLDT, S. Statistical mechanics of community detection. Physical Review E, v. 74, 2006. Citado na página 57.

REZENDE, S. O.; MELANDA, E. A.; FUJIMOTO, M. L.; SINOARA, R. A.; CARVALHO, V. O. Combining data-driven and user-driven evaluation measures to identify interesting rules. In: ZHAO, Y.; ZHANG, C.; CAO, L. (Ed.). Post-Mining of Association Rules: Techniques for Effective Knowledge Extraction. [S.1.]: IGI Global, 2009. cap. 3. Citado na página 40.

ROMERO, C.; LUNA, J. M.; ROMERO, J. R.; VENTURA, S. Rm-tool: A framework for discovering and evaluating association rules. Advances in Engineering Software, v. 42, n. 8, p. 566-576, 2011. Citado na página 43.

ROSSI, R. G.; LOPES, A. A.; REZENDE, S. O. A parameter-free label propagation algorithm using bipartite heterogeneous networks for text classification. In: In proceedings of the ACM Symposium on Applied Computing. [S.1.: s.n.], 2014. (SAC'14), p. 79-84. Citado na página 54.

SALAM, A.; KHAYAL, M. S. H. Mining top-k frequent patterns without minimum support threshold. Knowledge Information Systems., v. 30, p. 57-86, 2012. Citado na página 61.

SHENG HUIJUAN HOU, X. J. G.; CHEN, Y. A novel association rule mining method of big data for power transformers state parameters based on probabilistic graph model. IEEE TRANSACTIONS ON SMART GRID, v. 9, p. 695 - 702, 2018. Citado nas páginas 15, 64 e 65 .

SIKORA, M.; GRUCA, A. Induction and selection of the most interesting gene ontology based multiattribute rules for descriptions of gene groups. Pattern Recognition Letters, v. 32, p. 258-269, 2011. Citado na página 62.

SILVA, A.; MEIRA JR., W.; ZAKI, M. J. Mining attribute-structure correlated patterns in large attributed graphs. In: Proceedings of the VLDB Endowment. [S.1.: s.n.], 2012. p. 466-477. Citado na página 61.

SIVAKRITHIKA, V.; MERLIN, S. S.; SUGIRTHA, K. An efficient medical image diagnosis system using soft computing techniques. Journal of Theoretical and Applied Information Technology, v. 36, p. 190-198, 2012. Citado na página 64.

SULTHANA, A.; MURUGESWARI, B. Aripso: Association rule interactive postmining using schemas and ontologies. In: In proceedings of the International Conference on Emerging Trends in Electrical and Computer Technology (ICETECT). [S.1.: s.n.], 2011. p. 941-946. Citado na página 39.

SWEETLIN, C.; KALAIVANI, V. User interactive post-processing of association rules and correlation based redundancy removal. International Journal of Computer Applications, ICON3C, n. 3, p. 31-35, 2012. Citado nas páginas 39 e 42.

TAKIGAWA, I.; MAMITSUKA, H. Efficiently mining $\sigma$-tolerance closed frequent subgraphs. Machine Learning, v. 82, p. 95-121, 2011. Citado nas páginas 62 e 63.

TECHAPICHETVANICH, K.; DATTA, A. VisAR: A new technique for visualizing mined association rules. In: In proceedigns of the 1st International Conference on Advanced Data Mining and Applications. [S.1.: s.n.], 2005. v. 3584, p. 88-95. Citado na página 43. 
TZANETAKIS, G.; COOK, P. R. Musical genre classification of audio signals. IEEE Trans. Speech and Audio Processing, v. 10, n. 5, p. 293-302, 2002. Citado na página 84.

VIDELA-CAVIERES; F., I.; RíOS, S. A. Extending market basket analysis with graph mining techniques: A real case. Expert Systems with Application, v. 41, p. 1928-1936, 2014. Citado na página 62.

VIJAYALAKSHMI, R.; NADARAJAN, R.; RODDICK, J. F.; THILAGA, M.; NIRMALA, P. Fp-graphminer-a fast frequent pattern mining algorithm for network graphs. Journal of Graph Algorithms and Applications, v. 15, p. 753-776, 2011. Citado nas páginas 59, 60 e 61.

WANG, M.; SHANG, X.; LI, Z. Mfc: Mining maximal frequent dense subgraphs without candidate maintenance in imbalanced ppi networks. Journal of Software, v. 6, p. 498-507, 2011. Citado na página 61 .

WU, J. Z.; LIU, H. W.; WU, F. L. A recommender system based on car pairwise comparisons on a mobile application using association rules. In: In proceedings of the International Conference on Industrial Technology. [S.1.: s.n.], 2016. p. 1344 - 1346. Citado na página 31.

WULANDARI CHAO OU-YANG, H.-C. W. C. P. Applying mutual information for discretization to support the discovery of rare-unusual association rule in cerebrovascular examination dataset. Expert Systems with Applications, v. 118, p. 52-64, 2019. Citado na página 33.

XIAO, G. Association rules algorithm in bank risk assessment. Advanced Electrical and Electronics Engineering, v. 87, p. 675-681, 2011. Citado na página 31.

YANG, G.; MABU, S.; SHIMADA, K.; HIRASAWA, K. An evolutionary approach to rank class association rules with feedback mechanism. Expert Systems with Application, v. 38, p. 15040-15048, 2011. Citado nas páginas 64 e 66.

A novel evolutionary method to search interesting association rules by keywords. Expert Systems with Application, v. 38, p. 13378-13385, 2011. Citado nas páginas 15, 63 e 64.

YU, J.; HO, C.; HSU, Y.; WANG, J.; HSIEH, C. Traditional chinese medicine treatments for upper respiratory tract infections/common colds in taiwan. European Journal of Integrative Medicine, p. 538-544, 2014. ISSN 1876-3820. Citado na página 31.

ZHAO, Y.; ZHANG, C.; CAO, L. Post-Mining of Association Rules: Techniques for Effective Knowledge Extraction. [S.1.]: IGI Global, 2009. Citado na página 42.

ZHOU, D.; BOUSQUET, O.; LAL, T. N.; WESTON, J.; SCHÖLKOPF, B. Learning with local and global consistency. In: In proceedings of the Advances in Neural Information Processing Systems 16. [S.1.: s.n.], 2003. p. 321-328. Citado nas páginas 53, 54 e 55.

ZHOU, H.; HIRASAWA, K. Traffic density prediction with time-related data mining using genetic network programming. The Computer Journal, v. 57, p. 1395-1414, 2014. Citado na página 64.

ZHU, F.; QU, Q.; LO, D.; YAN, X.; HAN, J.; YU, P. S. Mining top-k large structural patterns in a massive network. In: Proceedings of the VLDB Endowment. [S.1.: s.n.], 2011. p. 807-818. Citado na página 61.

ZHU, X. Semi-supervised Learning with Graphs. Tese (Doutorado), Pittsburgh, PA, USA, 2005. Citado na página 52. 
ÖZKURAL, E.; UçAR, B.; AYKANAT, C. Parallel frequent item set mining with selective item replication. IEEE Transactions on Parallel and Distributed Systems, v. 22, p. 1632-1640, 2011. Citado na página 61. 

APÊNDICE

\section{A}

\section{TABELAS DE RESULTADOS}

Na Tabela 10 são apresentados todos os resultados obtidos utilizando a ARN. Na primeira coluna é apresentada a base de dados utilizada junto com a configuração para extração de regras. Por exemplo, a configuração balance-scaleSOCOLen2.0arn refere-se a base balance-scale com suporte mínimo igual a 0 (S0), confiança mínima igual a $0(\mathrm{C} 0)$ tamanho de regra igual a 2 (Len2) e item objetivo no índice 0 da base de dados (.0arn). Na segunda coluna é apresentada a quantidade de regras modeladas. Por fim, na última coluna é apresentada o valor médio de confiança das regras modeladas.

Tabela 10 - Resultados obtidos usando a abordagem ARN.

\begin{tabular}{ccc} 
Configuracao & Quantidade Regras & Confiança Média \\
\hline balance-scaleS0C0Len2.0arn & 14 & $6,6286 \%$ \\
\hline balance-scaleS0C0Len2.13arn & 14 & $39,5429 \%$ \\
\hline balance-scaleS0C0Len2.14arn & 14 & $39,5429 \%$ \\
\hline balance-scaleS0C10Len2.13arn & 36 & $37,6011 \%$ \\
\hline balance-scaleS0C10Len2.14arn & 36 & $37,6011 \%$ \\
\hline balance-scaleS0C15Len2.13arn & 36 & $37,6011 \%$ \\
\hline balance-scaleS0C15Len2.14arn & 36 & $37,6011 \%$ \\
\hline balance-scaleS0C25Len2.10arn & 28 & $45,0364 \%$ \\
\hline balance-scaleS0C25Len2.11arn & 28 & $45,0364 \%$ \\
\hline balance-scaleS0C5Len2.0arn & 36 & $24,8000 \%$ \\
\hline balance-scaleS0C5Len2.13arn & 36 & $37,6011 \%$ \\
\hline balance-scaleS0C5Len2.14arn & 36 & $37,6011 \%$ \\
\hline balance-scaleS10C0Len2.1arn & 24 & $45,0842 \%$ \\
\hline balance-scaleS10C0Len2.4arn & 24 & $45,0842 \%$ \\
\hline balance-scaleS10C10Len2.1arn & 24 & $45,0842 \%$ \\
\hline balance-scaleS10C10Len2.4arn & 24 & $45,0842 \%$ \\
\hline
\end{tabular}




\begin{tabular}{|c|c|c|}
\hline balance-scaleS10C15Len2.1arn & 24 & $45,0842 \%$ \\
\hline balance-scaleS10C15Len2.4arn & 24 & $45,0842 \%$ \\
\hline balance-scaleS10C25Len2.1arn & 22 & $47,0991 \%$ \\
\hline balance-scaleS10C25Len2.4arn & 22 & $47,0991 \%$ \\
\hline balance-scaleS10C5Len2.1arn & 24 & $45,0842 \%$ \\
\hline balance-scaleS10C5Len2.4arn & 24 & $45,0842 \%$ \\
\hline balance-scaleS1C0Len2.0arn & 36 & $24,8000 \%$ \\
\hline balance-scaleS1C0Len2.13arn & 36 & $37,6011 \%$ \\
\hline balance-scaleS1C0Len2.14arn & 36 & $37,6011 \%$ \\
\hline balance-scaleS1C10Len2.13arn & 36 & $37,6011 \%$ \\
\hline balance-scaleS1C10Len2.14arn & 36 & $37,6011 \%$ \\
\hline balance-scaleS1C15Len2.13arn & 36 & $37,6011 \%$ \\
\hline balance-scaleS1C15Len2.14arn & 36 & $37,6011 \%$ \\
\hline balance-scaleS1C25Len2.10arn & 28 & $45,0364 \%$ \\
\hline balance-scaleS1C25Len2.11arn & 28 & $45,0364 \%$ \\
\hline balance-scaleS1C5Len2.0arn & 36 & $24,8000 \%$ \\
\hline balance-scaleS1C5Len2.13arn & 36 & $37,6011 \%$ \\
\hline balance-scaleS1C5Len2.14arn & 36 & $37,6011 \%$ \\
\hline balance-scaleS5C0Len2.7arn & 24 & $39,7333 \%$ \\
\hline balance-scaleS5C0Len2.8arn & 24 & $39,7333 \%$ \\
\hline balance-scaleS5C10Len2.7arn & 24 & $39,7333 \%$ \\
\hline balance-scaleS5C10Len2.8arn & 24 & $39,7333 \%$ \\
\hline balance-scaleS5C15Len2.7arn & 24 & $39,7333 \%$ \\
\hline balance-scaleS5C15Len2.8arn & 24 & $39,7333 \%$ \\
\hline balance-scaleS5C25Len2.7arn & 22 & $46,3718 \%$ \\
\hline balance-scaleS5C25Len2.8arn & 22 & $46,3718 \%$ \\
\hline balance-scaleS5C5Len2.7arn & 24 & $39,7333 \%$ \\
\hline balance-scaleS5C5Len2.8arn & 24 & $39,7333 \%$ \\
\hline breast-cancerS0C0Len2.28arn & 42 & $31,4657 \%$ \\
\hline breast-cancerS0C0Len2.39arn & 42 & $66,1533 \%$ \\
\hline breast-cancerS0C10Len2.16arn & 72 & $61,4118 \%$ \\
\hline breast-cancerS0C10Len2.5arn & 132 & $45,8791 \%$ \\
\hline breast-cancerS0C15Len2.16arn & 70 & $62,8313 \%$ \\
\hline breast-cancerS0C15Len2.5arn & 145 & $49,0471 \%$ \\
\hline breast-cancerS0C25Len2.16arn & 64 & $66,9084 \%$ \\
\hline breast-cancerS0C25Len2.5arn & 130 & $44,1567 \%$ \\
\hline breast-cancerS0C5Len2.16arn & 77 & $57,9051 \%$ \\
\hline
\end{tabular}




\begin{tabular}{|c|c|c|}
\hline breast-cancerS0C5Len2.5arn & 140 & $43,6982 \%$ \\
\hline breast-cancerS10C0Len2.13arn & 77 & $58,3755 \%$ \\
\hline breast-cancerS10C0Len2.4arn & 37 & $62,4959 \%$ \\
\hline breast-cancerS10C10Len2.13arn & 77 & $58,3755 \%$ \\
\hline breast-cancerS10C10Len2.4arn & 37 & $62,4959 \%$ \\
\hline breast-cancerS10C15Len2.13arn & 77 & $58,3755 \%$ \\
\hline breast-cancerS10C15Len2.4arn & 37 & $62,4959 \%$ \\
\hline breast-cancerS10C25Len2.13arn & 64 & $50,2697 \%$ \\
\hline breast-cancerS10C25Len2.4arn & 37 & $62,4959 \%$ \\
\hline breast-cancerS10C5Len2.13arn & 77 & $58,3755 \%$ \\
\hline breast-cancerS10C5Len2.4arn & 37 & $62,4959 \%$ \\
\hline breast-cancerS1C0Len2.16arn & 106 & $46,6885 \%$ \\
\hline breast-cancerS1C0Len2.6arn & 80 & $54,0250 \%$ \\
\hline breast-cancerS1C10Len2.16arn & 98 & $50,0106 \%$ \\
\hline breast-cancerS1C10Len2.6arn & 73 & $58,6136 \%$ \\
\hline breast-cancerS1C15Len2.16arn & 101 & $52,6419 \%$ \\
\hline breast-cancerS1C15Len2.6arn & 71 & $59,9342 \%$ \\
\hline breast-cancerS1C25Len2.16arn & 104 & $45,2439 \%$ \\
\hline breast-cancerS1C25Len2.6arn & 65 & $63,6812 \%$ \\
\hline breast-cancerS1C5Len2.16arn & 103 & $47,9741 \%$ \\
\hline breast-cancerS1C5Len2.6arn & 77 & $55,9696 \%$ \\
\hline breast-cancerS5C0Len2.22arn & 86 & $51,3915 \%$ \\
\hline breast-cancerS5C0Len2.5arn & 51 & $57,0692 \%$ \\
\hline breast-cancerS5C10Len2.22arn & 85 & $51,8941 \%$ \\
\hline breast-cancerS5C10Len2.5arn & 51 & $57,0692 \%$ \\
\hline breast-cancerS5C15Len2.22arn & 83 & $52,8618 \%$ \\
\hline breast-cancerS5C15Len2.5arn & 51 & $57,0692 \%$ \\
\hline breast-cancerS5C25Len2.22arn & 86 & $47,4069 \%$ \\
\hline breast-cancerS5C25Len2.5arn & 46 & $61,0985 \%$ \\
\hline breast-cancerS5C5Len2.22arn & 86 & $51,3915 \%$ \\
\hline breast-cancerS5C5Len2.5arn & 51 & $57,0692 \%$ \\
\hline carS0C0Len2.0arn & 24 & $3,2913 \%$ \\
\hline carS0C0Len2.1arn & 24 & $3,4946 \%$ \\
\hline carS0C0Len2.24arn & 24 & $61,2704 \%$ \\
\hline carS0C0Len2.2arn & 24 & $19,4454 \%$ \\
\hline carS0C10Len2.0arn & 61 & $31,5395 \%$ \\
\hline carS0C10Len2.15arn & 40 & $25,2977 \%$ \\
\hline
\end{tabular}




\begin{tabular}{|c|c|c|}
\hline carS0C10Len2.18arn & 101 & $30,7403 \%$ \\
\hline carS0C10Len2.24arn & 69 & $47,3986 \%$ \\
\hline carS0C15Len2.18arn & 101 & $30,7403 \%$ \\
\hline carS0C15Len2.24arn & 69 & $47,3986 \%$ \\
\hline carS0C25Len2.16arn & 117 & $32,3515 \%$ \\
\hline carS0C25Len2.24arn & 60 & $51,4095 \%$ \\
\hline carS0C5Len2.0arn & 122 & $29,1736 \%$ \\
\hline carS0C5Len2.15arn & 123 & $29,5557 \%$ \\
\hline carS0C5Len2.18arn & 101 & $30,7403 \%$ \\
\hline carS0C5Len2.24arn & 69 & $47,3986 \%$ \\
\hline carS10C0Len2.0arn & 36 & $44,7689 \%$ \\
\hline carS10C0Len2.6arn & 25 & $66,8200 \%$ \\
\hline carS10C10Len2.0arn & 36 & $44,7689 \%$ \\
\hline carS10C10Len2.6arn & 25 & $66,8200 \%$ \\
\hline carS10C15Len2.0arn & 36 & $44,7689 \%$ \\
\hline carS10C15Len2.6arn & 25 & $66,8200 \%$ \\
\hline carS10C25Len2.0arn & 35 & $45,3940 \%$ \\
\hline carS10C25Len2.6arn & 25 & $66,8200 \%$ \\
\hline carS10C5Len2.0arn & 36 & $44,7689 \%$ \\
\hline carS10C5Len2.6arn & 25 & $66,8200 \%$ \\
\hline carS1C0Len2.0arn & 136 & $28,3972 \%$ \\
\hline carS1C0Len2.12arn & 136 & $28,8482 \%$ \\
\hline carS1C0Len2.16arn & 97 & $31,1811 \%$ \\
\hline carS1C0Len2.24arn & 65 & $49,0815 \%$ \\
\hline carS1C10Len2.0arn & 61 & $31,5395 \%$ \\
\hline carS1C10Len2.12arn & 40 & $25,2977 \%$ \\
\hline carS1C10Len2.16arn & 97 & $31,1811 \%$ \\
\hline carS1C10Len2.24arn & 65 & $49,0815 \%$ \\
\hline carS1C15Len2.16arn & 97 & $31,1811 \%$ \\
\hline carS1C15Len2.24arn & 65 & $49,0815 \%$ \\
\hline carS1C25Len2.16arn & 117 & $32,3515 \%$ \\
\hline carS1C25Len2.24arn & 60 & $51,4095 \%$ \\
\hline carS1C5Len2.0arn & 122 & $29,1736 \%$ \\
\hline carS1C5Len2.12arn & 123 & $29,5557 \%$ \\
\hline carS1C5Len2.16arn & 97 & $31,1811 \%$ \\
\hline carS1C5Len2.24arn & 65 & $49,0815 \%$ \\
\hline carS5C0Len2.0arn & 99 & $27,9411 \%$ \\
\hline
\end{tabular}




\begin{tabular}{|c|c|c|}
\hline carS5C0Len2.21arn & 37 & $54,3759 \%$ \\
\hline carS5C10Len2.0arn & 99 & $27,9411 \%$ \\
\hline carS5C10Len2.21arn & 37 & $54,3759 \%$ \\
\hline carS5C15Len2.0arn & 99 & $27,9411 \%$ \\
\hline carS5C15Len2.21arn & 37 & $54,3759 \%$ \\
\hline carS5C25Len2.0arn & 104 & $30,2129 \%$ \\
\hline carS5C25Len2.20arn & 35 & $56,1363 \%$ \\
\hline carS5C5Len2.0arn & 99 & $27,9411 \%$ \\
\hline carS5C5Len2.21arn & 37 & $54,3759 \%$ \\
\hline ecoliS0C0Len2.13arn & 26 & $15,0269 \%$ \\
\hline ecoliS0C0Len2.1 arn & 26 & $4,9258 \%$ \\
\hline ecoliS0C0Len2.21arn & 26 & $26,5481 \%$ \\
\hline ecoliS0C0Len2.2arn & 26 & $0,3088 \%$ \\
\hline ecoliS0C0Len2.3arn & 26 & $2,7619 \%$ \\
\hline ecoliS0C0Len2.6arn & 26 & $5,2573 \%$ \\
\hline ecoliS0C0Len2.7arn & 26 & $7,3565 \%$ \\
\hline ecoliS0C0Len2.9arn & 26 & $10,8892 \%$ \\
\hline ecoliS0C10Len2.15arn & 3 & $83,3333 \%$ \\
\hline ecoliS0C10Len2.18arn & 99 & $62,1509 \%$ \\
\hline ecoliS0C10Len2.1arn & 3 & $73,3333 \%$ \\
\hline ecoliS0C10Len2.20arn & 118 & $64,2416 \%$ \\
\hline ecoliS0C10Len2.21arn & 108 & $64,6475 \%$ \\
\hline ecoliS0C10Len2.24arn & 111 & $60,5214 \%$ \\
\hline ecoliS0C10Len2.25arn & 74 & $41,3057 \%$ \\
\hline ecoliS0C15Len2.15arn & 3 & $83,3333 \%$ \\
\hline ecoliS0C15Len2.19arn & 112 & $67,0762 \%$ \\
\hline ecoliS0C15Len2.1arn & 3 & $73,3333 \%$ \\
\hline ecoliS0C15Len2.22arn & 100 & $66,5324 \%$ \\
\hline ecoliS0C15Len2.23arn & 62 & $48,0653 \%$ \\
\hline ecoliS0C15Len2.24arn & 77 & $51,7656 \%$ \\
\hline ecoliS0C15Len2.26arn & 107 & $67,5253 \%$ \\
\hline ecoliS0C25Len2.15arn & 3 & $83,3333 \%$ \\
\hline ecoliS0C25Len2.1arn & 1 & $100,0000 \%$ \\
\hline ecoliS0C25Len2.20arn & 94 & $69,5221 \%$ \\
\hline ecoliS0C25Len2.21arn & 65 & $52,5629 \%$ \\
\hline ecoliS0C25Len2.23arn & 92 & $66,6649 \%$ \\
\hline ecoliS0C25Len2.24arn & 55 & $57,9904 \%$ \\
\hline
\end{tabular}




\begin{tabular}{|c|c|c|}
\hline ecoliS0C25Len2.26arn & 56 & $49,3214 \%$ \\
\hline ecoliS0C5Len2.15arn & 71 & $48,7068 \%$ \\
\hline ecoliS0C5Len2.18arn & 118 & $59,6549 \%$ \\
\hline ecoliS0C5Len2.1 arn & 60 & $36,2920 \%$ \\
\hline ecoliS0C5Len2.20arn & 122 & $62,3296 \%$ \\
\hline ecoliS0C5Len2.21arn & 113 & $60,1296 \%$ \\
\hline ecoliS0C5Len2.24arn & 121 & $56,0512 \%$ \\
\hline ecoliS0C5Len2.25arn & 114 & $58,0505 \%$ \\
\hline ecoliS10C0Len2.0arn & 36 & $93,7147 \%$ \\
\hline ecoliS10C0Len2.10arn & 48 & $74,2083 \%$ \\
\hline ecoliS10C0Len2.16arn & 53 & $75,6240 \%$ \\
\hline ecoliS10C0Len2.5arn & 56 & $77,6973 \%$ \\
\hline ecoliS10C10Len2.0arn & 36 & $93,7147 \%$ \\
\hline ecoliS10C10Len2.10arn & 48 & $74,2083 \%$ \\
\hline ecoliS10C10Len2.16arn & 53 & $75,6240 \%$ \\
\hline ecoliS10C10Len2.5arn & 56 & $77,6973 \%$ \\
\hline ecoliS10C15Len2.10arn & 48 & $74,2083 \%$ \\
\hline ecoliS10C15Len2.16arn & 53 & $75,6240 \%$ \\
\hline ecoliS10C15Len2.5arn & 56 & $77,6973 \%$ \\
\hline ecoliS10C25Len2.10arn & 48 & $74,2083 \%$ \\
\hline ecoliS10C25Len2.16arn & 44 & $62,0416 \%$ \\
\hline ecoliS10C25Len2.5arn & 47 & $66,0923 \%$ \\
\hline ecoliS10C5Len2.0arn & 36 & $93,7147 \%$ \\
\hline ecoliS10C5Len2.10arn & 48 & $74,2083 \%$ \\
\hline ecoliS10C5Len2.16arn & 53 & $75,6240 \%$ \\
\hline ecoliS10C5Len2.5arn & 56 & $77,6973 \%$ \\
\hline ecoliS1C0Len2.0arn & 81 & $52,4074 \%$ \\
\hline ecoliS1C0Len2.10arn & 91 & $60,3773 \%$ \\
\hline ecoliS1C0Len2.14arn & 102 & $54,7772 \%$ \\
\hline ecoliS1C0Len2.17arn & 99 & $59,6457 \%$ \\
\hline ecoliS1C0Len2.21arn & 106 & $59,4387 \%$ \\
\hline ecoliS1C0Len2.23arn & 90 & $60,4742 \%$ \\
\hline ecoliS1C10Len2.0arn & 1 & $50,0000 \%$ \\
\hline ecoliS1C10Len2.10arn & 85 & $61,7398 \%$ \\
\hline ecoliS1C10Len2.14arn & 61 & $35,7007 \%$ \\
\hline ecoliS1C10Len2.17arn & 85 & $61,8516 \%$ \\
\hline ecoliS1C10Len2.21arn & 99 & $63,5742 \%$ \\
\hline
\end{tabular}




\begin{tabular}{|c|c|c|}
\hline ecoliS1C10Len2.23arn & 88 & $64,9210 \%$ \\
\hline ecoliS1C15Len2.0arn & 1 & $50,0000 \%$ \\
\hline ecoliS1C15Len2.10arn & 81 & $65,4721 \%$ \\
\hline ecoliS1C15Len2.14arn & 49 & $42,6088 \%$ \\
\hline ecoliS1C15Len2.17arn & 71 & $52,7444 \%$ \\
\hline ecoliS1C15Len2.21arn & 95 & $65,7460 \%$ \\
\hline ecoliS1C15Len2.23arn & 85 & $67,0809 \%$ \\
\hline ecoliS1C25Len2.0arn & 1 & $50,0000 \%$ \\
\hline ecoliS1C25Len2.10arn & 77 & $67,8582 \%$ \\
\hline ecoliS1C25Len2.14arn & 61 & $52,8769 \%$ \\
\hline ecoliS1C25Len2.17arn & 81 & $67,5289 \%$ \\
\hline ecoliS1C25Len2.21arn & 45 & $54,9513 \%$ \\
\hline ecoliS1C25Len2.23arn & 45 & $48,4889 \%$ \\
\hline ecoliS1C5Len2.0arn & 59 & $42,4268 \%$ \\
\hline ecoliS1C5Len2.10arn & 91 & $58,0927 \%$ \\
\hline ecoliS1C5Len2.14arn & 97 & $55,7616 \%$ \\
\hline ecoliS1C5Len2.17arn & 94 & $61,7949 \%$ \\
\hline ecoliS1C5Len2.21arn & 102 & $61,8808 \%$ \\
\hline ecoliS1C5Len2.23arn & 88 & $61,7452 \%$ \\
\hline ecoliS5C0Len2.0arn & 65 & $66,0391 \%$ \\
\hline ecoliS5C0Len2.12arn & 74 & $64,0969 \%$ \\
\hline ecoliS5C0Len2.18arn & 65 & $65,4149 \%$ \\
\hline ecoliS5C0Len2.19arn & 71 & $66,3406 \%$ \\
\hline ecoliS5C0Len2.6arn & 71 & $70,0631 \%$ \\
\hline ecoliS5C10Len2.0arn & 49 & $44,5778 \%$ \\
\hline ecoliS5C10Len2.12arn & 74 & $64,0969 \%$ \\
\hline ecoliS5C10Len2.18arn & 65 & $65,4149 \%$ \\
\hline ecoliS5C10Len2.19arn & 71 & $66,3406 \%$ \\
\hline ecoliS5C10Len2.6arn & 65 & $67,6372 \%$ \\
\hline ecoliS5C15Len2.0arn & 68 & $56,7018 \%$ \\
\hline ecoliS5C15Len2.12arn & 74 & $64,0969 \%$ \\
\hline ecoliS5C15Len2.18arn & 65 & $65,4149 \%$ \\
\hline ecoliS5C15Len2.19arn & 70 & $68,7443 \%$ \\
\hline ecoliS5C15Len2.6arn & 56 & $53,5012 \%$ \\
\hline ecoliS5C25Len2.0arn & 52 & $54,9733 \%$ \\
\hline ecoliS5C25Len2.12arn & 36 & $50,0625 \%$ \\
\hline ecoliS5C25Len2.18arn & 62 & $67,5960 \%$ \\
\hline
\end{tabular}




\begin{tabular}{|c|c|c|}
\hline ecoliS5C25Len2.19arn & 45 & $51,8360 \%$ \\
\hline ecoliS5C25Len2.6arn & 68 & $65,3221 \%$ \\
\hline ecoliS5C5Len2.0arn & 65 & $66,0391 \%$ \\
\hline ecoliS5C5Len2.12arn & 74 & $64,0969 \%$ \\
\hline ecoliS5C5Len2.18arn & 65 & $65,4149 \%$ \\
\hline ecoliS5C5Len2.19arn & 71 & $66,3406 \%$ \\
\hline ecoliS5C5Len2.6arn & 71 & $70,0631 \%$ \\
\hline habermanS0C0Len2.15arn & 19 & $28,5984 \%$ \\
\hline habermanS0C0Len2.18arn & 19 & $66,1384 \%$ \\
\hline habermanS0C10Len2.4arn & 26 & $30,0442 \%$ \\
\hline habermanS0C10Len2.7arn & 26 & $57,5435 \%$ \\
\hline habermanS0C15Len2.4arn & 25 & $43,1608 \%$ \\
\hline habermanS0C15Len2.7arn & 22 & $65,7055 \%$ \\
\hline habermanS0C25Len2.4arn & 21 & $46,9443 \%$ \\
\hline habermanS0C25Len2.7arn & 21 & $68,0700 \%$ \\
\hline habermanS0C5Len2.4arn & 32 & $25,9944 \%$ \\
\hline habermanS0C5Len2.7arn & 30 & $51,0647 \%$ \\
\hline habermanS10C0Len2.4arn & 8 & $73,3463 \%$ \\
\hline habermanS10C0Len2.7arn & 8 & $82,3838 \%$ \\
\hline habermanS10C10Len2.4arn & 8 & $73,3463 \%$ \\
\hline habermanS10C10Len2.7arn & 8 & $82,3838 \%$ \\
\hline habermanS10C15Len2.4arn & 8 & $73,3463 \%$ \\
\hline habermanS10C15Len2.7arn & 8 & $82,3838 \%$ \\
\hline habermanS10C25Len2.4arn & 8 & $74,2613 \%$ \\
\hline habermanS10C25Len2.7arn & 8 & $82,3838 \%$ \\
\hline habermanS10C5Len2.4arn & 8 & $73,3463 \%$ \\
\hline habermanS10C5Len2.7arn & 8 & $82,3838 \%$ \\
\hline habermanS1C0Len2.1arn & 36 & $30,4503 \%$ \\
\hline habermanS1C0Len2.4arn & 32 & $47,2947 \%$ \\
\hline habermanS1C10Len2.1arn & 28 & $37,1025 \%$ \\
\hline habermanS1C10Len2.4arn & 25 & $58,5120 \%$ \\
\hline habermanS1C15Len2.1arn & 26 & $45,1492 \%$ \\
\hline habermanS1C15Len2.4arn & 21 & $67,2471 \%$ \\
\hline habermanS1C25Len2.1arn & 20 & $45,9580 \%$ \\
\hline habermanS1C25Len2.4arn & 20 & $69,8070 \%$ \\
\hline habermanS1C5Len2.1arn & 34 & $32,0453 \%$ \\
\hline habermanS1C5Len2.4arn & 29 & $51,6762 \%$ \\
\hline
\end{tabular}




\begin{tabular}{|c|c|c|}
\hline habermanS5C0Len2.14arn & 21 & $72,7514 \%$ \\
\hline habermanS5C0Len2.1arn & 17 & $72,9800 \%$ \\
\hline habermanS5C10Len2.14arn & 21 & $72,7514 \%$ \\
\hline habermanS5C10Len2.1arn & 17 & $72,9800 \%$ \\
\hline habermanS5C15Len2.14arn & 21 & $72,7514 \%$ \\
\hline habermanS5C15Len2.1arn & 17 & $72,9800 \%$ \\
\hline habermanS5C25Len2.14arn & 22 & $74,2941 \%$ \\
\hline habermanS5C25Len2.1arn & 17 & $72,9800 \%$ \\
\hline habermanS5C5Len2.14arn & 21 & $72,7514 \%$ \\
\hline habermanS5C5Len2.1arn & 17 & $72,9800 \%$ \\
\hline irisS0C0Len2.7arn & 14 & $29,5429 \%$ \\
\hline irisS0C0Len2.8arn & 14 & $25,2914 \%$ \\
\hline irisS0C0Len2.9arn & 14 & $30,8800 \%$ \\
\hline irisS0C10Len2.11arn & 32 & $49,3419 \%$ \\
\hline irisS0C10Len2.6arn & 18 & $52,5700 \%$ \\
\hline irisS0C10Len2.7arn & 27 & $50,8919 \%$ \\
\hline irisS0C15Len2.10arn & 27 & $56,2048 \%$ \\
\hline irisS0C15Len2.11arn & 21 & $58,5986 \%$ \\
\hline irisS0C15Len2.3arn & 17 & $55,0741 \%$ \\
\hline irisS0C25Len2.12arn & 23 & $63,8639 \%$ \\
\hline irisS0C25Len2.3arn & 14 & $62,1300 \%$ \\
\hline irisS0C25Len2.8arn & 23 & $65,9526 \%$ \\
\hline irisS0C5Len2.11arn & 35 & $45,6269 \%$ \\
\hline irisS0C5Len2.6arn & 18 & $52,5700 \%$ \\
\hline irisS0C5Len2.7arn & 29 & $43,2866 \%$ \\
\hline irisS10C0Len2.12arn & 21 & $61,7714 \%$ \\
\hline irisS10C0Len2.3arn & 19 & $62,6437 \%$ \\
\hline irisS10C0Len2.7arn & 21 & $62,9614 \%$ \\
\hline irisS10C10Len2.12arn & 21 & $61,7714 \%$ \\
\hline irisS10C10Len2.3arn & 19 & $62,6437 \%$ \\
\hline irisS10C10Len2.7arn & 21 & $62,9614 \%$ \\
\hline irisS10C15Len2.12arn & 21 & $61,7714 \%$ \\
\hline irisS10C15Len2.3arn & 19 & $62,6437 \%$ \\
\hline irisS10C15Len2.7arn & 21 & $62,9614 \%$ \\
\hline irisS10C25Len2.12arn & 21 & $61,7714 \%$ \\
\hline irisS10C25Len2.3arn & 19 & $62,6437 \%$ \\
\hline irisS10C25Len2.7arn & 21 & $62,9614 \%$ \\
\hline
\end{tabular}




\begin{tabular}{|c|c|c|}
\hline irisS10C5Len2.12arn & 21 & $61,7714 \%$ \\
\hline irisS10C5Len2.3arn & 19 & $62,6437 \%$ \\
\hline irisS10C5Len2.7arn & 21 & $62,9614 \%$ \\
\hline irisS1C0Len2.11arn & 34 & $46,4968 \%$ \\
\hline irisS1C0Len2.6arn & 28 & $49,4246 \%$ \\
\hline irisS1C0Len2.7arn & 30 & $41,9770 \%$ \\
\hline irisS1C10Len2.11arn & 32 & $49,3419 \%$ \\
\hline irisS1C10Len2.6arn & 18 & $52,5700 \%$ \\
\hline irisS1C10Len2.7arn & 27 & $50,8919 \%$ \\
\hline irisS1C15Len2.10arn & 27 & $56,2048 \%$ \\
\hline irisS1C15Len2.11arn & 21 & $58,5986 \%$ \\
\hline irisS1C15Len2.3arn & 17 & $55,0741 \%$ \\
\hline irisS1C25Len2.12arn & 23 & $63,8639 \%$ \\
\hline irisS1C25Len2.3arn & 14 & $62,1300 \%$ \\
\hline irisS1C25Len2.8arn & 23 & $65,9526 \%$ \\
\hline irisS1C5Len2.11arn & 35 & $45,6269 \%$ \\
\hline irisS1C5Len2.6arn & 18 & $52,5700 \%$ \\
\hline irisS1C5Len2.7arn & 29 & $43,2866 \%$ \\
\hline irisS5C0Len2.12arn & 23 & $62,9039 \%$ \\
\hline irisS5C0Len2.3arn & 17 & $55,0741 \%$ \\
\hline irisS5C0Len2.8arn & 24 & $64,0521 \%$ \\
\hline irisS5C10Len2.12arn & 23 & $62,9039 \%$ \\
\hline irisS5C10Len2.3arn & 17 & $55,0741 \%$ \\
\hline irisS5C10Len2.8arn & 24 & $64,0521 \%$ \\
\hline irisS5C15Len2.12arn & 23 & $62,9039 \%$ \\
\hline irisS5C15Len2.3arn & 17 & $55,0741 \%$ \\
\hline irisS5C15Len2.8arn & 24 & $64,0521 \%$ \\
\hline irisS5C25Len2.12arn & 23 & $63,8639 \%$ \\
\hline irisS5C25Len2.3arn & 14 & $62,1300 \%$ \\
\hline irisS5C25Len2.8arn & 23 & $65,9526 \%$ \\
\hline irisS5C5Len2.12arn & 23 & $62,9039 \%$ \\
\hline irisS5C5Len2.3arn & 17 & $55,0741 \%$ \\
\hline irisS5C5Len2.8arn & 24 & $64,0521 \%$ \\
\hline artist20S0C0Len2.0arn & 44 & $2,0548 \%$ \\
\hline artist20S0C0Len2.10arn & 44 & $2,7095 \%$ \\
\hline artist20S0C0Len2.11arn & 44 & $2,7107 \%$ \\
\hline artist20S0C0Len2.12arn & 44 & $3,0852 \%$ \\
\hline
\end{tabular}




\begin{tabular}{|c|c|c|}
\hline artist20S0C0Len2.13arn & 44 & $3,2448 \%$ \\
\hline artist20S0C0Len2.14arn & 44 & $2,9173 \%$ \\
\hline artist20S0C0Len2.15arn & 44 & $3,1341 \%$ \\
\hline artist20S0C0Len2.16arn & 44 & $3,3495 \%$ \\
\hline artist20S0C0Len2.17arn & 44 & $3,5261 \%$ \\
\hline artist20S0C0Len2.18arn & 44 & $3,7316 \%$ \\
\hline artist20S0C0Len2.19arn & 44 & $3,9809 \%$ \\
\hline artist20S0C0Len2.1arn & 44 & $2,2284 \%$ \\
\hline artist20S0C0Len2.2arn & 44 & $2,1670 \%$ \\
\hline artist20S0C0Len2.3arn & 44 & $2,3223 \%$ \\
\hline artist20S0C0Len2.4arn & 44 & $2,3014 \%$ \\
\hline artist20S0C0Len2.5arn & 44 & $2,6677 \%$ \\
\hline artist20S0C0Len2.6arn & 44 & $2,5564 \%$ \\
\hline artist20S0C0Len2.7arn & 44 & $2,9170 \%$ \\
\hline artist20S0C0Len2.8arn & 44 & $2,5250 \%$ \\
\hline artist20S0C0Len2.9arn & 44 & $2,6925 \%$ \\
\hline artist20S0C10Len2.30arn & 242 & $44,9879 \%$ \\
\hline artist20S0C10Len2.32arn & 165 & $38,6671 \%$ \\
\hline artist20S0C10Len2.34arn & 88 & $34,6675 \%$ \\
\hline artist20S0C10Len2.38arn & 86 & $37,8017 \%$ \\
\hline artist20S0C10Len2.42arn & 124 & $35,0715 \%$ \\
\hline artist20S0C10Len2.43arn & 130 & $38,9442 \%$ \\
\hline artist20S0C10Len2.44arn & 122 & $45,4829 \%$ \\
\hline artist20S0C15Len2.30arn & 268 & $49,2584 \%$ \\
\hline artist20S0C15Len2.32arn & 268 & $49,3902 \%$ \\
\hline artist20S0C15Len2.43arn & 297 & $47,1201 \%$ \\
\hline artist20S0C5Len2.0arn & 157 & $40,9594 \%$ \\
\hline artist20S0C5Len2.26arn & 281 & $44,3289 \%$ \\
\hline artist20S0C5Len2.27arn & 296 & $50,4865 \%$ \\
\hline artist20S0C5Len2.28arn & 126 & $42,4838 \%$ \\
\hline artist20S0C5Len2.29arn & 234 & $49,0063 \%$ \\
\hline artist20S0C5Len2.30arn & 150 & $38,5679 \%$ \\
\hline artist20S0C5Len2.31 arn & 396 & $42,8830 \%$ \\
\hline artist20S0C5Len2.32arn & 281 & $44,2932 \%$ \\
\hline artist20S0C5Len2.33arn & 350 & $53,6749 \%$ \\
\hline artist20S0C5Len2.34arn & 374 & $48,8364 \%$ \\
\hline artist20S0C5Len2.35arn & 450 & $44,8324 \%$ \\
\hline
\end{tabular}




\begin{tabular}{|c|c|c|}
\hline artist20S0C5Len2.36arn & 350 & $56,0454 \%$ \\
\hline artist20S0C5Len2.37arn & 464 & $44,3308 \%$ \\
\hline artist20S0C5Len2.38arn & 435 & $44,5688 \%$ \\
\hline artist20S0C5Len2.39arn & 416 & $49,3425 \%$ \\
\hline artist20S0C5Len2.40arn & 463 & $47,3694 \%$ \\
\hline artist20S0C5Len2.41arn & 479 & $48,5362 \%$ \\
\hline artist20S0C5Len2.42arn & 464 & $46,0680 \%$ \\
\hline artist20S0C5Len2.43arn & 435 & $48,0529 \%$ \\
\hline artist20S0C5Len2.44arn & 471 & $49,3558 \%$ \\
\hline artist20S1C0Len2.0arn & 459 & $53,6244 \%$ \\
\hline artist20S1C0Len2.19arn & 442 & $53,5156 \%$ \\
\hline artist20S1C0Len2.23arn & 463 & $50,7350 \%$ \\
\hline artist20S1C0Len2.27arn & 461 & $50,4139 \%$ \\
\hline artist20S1C0Len2.29arn & 469 & $52,7323 \%$ \\
\hline artist20S1C0Len2.30arn & 448 & $51,5915 \%$ \\
\hline artist20S1C0Len2.31 arn & 457 & $49,9850 \%$ \\
\hline artist20S1C0Len2.32arn & 422 & $53,8475 \%$ \\
\hline artist20S1C0Len2.33arn & 459 & $51,4137 \%$ \\
\hline artist20S1C0Len2.34arn & 458 & $49,8825 \%$ \\
\hline artist20S1C0Len2.35arn & 466 & $50,5667 \%$ \\
\hline artist20S1C0Len2.36arn & 470 & $52,1557 \%$ \\
\hline artist20S1C0Len2.37arn & 440 & $50,2906 \%$ \\
\hline artist20S1C0Len2.38arn & 435 & $51,4055 \%$ \\
\hline artist20S1C0Len2.39arn & 462 & $50,3198 \%$ \\
\hline artist20S1C0Len2.40arn & 453 & $49,7464 \%$ \\
\hline artist20S1C0Len2.41arn & 440 & $50,2432 \%$ \\
\hline artist20S1C0Len2.42arn & 454 & $50,0545 \%$ \\
\hline artist20S1C0Len2.43arn & 443 & $51,6714 \%$ \\
\hline artist20S1C0Len2.44arn & 435 & $51,2771 \%$ \\
\hline artist20S1C10Len2.30arn & 290 & $47,4907 \%$ \\
\hline artist20S1C10Len2.32arn & 197 & $43,8525 \%$ \\
\hline artist20S1C10Len2.34arn & 218 & $49,0980 \%$ \\
\hline artist20S1C10Len2.38arn & 190 & $49,2724 \%$ \\
\hline artist20S1C10Len2.42arn & 144 & $40,9285 \%$ \\
\hline artist20S1C10Len2.43arn & 139 & $42,8544 \%$ \\
\hline artist20S1C10Len2.44arn & 118 & $46,4081 \%$ \\
\hline artist20S1C15Len2.30arn & 310 & $50,9140 \%$ \\
\hline
\end{tabular}




\begin{tabular}{|c|c|c|}
\hline artist20S1C15Len2.32arn & 310 & $51,0280 \%$ \\
\hline artist20S1C15Len2.43arn & 306 & $47,9958 \%$ \\
\hline artist20S1C5Len2.0arn & 146 & $43,1225 \%$ \\
\hline artist20S1C5Len2.19arn & 258 & $47,1309 \%$ \\
\hline artist20S1C5Len2.23arn & 280 & $52,5773 \%$ \\
\hline artist20S1C5Len2.27arn & 115 & $45,1890 \%$ \\
\hline artist20S1C5Len2.29arn & 224 & $50,4547 \%$ \\
\hline artist20S1C5Len2.30arn & 137 & $40,9682 \%$ \\
\hline artist20S1C5Len2.31arn & 361 & $45,5898 \%$ \\
\hline artist20S1C5Len2.32arn & 257 & $47,1645 \%$ \\
\hline artist20S1C5Len2.33arn & 336 & $55,3021 \%$ \\
\hline artist20S1C5Len2.34arn & 356 & $50,5431 \%$ \\
\hline artist20S1C5Len2.35arn & 418 & $47,0317 \%$ \\
\hline artist20S1C5Len2.36arn & 344 & $56,7700 \%$ \\
\hline artist20S1C5Len2.37arn & 419 & $47,4217 \%$ \\
\hline artist20S1C5Len2.38arn & 388 & $48,1998 \%$ \\
\hline artist20S1C5Len2.39arn & 396 & $51,0617 \%$ \\
\hline artist20S1C5Len2.40arn & 426 & $50,1772 \%$ \\
\hline artist20S1C5Len2.41arn & 448 & $50,8856 \%$ \\
\hline artist20S1C5Len2.42arn & 422 & $49,1254 \%$ \\
\hline artist20S1C5Len2.43arn & 396 & $51,4212 \%$ \\
\hline artist20S1C5Len2.44arn & 433 & $52,4946 \%$ \\
\hline artist20S5C0Len2.0arn & 31 & $78,1223 \%$ \\
\hline artist20S5C0Len2.2arn & 54 & $68,4789 \%$ \\
\hline artist20S5C0Len2.4arn & 32 & $73,3025 \%$ \\
\hline artist20S5C0Len2.6arn & 31 & $78,0626 \%$ \\
\hline artist20S5C0Len2.7arn & 74 & $50,0601 \%$ \\
\hline artist20S5C10Len2.7arn & 53 & $50,7779 \%$ \\
\hline artist20S5C5Len2.0arn & 31 & $78,1223 \%$ \\
\hline artist20S5C5Len2.2arn & 54 & $68,4789 \%$ \\
\hline artist20S5C5Len2.4arn & 32 & $73,3025 \%$ \\
\hline artist20S5C5Len2.6arn & 31 & $78,0626 \%$ \\
\hline artist20S5C5Len2.7arn & 74 & $50,0601 \%$ \\
\hline genreS0C0Len2.10arn & 34 & $5,9426 \%$ \\
\hline genreS0C0Len2.11arn & 34 & $6,6182 \%$ \\
\hline genreS0C0Len2.12arn & 34 & $6,5288 \%$ \\
\hline genreS0C0Len2.14arn & 34 & $6,8238 \%$ \\
\hline
\end{tabular}




\begin{tabular}{|c|c|c|}
\hline genreS0C0Len2.15arn & 34 & $8,3641 \%$ \\
\hline genreS0C0Len2.18arn & 34 & $8,2206 \%$ \\
\hline genreSOC0Len2.23arn & 34 & $13,8635 \%$ \\
\hline genreS0C0Len2.7arn & 34 & $6,0641 \%$ \\
\hline genreS0C0Len2.8arn & 34 & $5,8497 \%$ \\
\hline genreS0C0Len2.9arn & 34 & $5,2524 \%$ \\
\hline genreS0C10Len2.11arn & 86 & $24,7828 \%$ \\
\hline genreS0C10Len2.14arn & 88 & $21,6231 \%$ \\
\hline genreS0C10Len2.15arn & 103 & $22,9615 \%$ \\
\hline genreS0C10Len2.17arn & 94 & $23,3531 \%$ \\
\hline genreS0C10Len2.19arn & 95 & $25,8948 \%$ \\
\hline genreS0C10Len2.25arn & 98 & $22,2508 \%$ \\
\hline genreS0C10Len2.29arn & 89 & $24,5747 \%$ \\
\hline genreS0C10Len2.3arn & 104 & $24,2594 \%$ \\
\hline genreS0C10Len2.4arn & 101 & $26,5546 \%$ \\
\hline genreS0C10Len2.5arn & 106 & $23,4114 \%$ \\
\hline genreS0C15Len2.13arn & 71 & $27,2604 \%$ \\
\hline genreS0C15Len2.15arn & 72 & $29,4249 \%$ \\
\hline genreS0C15Len2.20arn & 77 & $28,7699 \%$ \\
\hline genreS0C15Len2.21arn & 80 & $29,0779 \%$ \\
\hline genreS0C15Len2.26arn & 73 & $30,1644 \%$ \\
\hline genreS0C15Len2.30arn & 68 & $27,6056 \%$ \\
\hline genreS0C15Len2.33arn & 77 & $31,3865 \%$ \\
\hline genreS0C15Len2.3arn & 83 & $30,6333 \%$ \\
\hline genreS0C15Len2.4arn & 77 & $27,1213 \%$ \\
\hline genreS0C15Len2.9arn & 69 & $28,1816 \%$ \\
\hline genreS0C25Len2.10arn & 50 & $43,9386 \%$ \\
\hline genreS0C25Len2.15arn & 1 & $25,7100 \%$ \\
\hline genreS0C25Len2.20arn & 16 & $40,2119 \%$ \\
\hline genreS0C25Len2.2arn & 50 & $43,4650 \%$ \\
\hline genreS0C25Len2.7arn & 46 & $42,6700 \%$ \\
\hline genreS0C5Len2.12arn & 123 & $19,0902 \%$ \\
\hline genreS0C5Len2.17arn & 138 & $19,4500 \%$ \\
\hline genreS0C5Len2.18arn & 141 & $18,2182 \%$ \\
\hline genreS0C5Len2.19arn & 139 & $19,0941 \%$ \\
\hline genreS0C5Len2.21arn & 131 & $18,2977 \%$ \\
\hline genreS0C5Len2.23arn & 140 & $19,0129 \%$ \\
\hline
\end{tabular}




\begin{tabular}{|c|c|c|}
\hline genreS0C5Len2.29arn & 135 & $18,0211 \%$ \\
\hline genreS0C5Len2.3arn & 140 & $18,0816 \%$ \\
\hline genreS0C5Len2.4arn & 133 & $20,1999 \%$ \\
\hline genreS0C5Len2.5arn & 133 & $19,7861 \%$ \\
\hline genreS1C0Len2.10arn & 107 & $26,7543 \%$ \\
\hline genreS1C0Len2.16arn & 98 & $25,9362 \%$ \\
\hline genreS1C0Len2.17arn & 107 & $25,9296 \%$ \\
\hline genreS1C0Len2.18arn & 103 & $24,4768 \%$ \\
\hline genreS1C0Len2.23arn & 99 & $27,4335 \%$ \\
\hline genreS1C0Len2.28arn & 96 & $25,1726 \%$ \\
\hline genreS1C0Len2.2arn & 101 & $25,1952 \%$ \\
\hline genreS1C0Len2.33arn & 99 & $28,0739 \%$ \\
\hline genreS1C0Len2.6arn & 87 & $24,0556 \%$ \\
\hline genreS1C0Len2.8arn & 100 & $23,4244 \%$ \\
\hline genreS1C10Len2.10arn & 89 & $27,3747 \%$ \\
\hline genreS1C10Len2.16arn & 98 & $24,1277 \%$ \\
\hline genreS1C10Len2.17arn & 104 & $26,4379 \%$ \\
\hline genreS1C10Len2.18arn & 98 & $25,2987 \%$ \\
\hline genreS1C10Len2.23arn & 87 & $28,2178 \%$ \\
\hline genreS1C10Len2.28arn & 100 & $23,1435 \%$ \\
\hline genreS1C10Len2.2arn & 97 & $25,2103 \%$ \\
\hline genreS1C10Len2.33arn & 95 & $28,4538 \%$ \\
\hline genreS1C10Len2.6arn & 81 & $25,4444 \%$ \\
\hline genreS1C10Len2.8arn & 92 & $24,4551 \%$ \\
\hline genreS1C15Len2.10arn & 71 & $29,3886 \%$ \\
\hline genreS1C15Len2.16arn & 76 & $28,7274 \%$ \\
\hline genreS1C15Len2.17arn & 79 & $29,0409 \%$ \\
\hline genreS1C15Len2.22arn & 71 & $30,9515 \%$ \\
\hline genreS1C15Len2.27arn & 69 & $28,2613 \%$ \\
\hline genreS1C15Len2.2arn & 82 & $30,6166 \%$ \\
\hline genreS1C15Len2.32arn & 76 & $32,0201 \%$ \\
\hline genreS1C15Len2.33arn & 78 & $30,0390 \%$ \\
\hline genreS1C15Len2.6arn & 69 & $28,1816 \%$ \\
\hline genreS1C15Len2.8arn & 70 & $30,0551 \%$ \\
\hline genreS1C25Len2.14arn & 1 & $25,7100 \%$ \\
\hline genreS1C25Len2.19arn & 15 & $41,0747 \%$ \\
\hline genreS1C25Len2.2arn & 49 & $43,6990 \%$ \\
\hline
\end{tabular}




\begin{tabular}{|c|c|c|}
\hline genreS1C25Len2.6arn & 46 & $42,6700 \%$ \\
\hline genreS1C25Len2.8arn & 48 & $44,5346 \%$ \\
\hline genreS1C5Len2.10arn & 107 & $26,7543 \%$ \\
\hline genreS1C5Len2.16arn & 98 & $25,9362 \%$ \\
\hline genreS1C5Len2.17arn & 107 & $25,9296 \%$ \\
\hline genreS1C5Len2.18arn & 103 & $24,4768 \%$ \\
\hline genreS1C5Len2.23arn & 99 & $27,4335 \%$ \\
\hline genreS1C5Len2.28arn & 96 & $25,1726 \%$ \\
\hline genreS1C5Len2.2arn & 101 & $25,1952 \%$ \\
\hline genreS1C5Len2.33arn & 99 & $28,0739 \%$ \\
\hline genreS1C5Len2.6arn & 87 & $24,0556 \%$ \\
\hline genreS1C5Len2.8arn & 100 & $23,4244 \%$ \\
\hline tic-tac-toeS0C0Len2.13arn & 28 & $33,2386 \%$ \\
\hline tic-tac-toeS0C0Len2.28arn & 28 & $63,1900 \%$ \\
\hline tic-tac-toeS0C10Len2.13arn & 54 & $33,9007 \%$ \\
\hline tic-tac-toeS0C10Len2.26arn & 54 & $49,4319 \%$ \\
\hline tic-tac-toeS0C15Len2.13arn & 54 & $33,9007 \%$ \\
\hline tic-tac-toeS0C15Len2.26arn & 53 & $50,0917 \%$ \\
\hline tic-tac-toeS0C25Len2.18arn & 45 & $55,2218 \%$ \\
\hline tic-tac-toeS0C25Len2.5arn & 66 & $35,2344 \%$ \\
\hline tic-tac-toeS0C5Len2.13arn & 54 & $33,9007 \%$ \\
\hline tic-tac-toeS0C5Len2.26arn & 54 & $49,4319 \%$ \\
\hline tic-tac-toeS1C0Len2.13arn & 54 & $33,9007 \%$ \\
\hline tic-tac-toeS1C0Len2.26arn & 54 & $49,4319 \%$ \\
\hline tic-tac-toeS1C10Len2.13arn & 54 & $33,9007 \%$ \\
\hline tic-tac-toeS1C10Len2.26arn & 54 & $49,4319 \%$ \\
\hline tic-tac-toeS1C15Len2.13arn & 54 & $33,9007 \%$ \\
\hline tic-tac-toeS1C15Len2.26arn & 53 & $50,0917 \%$ \\
\hline tic-tac-toeS1C25Len2.18arn & 45 & $55,2218 \%$ \\
\hline tic-tac-toeS1C25Len2.5arn & 66 & $35,2344 \%$ \\
\hline tic-tac-toeS1C5Len2.13arn & 54 & $33,9007 \%$ \\
\hline tic-tac-toeS1C5Len2.26arn & 54 & $49,4319 \%$ \\
\hline zooS0C0Len2.100arn & 139 & $3,0269 \%$ \\
\hline zooS0C0Len2.101arn & 139 & $4,6680 \%$ \\
\hline zooS0C0Len2.102arn & 139 & $8,2932 \%$ \\
\hline zooS0C0Len2.104arn & 139 & $10,0245 \%$ \\
\hline zooS0C0Len2.107arn & 139 & $12,5927 \%$ \\
\hline
\end{tabular}




\begin{tabular}{|c|c|c|}
\hline zooS0C0Len2.110arn & 139 & $19,0214 \%$ \\
\hline zooS0C0Len2.118arn & 139 & $38,0568 \%$ \\
\hline zooS0C10Len2.1arn & 1139 & $89,8059 \%$ \\
\hline zooS0C10Len2.20arn & 963 & $88,7755 \%$ \\
\hline zooS0C10Len2.30arn & 645 & $81,7977 \%$ \\
\hline zooS0C10Len2.35arn & 525 & $87,3771 \%$ \\
\hline zooS0C10Len2.38arn & 925 & $87,6596 \%$ \\
\hline zooS0C10Len2.48arn & 1083 & $90,2009 \%$ \\
\hline zooS0C10Len2.52arn & 797 & $84,0307 \%$ \\
\hline zooS0C15Len2.1arn & 1085 & $90,7665 \%$ \\
\hline zooS0C15Len2.20arn & 947 & $90,0767 \%$ \\
\hline zooS0C15Len2.30arn & 725 & $89,9410 \%$ \\
\hline zooS0C15Len2.35arn & 3 & $100,0000 \%$ \\
\hline zooS0C15Len2.38arn & 880 & $88,8986 \%$ \\
\hline zooS0C15Len2.48arn & 900 & $88,7203 \%$ \\
\hline zooS0C15Len2.52arn & 1028 & $89,7060 \%$ \\
\hline zooS0C25Len2.1arn & 490 & $87,2038 \%$ \\
\hline zooS0C25Len2.20arn & 773 & $90,8523 \%$ \\
\hline zooS0C25Len2.30arn & 721 & $90,2520 \%$ \\
\hline zooS0C25Len2.35arn & 3 & $100,0000 \%$ \\
\hline zooS0C25Len2.38arn & 649 & $91,0985 \%$ \\
\hline zooS0C25Len2.48arn & 777 & $93,6529 \%$ \\
\hline zooS0C25Len2.52arn & 769 & $91,7955 \%$ \\
\hline zooS0C5Len2.1arn & 1224 & $89,9704 \%$ \\
\hline zooS0C5Len2.20arn & 995 & $87,7598 \%$ \\
\hline zooS0C5Len2.30arn & 1133 & $88,5498 \%$ \\
\hline zooS0C5Len2.35arn & 867 & $85,4108 \%$ \\
\hline zooS0C5Len2.38arn & 1188 & $89,2010 \%$ \\
\hline zooS0C5Len2.48arn & 1207 & $88,3190 \%$ \\
\hline zooS0C5Len2.52arn & 1337 & $92,0499 \%$ \\
\hline zooS1C0Len2.18arn & 351 & $71,1417 \%$ \\
\hline zooS1C0Len2.1arn & 337 & $68,9085 \%$ \\
\hline zooS1C0Len2.23arn & 320 & $62,6025 \%$ \\
\hline zooS1C0Len2.24arn & 316 & $63,7942 \%$ \\
\hline zooS1C0Len2.33arn & 332 & $64,3655 \%$ \\
\hline zooS1C0Len2.37arn & 326 & $65,8000 \%$ \\
\hline zooS1C0Len2.39arn & 281 & $66,8817 \%$ \\
\hline
\end{tabular}




\begin{tabular}{|c|c|c|}
\hline zooS1C10Len2.18arn & 228 & $44,9000 \%$ \\
\hline zooS1C10Len2.1arn & 91 & $38,7600 \%$ \\
\hline zooS1C10Len2.23arn & 236 & $51,7775 \%$ \\
\hline zooS1C10Len2.24arn & 285 & $61,5356 \%$ \\
\hline zooS1C10Len2.33arn & 311 & $68,3841 \%$ \\
\hline zooS1C10Len2.37arn & 313 & $66,2585 \%$ \\
\hline zooS1C10Len2.39arn & 285 & $66,6872 \%$ \\
\hline zooS1C15Len2.18arn & 245 & $57,2155 \%$ \\
\hline zooS1C15Len2.1arn & 1 & $100,0000 \%$ \\
\hline zooS1C15Len2.23arn & 113 & $38,6478 \%$ \\
\hline zooS1C15Len2.24arn & 195 & $51,7733 \%$ \\
\hline zooS1C15Len2.33arn & 287 & $65,4469 \%$ \\
\hline zooS1C15Len2.37arn & 304 & $68,4924 \%$ \\
\hline zooS1C15Len2.39arn & 278 & $68,0670 \%$ \\
\hline zooS1C25Len2.18arn & 182 & $65,8833 \%$ \\
\hline zooS1C25Len2.1arn & 1 & $100,0000 \%$ \\
\hline zooS1C25Len2.23arn & 184 & $62,4818 \%$ \\
\hline zooS1C25Len2.24arn & 154 & $63,2984 \%$ \\
\hline zooS1C25Len2.33arn & 144 & $65,7523 \%$ \\
\hline zooS1C25Len2.37arn & 253 & $72,8412 \%$ \\
\hline zooS1C25Len2.39arn & 187 & $66,8709 \%$ \\
\hline zooS1C5Len2.18arn & 339 & $71,1299 \%$ \\
\hline zooS1C5Len2.1arn & 279 & $60,4331 \%$ \\
\hline zooS1C5Len2.23arn & 306 & $62,2827 \%$ \\
\hline zooS1C5Len2.24arn & 313 & $62,9883 \%$ \\
\hline zooS1C5Len2.33arn & 328 & $65,0920 \%$ \\
\hline zooS1C5Len2.37arn & 319 & $67,1425 \%$ \\
\hline zooS1C5Len2.39arn & 286 & $64,9397 \%$ \\
\hline
\end{tabular}

Na Tabela 11 são apresentados todos os resultados obtidos utilizando a rede Bayesiana. A disposição das informações na tabela é igual a tabela anterior, entretanto, não há a seleção de um único item objetivo, portanto, não há informações do índice.

Tabela 11 - Resultados obtidos usando rede Bayesiana.

\begin{tabular}{ccc} 
Configuracao & Quantidade Regras & Confiança Média \\
\hline balance-scaleS0C0 & 36 & $33,3333 \%$ \\
\hline balance-scaleS0C10 & 36 & $33,3333 \%$ \\
\hline balance-scaleS0C15 & 36 & $33,3333 \%$
\end{tabular}




\begin{tabular}{|c|c|c|}
\hline balance-scaleS0C25 & 16 & $49,4012 \%$ \\
\hline balance-scaleS0C5 & 36 & $33,3333 \%$ \\
\hline balance-scaleS10C0 & 24 & $33,3333 \%$ \\
\hline balance-scaleS10C10 & 24 & $33,3333 \%$ \\
\hline balance-scaleS10C15 & 24 & $33,3333 \%$ \\
\hline balance-scaleS10C25 & 8 & $57,9861 \%$ \\
\hline balance-scaleS10C5 & 24 & $33,3333 \%$ \\
\hline balance-scaleS1C0 & 36 & $33,3333 \%$ \\
\hline balance-scaleS1C10 & 36 & $33,3333 \%$ \\
\hline balance-scaleS1C15 & 36 & $33,3333 \%$ \\
\hline balance-scaleS1C25 & 16 & $49,4012 \%$ \\
\hline balance-scaleS1C5 & 36 & $33,3333 \%$ \\
\hline balance-scaleS5C0 & 36 & $33,3333 \%$ \\
\hline balance-scaleS5C10 & 36 & $33,3333 \%$ \\
\hline balance-scaleS5C15 & 36 & $33,3333 \%$ \\
\hline balance-scaleS5C25 & 16 & $49,4012 \%$ \\
\hline balance-scaleS5C5 & 36 & $33,3333 \%$ \\
\hline breast-cancerSOC0 & 82 & $21,9512 \%$ \\
\hline breast-cancerS0C10 & 48 & $35,0307 \%$ \\
\hline breast-cancerS0C15 & 41 & $38,9960 \%$ \\
\hline breast-cancerS0C25 & 29 & $47,4711 \%$ \\
\hline breast-cancerS0C5 & 58 & $30,3245 \%$ \\
\hline breast-cancerS10C0 & 50 & $33,7289 \%$ \\
\hline breast-cancerS10C10 & 47 & $35,5134 \%$ \\
\hline breast-cancerS10C15 & 41 & $38,9960 \%$ \\
\hline breast-cancerS10C25 & 29 & $47,4711 \%$ \\
\hline breast-cancerS10C5 & 49 & $34,3920 \%$ \\
\hline breast-cancerS1C0 & 78 & $23,0546 \%$ \\
\hline breast-cancerS1C10 & 48 & $35,0307 \%$ \\
\hline breast-cancerS1C15 & 41 & $38,9960 \%$ \\
\hline breast-cancerS1C25 & 29 & $47,4711 \%$ \\
\hline breast-cancerS1C5 & 58 & $30,3245 \%$ \\
\hline breast-cancerS5C0 & 60 & $29,3732 \%$ \\
\hline breast-cancerS5C10 & 48 & $35,0307 \%$ \\
\hline breast-cancerS5C15 & 41 & $38,9960 \%$ \\
\hline breast-cancerS5C25 & 29 & $47,4711 \%$ \\
\hline breast-cancerS5C5 & 57 & $30,7482 \%$ \\
\hline
\end{tabular}




\begin{tabular}{|c|c|c|}
\hline carSOC0 & 84 & $28,5714 \%$ \\
\hline carS0C10 & 69 & $34,7826 \%$ \\
\hline carS0C15 & 69 & $34,7826 \%$ \\
\hline carS0C25 & 52 & $39,0452 \%$ \\
\hline carS0C5 & 69 & $34,7826 \%$ \\
\hline carS10C0 & 42 & $28,5714 \%$ \\
\hline carS10C10 & 40 & $30,0000 \%$ \\
\hline carS10C15 & 40 & $30,0000 \%$ \\
\hline carS10C25 & 27 & $33,7241 \%$ \\
\hline carS10C5 & 40 & $30,0000 \%$ \\
\hline carS1C0 & 84 & $28,5714 \%$ \\
\hline carS1C10 & 69 & $34,7826 \%$ \\
\hline carS1C15 & 69 & $34,7826 \%$ \\
\hline carS1C25 & 52 & $39,0452 \%$ \\
\hline carS1C5 & 69 & $34,7826 \%$ \\
\hline carS5C0 & 42 & $28,5714 \%$ \\
\hline carS5C10 & 40 & $30,0000 \%$ \\
\hline carS5C15 & 40 & $30,0000 \%$ \\
\hline carS5C25 & 27 & $33,7241 \%$ \\
\hline carS5C5 & 40 & $30,0000 \%$ \\
\hline ecoliSOC0 & 152 & $36,8421 \%$ \\
\hline ecoliS0C10 & 84 & $65,6166 \%$ \\
\hline ecoliS0C15 & 79 & $68,9904 \%$ \\
\hline ecoliS0C25 & 74 & $72,2428 \%$ \\
\hline ecoliS0C5 & 91 & $61,0864 \%$ \\
\hline ecoliS10C0 & 64 & $43,5054 \%$ \\
\hline ecoliS10C10 & 44 & $61,9727 \%$ \\
\hline ecoliS10C15 & 41 & $65,4937 \%$ \\
\hline ecoliS10C25 & 37 & $70,2963 \%$ \\
\hline ecoliS10C5 & 49 & $56,3033 \%$ \\
\hline ecoliS1C0 & 108 & $38,8889 \%$ \\
\hline ecoliS1C10 & 64 & $64,2468 \%$ \\
\hline ecoliS1C15 & 59 & $68,6481 \%$ \\
\hline ecoliS1C25 & 54 & $73,0734 \%$ \\
\hline ecoliS1C5 & 71 & $58,5755 \%$ \\
\hline ecoliS5C0 & 80 & $43,4918 \%$ \\
\hline ecoliS5C10 & 55 & $62,0327 \%$ \\
\hline
\end{tabular}




\begin{tabular}{|c|c|c|}
\hline ecoliS5C15 & 50 & $67,0048 \%$ \\
\hline ecoliS5C25 & 46 & $70,9992 \%$ \\
\hline ecoliS5C5 & 61 & $56,6207 \%$ \\
\hline habermanSOC0 & 36 & $16,6667 \%$ \\
\hline habermanS0C10 & 16 & $29,8302 \%$ \\
\hline habermanS0C15 & 7 & $53,2698 \%$ \\
\hline habermanS0C25 & 6 & $59,4733 \%$ \\
\hline habermanS0C5 & 26 & $21,6828 \%$ \\
\hline habermanS10C0 & 12 & $35,6667 \%$ \\
\hline habermanS10C10 & 11 & $38,0112 \%$ \\
\hline habermanS10C15 & 6 & $59,4733 \%$ \\
\hline habermanS10C25 & 6 & $59,4733 \%$ \\
\hline habermanS10C5 & 12 & $35,6667 \%$ \\
\hline habermanS1C0 & 34 & $17,5614 \%$ \\
\hline habermanS1C10 & 16 & $29,8302 \%$ \\
\hline habermanS1C15 & 7 & $53,2698 \%$ \\
\hline habermanS1C25 & 6 & $59,4733 \%$ \\
\hline habermanS1C5 & 26 & $21,6828 \%$ \\
\hline habermanS5C0 & 30 & $19,3630 \%$ \\
\hline habermanS5C10 & 16 & $29,8302 \%$ \\
\hline habermanS5C15 & 7 & $53,2698 \%$ \\
\hline habermanS5C25 & 6 & $59,4733 \%$ \\
\hline habermanS5C5 & 26 & $21,6828 \%$ \\
\hline irisSOCO & 36 & $33,3333 \%$ \\
\hline irisS0C10 & 19 & $61,7895 \%$ \\
\hline irisS0C15 & 17 & $67,7647 \%$ \\
\hline irisS0C25 & 16 & $70,6250 \%$ \\
\hline irisS0C5 & 21 & $56,4762 \%$ \\
\hline irisS10C0 & 36 & $33,3333 \%$ \\
\hline irisS10C10 & 19 & $61,7895 \%$ \\
\hline irisS10C15 & 17 & $67,7647 \%$ \\
\hline irisS10C25 & 16 & $70,6250 \%$ \\
\hline irisS10C5 & 21 & $56,4762 \%$ \\
\hline irisS1C0 & 36 & $33,3333 \%$ \\
\hline irisS1C10 & 19 & $61,7895 \%$ \\
\hline irisS1C15 & 17 & $67,7647 \%$ \\
\hline irisS1C25 & 16 & $70,6250 \%$ \\
\hline
\end{tabular}




\begin{tabular}{|c|c|c|}
\hline irisS1C5 & 21 & $56,4762 \%$ \\
\hline irisS5C0 & 36 & $33,3333 \%$ \\
\hline irisS5C10 & 19 & $61,7895 \%$ \\
\hline irisS5C15 & 17 & $67,7647 \%$ \\
\hline irisS5C25 & 16 & $70,6250 \%$ \\
\hline irisS5C5 & 21 & $56,4762 \%$ \\
\hline artist20S0C0 & 500 & $46,8506 \%$ \\
\hline artist20S0C10 & 469 & $49,6232 \%$ \\
\hline artist20S0C15 & 454 & $50,8459 \%$ \\
\hline artist20S0C25 & 393 & $55,5980 \%$ \\
\hline artist20S0C5 & 485 & $48,2296 \%$ \\
\hline artist20S1C0 & 500 & $46,8506 \%$ \\
\hline artist20S1C10 & 469 & $49,6232 \%$ \\
\hline artist20S1C15 & 454 & $50,8459 \%$ \\
\hline artist20S1C25 & 393 & $55,5980 \%$ \\
\hline artist20S1C5 & 485 & $48,2296 \%$ \\
\hline artist20S5C0 & 275 & $46,3329 \%$ \\
\hline artist20S5C10 & 257 & $49,1810 \%$ \\
\hline artist20S5C15 & 249 & $50,3393 \%$ \\
\hline artist20S5C25 & 211 & $55,7563 \%$ \\
\hline artist20S5C5 & 269 & $47,3174 \%$ \\
\hline genreoutSOC0 & 250 & $10,2680 \%$ \\
\hline genreoutS0C10 & 91 & $23,4505 \%$ \\
\hline genreoutS0C15 & 71 & $26,5775 \%$ \\
\hline genreoutS0C25 & 31 & $35,8387 \%$ \\
\hline genreoutS0C5 & 122 & $19,5656 \%$ \\
\hline genreoutS10C0 & 130 & $13,3154 \%$ \\
\hline genreoutS10C10 & 63 & $24,4603 \%$ \\
\hline genreoutS10C15 & 52 & $27,0000 \%$ \\
\hline genreoutS10C25 & 27 & $33,8148 \%$ \\
\hline genreoutS10C5 & 74 & $22,1081 \%$ \\
\hline genreoutS1C0 & 250 & $10,2680 \%$ \\
\hline genreoutS1C10 & 91 & $23,4505 \%$ \\
\hline genreoutS1C15 & 71 & $26,5775 \%$ \\
\hline genreoutS1C25 & 31 & $35,8387 \%$ \\
\hline genreoutS1C5 & 122 & $19,5656 \%$ \\
\hline genreoutS5C0 & 220 & $11,2091 \%$ \\
\hline
\end{tabular}




\begin{tabular}{|c|c|c|}
\hline genreoutS5C10 & 88 & $23,5795 \%$ \\
\hline genreoutS5C15 & 69 & $26,6812 \%$ \\
\hline genreoutS5C25 & 31 & $35,8387 \%$ \\
\hline genreoutS5C5 & 115 & $20,0000 \%$ \\
\hline tic-tac-toesOCO & 54 & $33,3333 \%$ \\
\hline tic-tac-toeS0C10 & 54 & $33,3333 \%$ \\
\hline tic-tac-toeS0C15 & 53 & $33,6895 \%$ \\
\hline tic-tac-toeS0C25 & 39 & $38,0358 \%$ \\
\hline tic-tac-toeS0C5 & 54 & $33,3333 \%$ \\
\hline tic-tac-toeS10C0 & 54 & $33,3333 \%$ \\
\hline tic-tac-toeS10C10 & 54 & $33,3333 \%$ \\
\hline tic-tac-toeS10C15 & 53 & $33,6895 \%$ \\
\hline tic-tac-toeS10C25 & 39 & $38,0358 \%$ \\
\hline tic-tac-toeS10C5 & 54 & $33,3333 \%$ \\
\hline tic-tac-toeS1C0 & 54 & $33,3333 \%$ \\
\hline tic-tac-toeS1C10 & 54 & $33,3333 \%$ \\
\hline tic-tac-toeS1C15 & 53 & $33,6895 \%$ \\
\hline tic-tac-toeS1C25 & 39 & $38,0358 \%$ \\
\hline tic-tac-toeS1C5 & 54 & $33,3333 \%$ \\
\hline tic-tac-toeS5C0 & 54 & $33,3333 \%$ \\
\hline tic-tac-toeS5C10 & 54 & $33,3333 \%$ \\
\hline tic-tac-toeS5C15 & 53 & $33,6895 \%$ \\
\hline tic-tac-toeS5C25 & 39 & $38,0358 \%$ \\
\hline tic-tac-toeS5C5 & 54 & $33,3333 \%$ \\
\hline zooS0C0 & 931 & $12,7820 \%$ \\
\hline zooS0C10 & 163 & $70,1241 \%$ \\
\hline zooS0C15 & 151 & $74,6752 \%$ \\
\hline zooS0C25 & 132 & $82,5387 \%$ \\
\hline zooS0C5 & 192 & $60,8613 \%$ \\
\hline zooS10C0 & 96 & $49,9199 \%$ \\
\hline zooS $10 \mathrm{C} 10$ & 61 & $78,0365 \%$ \\
\hline zooS10C15 & 59 & $80,1857 \%$ \\
\hline zooS $10 \mathrm{C} 25$ & 54 & $85,7427 \%$ \\
\hline zooS10C5 & 63 & $75,8361 \%$ \\
\hline zooS1C0 & 238 & $47,2689 \%$ \\
\hline zooS1C10 & 148 & $75,5421 \%$ \\
\hline zooS1C15 & 144 & $77,2636 \%$ \\
\hline
\end{tabular}




\begin{tabular}{ccc}
\hline zooS1C25 & 130 & $83,4239 \%$ \\
\hline zooS1C5 & 154 & $72,9569 \%$ \\
\hline zooS5C0 & 165 & $48,4848 \%$ \\
\hline zooS5C10 & 104 & $76,2522 \%$ \\
\hline zooS5C15 & 100 & $78,7596 \%$ \\
\hline zooS5C25 & 92 & $83,8598 \%$ \\
\hline zooS5C5 & 110 & $72,5942 \%$
\end{tabular}

Na Tabela 12 são apresentados os resultados obtidos utilizando a abordagem ConexARN. As informações estão dispostas no mesmo formato da tabela anterior.

Tabela 12 - Resultados obtidos usando a abordagem ConexARN.

$$
\text { Configuracao Quantidade Regras Confiança Média }
$$

\begin{tabular}{ccc}
\hline balance-scaleS0C0Len2 & 36 & $33,3333 \%$ \\
\hline balance-scaleS0C10Len2 & 24 & $46,1333 \%$ \\
\hline balance-scaleS0C15Len2 & 24 & $46,1333 \%$ \\
\hline balance-scaleS0C25Len2 & 20 & $50,5600 \%$ \\
\hline balance-scaleS0C5Len2 & 36 & $33,3333 \%$ \\
\hline balance-scaleS10C0Len2 & 16 & $52,6000 \%$ \\
\hline balance-scaleS10C10Len2 & 16 & $52,6000 \%$ \\
\hline balance-scaleS10C15Len2 & 16 & $52,6000 \%$ \\
\hline balance-scaleS10C25Len2 & 16 & $52,6000 \%$ \\
\hline balance-scaleS10C5Len2 & 16 & $52,6000 \%$ \\
\hline balance-scaleS1C0Len2 & 36 & $33,3333 \%$ \\
\hline balance-scaleS1C10Len2 & 24 & $46,1333 \%$ \\
\hline balance-scaleS1C15Len2 & 24 & $46,1333 \%$ \\
\hline balance-scaleS1C25Len2 & 20 & $50,5600 \%$ \\
\hline balance-scaleS1C5Len2 & 36 & $33,3333 \%$ \\
\hline balance-scaleS5C0Len2 & 24 & $46,1333 \%$ \\
\hline balance-scaleS5C10Len2 & 24 & $46,1333 \%$ \\
\hline balance-scaleS5C15Len2 & 24 & $46,1333 \%$ \\
\hline balance-scaleS5C25Len2 & 20 & $50,5600 \%$ \\
\hline balance-scaleS5C5Len2 & 24 & $46,1333 \%$ \\
\hline breast-cancerS0C0Len2 & 82 & $50,0000 \%$ \\
\hline breast-cancerS0C10Len2 & 76 & $53,9004 \%$ \\
\hline breast-cancerS0C15Len2 & 74 & $55,0039 \%$ \\
\hline breast-cancerS0C25Len2 & 67 & $58,4739 \%$ \\
\hline breast-cancerS0C5Len2 & 76 & $53,9004 \%$ \\
\hline
\end{tabular}




\begin{tabular}{|c|c|c|}
\hline breast-cancerS10C0Len2 & 33 & $57,5188 \%$ \\
\hline breast-cancerS10C10Len2 & 33 & $57,5188 \%$ \\
\hline breast-cancerS10C15Len2 & 33 & $57,5188 \%$ \\
\hline breast-cancerS10C25Len2 & 29 & $62,3966 \%$ \\
\hline breast-cancerS10C5Len2 & 33 & $57,5188 \%$ \\
\hline breast-cancerS1C0Len2 & 71 & $55,7093 \%$ \\
\hline breast-cancerS1C10Len2 & 71 & $55,7093 \%$ \\
\hline breast-cancerS1C15Len2 & 70 & $56,3103 \%$ \\
\hline breast-cancerS1C25Len2 & 63 & $60,1457 \%$ \\
\hline breast-cancerS1C5Len2 & 71 & $55,7093 \%$ \\
\hline breast-cancerS5C0Len2 & 51 & $55,1294 \%$ \\
\hline breast-cancerS5C10Len2 & 51 & $55,1294 \%$ \\
\hline breast-cancerS5C15Len2 & 51 & $55,1294 \%$ \\
\hline breast-cancerS5C25Len2 & 46 & $58,6696 \%$ \\
\hline breast-cancerS5C5Len2 & 51 & $55,1294 \%$ \\
\hline carS0C0Len2 & 84 & $25,0005 \%$ \\
\hline carS0C10Len2 & 43 & $45,8084 \%$ \\
\hline carS0C15Len2 & 40 & $48,4295 \%$ \\
\hline carS0C25Len2 & 29 & $58,8645 \%$ \\
\hline carS0C5Len2 & 56 & $36,6014 \%$ \\
\hline carS10C0Len2 & 25 & $64,1532 \%$ \\
\hline carS10C10Len2 & 25 & $64,1532 \%$ \\
\hline carS10C15Len2 & 25 & $64,1532 \%$ \\
\hline carS10C25Len2 & 25 & $64,1532 \%$ \\
\hline carS10C5Len2 & 25 & $64,1532 \%$ \\
\hline carS1C0Len2 & 65 & $32,1197 \%$ \\
\hline carS1C10Len2 & 43 & $45,8084 \%$ \\
\hline carS1C15Len2 & 40 & $48,4295 \%$ \\
\hline carS1C25Len2 & 29 & $58,8645 \%$ \\
\hline carS1C5Len2 & 56 & $36,6014 \%$ \\
\hline carS5C0Len2 & 37 & $50,9484 \%$ \\
\hline carS5C10Len2 & 37 & $50,9484 \%$ \\
\hline carS5C15Len2 & 37 & $50,9484 \%$ \\
\hline carS5C25Len2 & 29 & $58,8645 \%$ \\
\hline carS5C5Len2 & 37 & $50,9484 \%$ \\
\hline ecoliS0C0Len2 & 152 & $12,4996 \%$ \\
\hline ecoliSOC10Len2 & 56 & $31,8070 \%$ \\
\hline
\end{tabular}




\begin{tabular}{|c|c|c|}
\hline ecoliS0C15Len2 & 42 & $38,5864 \%$ \\
\hline ecoliS0C25Len2 & 27 & $49,0367 \%$ \\
\hline ecoliS0C5Len2 & 63 & $28,9329 \%$ \\
\hline ecoliS10C0Len2 & 38 & $53,8626 \%$ \\
\hline ecoliS10C10Len2 & 38 & $53,8626 \%$ \\
\hline ecoliS10C15Len2 & 36 & $56,2750 \%$ \\
\hline ecoliS10C25Len2 & 30 & $63,6430 \%$ \\
\hline ecoliS10C5Len2 & 38 & $53,8626 \%$ \\
\hline ecoliS1C0Len2 & 64 & $25,9220 \%$ \\
\hline ecoliS1C10Len2 & 48 & $33,0573 \%$ \\
\hline ecoliS1C15Len2 & 39 & $37,9079 \%$ \\
\hline ecoliS1C25Len2 & 26 & $47,0765 \%$ \\
\hline ecoliS1C5Len2 & 55 & $29,6060 \%$ \\
\hline ecoliS5C0Len2 & 43 & $32,2772 \%$ \\
\hline ecoliS5C10Len2 & 40 & $34,2203 \%$ \\
\hline ecoliS5C15Len2 & 33 & $38,8764 \%$ \\
\hline ecoliS5C25Len2 & 23 & $47,3852 \%$ \\
\hline ecoliS5C5Len2 & 43 & $32,2772 \%$ \\
\hline habermanS0C0Len2 & 36 & $50,0000 \%$ \\
\hline habermanS0C10Len2 & 36 & $50,0000 \%$ \\
\hline habermanS0C15Len2 & 34 & $52,1815 \%$ \\
\hline habermanS0C25Len2 & 29 & $57,4097 \%$ \\
\hline habermanS0C5Len2 & 36 & $50,0000 \%$ \\
\hline habermanS10C0Len2 & 8 & $71,2675 \%$ \\
\hline habermanS10C10Len2 & 8 & $71,2675 \%$ \\
\hline habermanS10C15Len2 & 8 & $71,2675 \%$ \\
\hline habermanS10C25Len2 & 7 & $77,9514 \%$ \\
\hline habermanS10C5Len2 & 8 & $71,2675 \%$ \\
\hline habermanS1C0Len2 & 32 & $52,0431 \%$ \\
\hline habermanS1C10Len2 & 32 & $52,0431 \%$ \\
\hline habermanS1C15Len2 & 31 & $53,2610 \%$ \\
\hline habermanS1C25Len2 & 27 & $57,9585 \%$ \\
\hline habermanS1C5Len2 & 32 & $52,0431 \%$ \\
\hline habermanS5C0Len2 & 17 & $67,2900 \%$ \\
\hline habermanS5C10Len2 & 17 & $67,2900 \%$ \\
\hline habermanS5C15Len2 & 17 & $67,2900 \%$ \\
\hline habermanS5C25Len2 & 15 & $73,0100 \%$ \\
\hline
\end{tabular}




\begin{tabular}{|c|c|c|}
\hline habermanS5C5Len2 & 17 & $67,2900 \%$ \\
\hline irisS0C0Len2 & 36 & $33,3333 \%$ \\
\hline irisS0C10Len2 & 20 & $58,8085 \%$ \\
\hline irisS0C15Len2 & 18 & $63,9850 \%$ \\
\hline irisS0C25Len2 & 16 & $69,8806 \%$ \\
\hline irisS0C5Len2 & 21 & $56,4490 \%$ \\
\hline irisS10C0Len2 & 15 & $68,7613 \%$ \\
\hline irisS10C10Len2 & 15 & $68,7613 \%$ \\
\hline irisS10C15Len2 & 15 & $68,7613 \%$ \\
\hline irisS10C25Len2 & 15 & $68,7613 \%$ \\
\hline irisS10C5Len2 & 15 & $68,7613 \%$ \\
\hline irisS1C0Len2 & 23 & $51,9135 \%$ \\
\hline irisS1C10Len2 & 20 & $58,8085 \%$ \\
\hline irisS1C15Len2 & 18 & $63,9850 \%$ \\
\hline irisS1C25Len2 & 16 & $69,8806 \%$ \\
\hline irisS1C5Len2 & 21 & $56,4490 \%$ \\
\hline irisS5C0Len2 & 17 & $66,8665 \%$ \\
\hline irisS5C10Len2 & 17 & $66,8665 \%$ \\
\hline irisS5C15Len2 & 17 & $66,8665 \%$ \\
\hline irisS5C25Len2 & 16 & $69,8806 \%$ \\
\hline irisS5C5Len2 & 17 & $66,8665 \%$ \\
\hline artist20S0C0Len2 & 500 & $5,0004 \%$ \\
\hline artist20S0C10Len2 & 165 & $33,5142 \%$ \\
\hline artist20S0C15Len2 & 112 & $43,9486 \%$ \\
\hline artist20S0C5Len2 & 226 & $7,1337 \%$ \\
\hline artist20S1C0Len2 & 422 & $5,5773 \%$ \\
\hline artist20S1C10Len2 & 165 & $33,5142 \%$ \\
\hline artist20S1C15Len2 & 112 & $43,9486 \%$ \\
\hline artist20S1C5Len2 & 226 & $7,1337 \%$ \\
\hline artist20S5C0Len2 & 122 & $56,4342 \%$ \\
\hline artist20S5C10Len2 & 48 & $47,0919 \%$ \\
\hline artist20S5C5Len2 & 122 & $56,4342 \%$ \\
\hline genreS0C0Len2 & 250 & $9,9998 \%$ \\
\hline genreS0C10Len 2 & 100 & $21,3196 \%$ \\
\hline genreS0C15Len 2 & 61 & $27,1939 \%$ \\
\hline genreS0C25Len2 & 37 & $42,3554 \%$ \\
\hline genreS0C5Len2 & 130 & $18,1235 \%$ \\
\hline
\end{tabular}




\begin{tabular}{|c|c|c|}
\hline genreS1C0Len2 & 99 & $21,0717 \%$ \\
\hline genreS1C10Len2 & 91 & $22,1782 \%$ \\
\hline genreS1C15Len2 & 60 & $27,3442 \%$ \\
\hline genreS1C25Len2 & 37 & $42,3554 \%$ \\
\hline genreS1C5Len2 & 99 & $21,0717 \%$ \\
\hline tic-tac-toeS0C0Len2 & 54 & $50,0000 \%$ \\
\hline tic-tac-toeS0C10Len2 & 54 & $50,0000 \%$ \\
\hline tic-tac-toeS0C15Len2 & 54 & $50,0000 \%$ \\
\hline tic-tac-toeS0C25Len2 & 53 & $50,5643 \%$ \\
\hline tic-tac-toeS0C5Len2 & 54 & $50,0000 \%$ \\
\hline tic-tac-toeS1C0Len2 & 54 & $50,0000 \%$ \\
\hline tic-tac-toeS1C10Len2 & 54 & $50,0000 \%$ \\
\hline tic-tac-toeS1C15Len2 & 54 & $50,0000 \%$ \\
\hline tic-tac-toeS1C25Len2 & 53 & $50,5643 \%$ \\
\hline tic-tac-toeS1C5Len2 & 54 & $50,0000 \%$ \\
\hline zooS0C0Len2 & 931 & $14,2857 \%$ \\
\hline zooS0C10Len2 & 193 & $67,0978 \%$ \\
\hline zooS0C15Len2 & 175 & $72,7181 \%$ \\
\hline zooS0C25Len2 & 165 & $81,4799 \%$ \\
\hline zooS0C5Len2 & 233 & $56,7718 \%$ \\
\hline zooS1C0Len2 & 140 & $23,7659 \%$ \\
\hline zooS1C10Len2 & 92 & $32,8791 \%$ \\
\hline zooS1C15Len2 & 76 & $37,1797 \%$ \\
\hline zooS1C25Len2 & 66 & $53,6998 \%$ \\
\hline zooS1C5Len2 & 130 & $25,2881 \%$ \\
\hline
\end{tabular}

Na Tabela 12 são apresentados os resultados obtidos utilizando a abordagem Greedy exARN. As informações estão dispostas no mesmo formato da tabela anterior.

Tabela 13 - Resultados obtidos usando a abordagem Greedy exARN.

Configuracao Quantidade Regras Confiança Média

\begin{tabular}{ccc}
\hline balance-scaleS0C0Len4 & 13 & $99,1538 \%$ \\
\hline balance-scaleS0C10Len4 & 13 & $99,1538 \%$ \\
\hline balance-scaleS0C15Len4 & 13 & $99,1538 \%$ \\
\hline balance-scaleS0C25Len4 & 13 & $99,1538 \%$ \\
\hline balance-scaleS0C5Len4 & 13 & $99,1538 \%$ \\
\hline balance-scaleS10C0Len4 & 6 & $74,8000 \%$ \\
\hline balance-scaleS10C10Len4 & 6 & $74,8000 \%$ \\
\hline
\end{tabular}




\begin{tabular}{|c|c|c|}
\hline balance-scaleS10C15Len4 & 6 & $74,8000 \%$ \\
\hline balance-scaleS10C25Len4 & 6 & $74,8000 \%$ \\
\hline balance-scaleS10C5Len4 & 6 & $74,8000 \%$ \\
\hline balance-scaleS1C0Len4 & 5 & $82,5000 \%$ \\
\hline balance-scaleS1C10Len4 & 5 & $82,5000 \%$ \\
\hline balance-scaleS1C15Len4 & 5 & $82,5000 \%$ \\
\hline balance-scaleS1C25Len4 & 4 & $98,7500 \%$ \\
\hline balance-scaleS1C5Len4 & 5 & $82,5000 \%$ \\
\hline balance-scaleS5C0Len 4 & 4 & $89,0000 \%$ \\
\hline balance-scaleS5C10Len4 & 4 & $89,0000 \%$ \\
\hline balance-scaleS5C15Len4 & 4 & $89,0000 \%$ \\
\hline balance-scaleS5C25Len4 & 4 & $89,0000 \%$ \\
\hline balance-scaleS5C5Len4 & 4 & $89,0000 \%$ \\
\hline breast-cancerS0C0Len 4 & 7 & $100,0000 \%$ \\
\hline breast-cancerS0C10Len4 & 7 & $100,0000 \%$ \\
\hline breast-cancerS0C15Len4 & 7 & $100,0000 \%$ \\
\hline breast-cancerS0C25Len4 & 7 & $100,0000 \%$ \\
\hline breast-cancerS0C5Len4 & 7 & $100,0000 \%$ \\
\hline breast-cancerS10C0Len4 & 5 & $80,1460 \%$ \\
\hline breast-cancerS10C10Len4 & 5 & $80,1460 \%$ \\
\hline breast-cancerS10C15Len4 & 5 & $80,1460 \%$ \\
\hline breast-cancerS10C25Len4 & 5 & $80,1460 \%$ \\
\hline breast-cancerS10C5Len4 & 5 & $80,1460 \%$ \\
\hline breast-cancerS1C0Len 4 & 7 & $100,0000 \%$ \\
\hline breast-cancerS1C10Len4 & 7 & $100,0000 \%$ \\
\hline breast-cancerS1C15Len4 & 7 & $100,0000 \%$ \\
\hline breast-cancerS1C25Len4 & 7 & $100,0000 \%$ \\
\hline breast-cancerS1C5Len 4 & 7 & $100,0000 \%$ \\
\hline breast-cancerS5C0Len4 & 4 & $100,0000 \%$ \\
\hline breast-cancerS5C10Len4 & 4 & $100,0000 \%$ \\
\hline breast-cancerS5C15Len4 & 4 & $100,0000 \%$ \\
\hline breast-cancerS5C25Len4 & 4 & $100,0000 \%$ \\
\hline breast-cancerS5C5Len 4 & 4 & $100,0000 \%$ \\
\hline carS0C0Len4 & 8 & $100,0000 \%$ \\
\hline carS0C10Len4 & 8 & $100,0000 \%$ \\
\hline carS0C15Len4 & 8 & $100,0000 \%$ \\
\hline carS0C25Len4 & 8 & $100,0000 \%$ \\
\hline
\end{tabular}




\begin{tabular}{|c|c|c|}
\hline carS0C5Len4 & 8 & $100,0000 \%$ \\
\hline carS10C0Len4 & 10 & $77,2800 \%$ \\
\hline carS10C10Len4 & 10 & $77,2800 \%$ \\
\hline carS10C15Len4 & 10 & $77,2800 \%$ \\
\hline carS10C25Len4 & 10 & $77,2800 \%$ \\
\hline carS10C5Len4 & 10 & $77,2800 \%$ \\
\hline carS1C0Len4 & 6 & $74,3833 \%$ \\
\hline carS1C10Len4 & 6 & $74,3833 \%$ \\
\hline carS1C15Len4 & 6 & $74,3833 \%$ \\
\hline carS1C25Len4 & 6 & $87,5000 \%$ \\
\hline carS1C5Len4 & 6 & $74,3833 \%$ \\
\hline carS5C0Len4 & 6 & $90,6250 \%$ \\
\hline carS5C10Len4 & 6 & $90,6250 \%$ \\
\hline carS5C15Len4 & 6 & $90,6250 \%$ \\
\hline carS5C25Len4 & 6 & $90,6250 \%$ \\
\hline carS5C5Len4 & 6 & $90,6250 \%$ \\
\hline ecoliS0C0Len4 & 13 & $100,0000 \%$ \\
\hline ecoliS0C10Len4 & 13 & $100,0000 \%$ \\
\hline ecoliS0C15Len4 & 13 & $100,0000 \%$ \\
\hline ecoliS0C25Len4 & 13 & $100,0000 \%$ \\
\hline ecoliS0C5Len4 & 13 & $100,0000 \%$ \\
\hline ecoliS10C0Len4 & 5 & $73,3860 \%$ \\
\hline ecoliS10C10Len4 & 5 & $73,3860 \%$ \\
\hline ecoliS10C15Len4 & 4 & $89,1200 \%$ \\
\hline ecoliS10C25Len4 & 4 & $89,1200 \%$ \\
\hline ecoliS10C5Len4 & 5 & $73,3860 \%$ \\
\hline ecoliS1C0Len4 & 6 & $94,4450 \%$ \\
\hline ecoliS1C10Len4 & 6 & $94,4450 \%$ \\
\hline ecoliS1C15Len4 & 6 & $94,4450 \%$ \\
\hline ecoliS1C25Len4 & 6 & $94,4450 \%$ \\
\hline ecoliS1C5Len4 & 6 & $94,4450 \%$ \\
\hline ecoliS5C0Len4 & 5 & $80,6480 \%$ \\
\hline ecoliS5C10Len4 & 5 & $80,6480 \%$ \\
\hline ecoliS5C15Len4 & 5 & $80,6480 \%$ \\
\hline ecoliS5C25Len4 & 5 & $80,6480 \%$ \\
\hline ecoliS5C5Len4 & 5 & $80,6480 \%$ \\
\hline habermanSOC0Len4 & 6 & $100,0000 \%$ \\
\hline
\end{tabular}




\begin{tabular}{|c|c|c|}
\hline habermanS0C10Len4 & 6 & $100,0000 \%$ \\
\hline habermanS0C15Len4 & 6 & $100,0000 \%$ \\
\hline habermanS0C25Len4 & 6 & $100,0000 \%$ \\
\hline habermanS0C5Len4 & 6 & $100,0000 \%$ \\
\hline habermanS10C0Len4 & 4 & $51,0700 \%$ \\
\hline habermanS10C10Len4 & 4 & $51,0700 \%$ \\
\hline habermanS10C15Len4 & 4 & $51,0700 \%$ \\
\hline habermanS10C25Len4 & 3 & $59,9333 \%$ \\
\hline habermanS10C5Len4 & 4 & $51,0700 \%$ \\
\hline habermanS1C0Len4 & 6 & $88,3000 \%$ \\
\hline habermanS1C10Len4 & 6 & $88,3000 \%$ \\
\hline habermanS1C15Len4 & 6 & $88,3000 \%$ \\
\hline habermanS1C25Len4 & 6 & $88,3000 \%$ \\
\hline habermanS1C5Len4 & 6 & $88,3000 \%$ \\
\hline habermanS5C0Len4 & 9 & $73,6144 \%$ \\
\hline habermanS5C10Len4 & 9 & $73,6144 \%$ \\
\hline habermanS5C15Len4 & 9 & $73,6144 \%$ \\
\hline habermanS5C25Len4 & 9 & $73,6144 \%$ \\
\hline habermanS5C5Len4 & 9 & $73,6144 \%$ \\
\hline irisS0C0Len4 & 8 & $100,0000 \%$ \\
\hline irisS0C10Len4 & 8 & $100,0000 \%$ \\
\hline irisS0C15Len4 & 8 & $100,0000 \%$ \\
\hline irisS0C25Len4 & 8 & $100,0000 \%$ \\
\hline irisS0C5Len4 & 8 & $100,0000 \%$ \\
\hline irisS10C0Len4 & 6 & $98,9550 \%$ \\
\hline irisS10C10Len4 & 6 & $98,9550 \%$ \\
\hline irisS10C15Len4 & 6 & $98,9550 \%$ \\
\hline irisS10C25Len4 & 6 & $98,9550 \%$ \\
\hline irisS10C5Len4 & 6 & $98,9550 \%$ \\
\hline irisS1C0Len4 & 7 & $100,0000 \%$ \\
\hline irisS1C10Len4 & 7 & $100,0000 \%$ \\
\hline irisS1C15Len4 & 7 & $100,0000 \%$ \\
\hline irisS1C25Len4 & 7 & $100,0000 \%$ \\
\hline irisS1C5Len4 & 7 & $100,0000 \%$ \\
\hline irisS5C0Len4 & 6 & $99,4050 \%$ \\
\hline irisS5C10Len4 & 6 & $99,4050 \%$ \\
\hline irisS5C15Len4 & 6 & $99,4050 \%$ \\
\hline
\end{tabular}




\begin{tabular}{|c|c|c|}
\hline irisS5C25Len4 & 6 & $99,4050 \%$ \\
\hline irisS5C5Len4 & 6 & $99,4050 \%$ \\
\hline artist20S0C0Len4 & 20 & $22,6385 \%$ \\
\hline artist20S0C10Len4 & 20 & $22,6385 \%$ \\
\hline artist20S0C15Len4 & 17 & $24,2582 \%$ \\
\hline artist20S0C25Len4 & 5 & $35,4840 \%$ \\
\hline $\operatorname{artist20S0C5Len4}$ & 20 & $22,6385 \%$ \\
\hline artist20S1C0Len4 & 20 & $20,1040 \%$ \\
\hline artist20S1C10Len4 & 20 & $20,1040 \%$ \\
\hline artist20S1C15Len4 & 15 & $22,6380 \%$ \\
\hline artist20S1C25Len 4 & 5 & $30,8440 \%$ \\
\hline artist20S1C5Len4 & 20 & $20,1040 \%$ \\
\hline $\operatorname{artist20S5C0Len4}$ & 8 & $8,2737 \%$ \\
\hline artist20S5C10Len4 & 2 & $10,6500 \%$ \\
\hline artist20S5C5Len4 & 8 & $8,2737 \%$ \\
\hline genreS1C0Len4 & 10 & $47,4520 \%$ \\
\hline genreS1C10Len4 & 10 & $47,4520 \%$ \\
\hline genreS1C15Len4 & 10 & $47,4520 \%$ \\
\hline genreS1C25Len4 & 9 & $49,9856 \%$ \\
\hline genreS1C5Len4 & 10 & $47,4520 \%$ \\
\hline tic-tac-toeS1C0Len4 & 4 & $100,0000 \%$ \\
\hline tic-tac-toeS1C10Len 4 & 4 & $100,0000 \%$ \\
\hline tic-tac-toeS1C15Len 4 & 4 & $100,0000 \%$ \\
\hline tic-tac-toeS1C25Len4 & 4 & $100,0000 \%$ \\
\hline tic-tac-toeS1C5Len4 & 4 & $100,0000 \%$ \\
\hline zooS1C0Len4 & 7 & $100,0000 \%$ \\
\hline zooS1C10Len4 & 7 & $100,0000 \%$ \\
\hline zooS1C15Len4 & 7 & $100,0000 \%$ \\
\hline zooS1C25Len4 & 7 & $100,0000 \%$ \\
\hline zooS1C5Len4 & 7 & $100,0000 \%$ \\
\hline
\end{tabular}




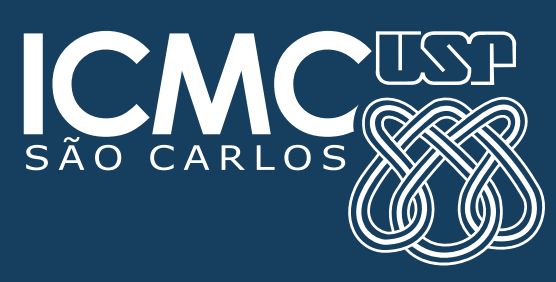

